\title{
ipen
}

INSTITUTO DE PESQUISAS ENERGÉTICAS E NUCLEARES AUTARQUIA ASSOCIADA À UNIVERSIDADE DE SÃO PAULO

\section{OTIMIZAÇÃO DA METODOLOGIA DE PREPARAÇÃO DO CRISTAL DE BROMETO DE TÁLIO PARA SUA APLICAÇÃO COMO DETECTOR DE RADIAÇÃO}

ROBINSON ALVES DOS SANTOS

Dissertação apresentada como parte dos requisitos para obtenção do grau de Mestre em Ciências na Area de Tecnologia Nuclear Aplicações.

Orientadora: Dra. Margarida Mizue Hamada 
A S.S. Jayapataka Svami e a memória de Francisco Alves dos Santos Filho. 


\section{AGRADECIMENTOS}

À Dra. Margarida Mizue Hamada pelo grande apoio, amizade e orientação constantes e muito valiosas, bem como pelo exemplo de pessoa e de profissional da ciência.

Ao Dr. Fábio Eduardo da Costa pelas discussões, pelo auxílio nas montagens eletrônicas, caracterização dos cristais e ótimas explicações.

Ao Dr. Carlos Henrique de Mesquita pelo auxilio com a análise compartimental, pelo grande apoio, incentivo e ótimas discussões.

A Dra. Roseli F. Gennari, do Laboratório de Cristais Iônicos, Filmes e Datação do Instituto de Física da Universidade de São Paulo.

Ao Dr. Wilson Aparecido Parejo Calvo pela grande disposição e recepção junto ao Centro de Tecnologia das Radiações do Instituto de Pesquisas Energéticas e Nucleares.

Ao Sr. Galdino e demais profissionais da IEON / IPEN pelo ótimo trabalho de confecção e selamento dos tubos de quartzo dos trabalhos iniciais.

Ao Dr. Nelson Batista de Lima, do Centro de Ciências e Tecnologia dos Materiais do Instituto de Pesquisas Energéticas e Nucleares (CCTM / IPEN - SP), pelas análises com Difração de Raios X.

Ao técnico Vinicius Freire Elias, do Laboratório de Microscopia Eletrônica de Varredura da Escola Politécnica da Universidade de São Paulo.

Ao Centro de Tecnologia das Radiações do Instituto de Pesquisas Energéticas e Nucleares pela infra-estrutura cedida, fundamental para a realização deste trabalho.

A Comissão Nacional de Energia Nuclear pela projeção e intercâmbio acadêmico e científico que me foram proporcionados e pelo apoio financeiro. 
A Neusa de Melo Santos, Keile Alves dos Santos, Ariane Alves dos Santos, Suniti Devi Dasi, Lucy Rigonato e Dorival Francisco Adame pelo apoio e ensinamentos.

Aos meus amigos Fabio Paiva, João Santana, João Trencher, Diego Vergaças, Felipe Felix, Andre Luiz Silva, Prema Avatara Das, Gourasundar Dasa, Doyal Nitay Caitanya Das, Keshava Kasmiri Das, Marcos Carmelo, Ailton Silva, Marcelo Cleto, Renan Francisco, Alicio Francisco, Mestre José Carlos dos Santos e todos meus colegas do IPEN pela amizade inspiradora. 
"Conhecimento verdadeiro significa conhecer a matéria, o espirito e o controlador de ambos".

A.C.B.S. Prabhupada

"Pense como um homem de ação e aja como um homem de pensamento".

Henri Poincaré 


\section{OTIMIZAÇÃO DA METODOLOGIA DE PREPARAÇÃO DO CRISTAL DE BROMETO DE TÁLIO PARA SUA APLICAÇÃO COMO DETECTOR DE RADIAÇÃO}

\section{ROBINSON ALVES DOS SANTOS}

\section{RESUMO}

Neste trabalho, cristais de TlBr foram crescidos e purificados pelo método de Bridgman Repetido a partir de sais comerciais de $\mathrm{TlBr}$ e caracterizados para serem usados como detectores de radiação à temperatura ambiente. Para avaliar a eficiência de purificação, estudos da diminuição da concentração de impurezas foram feitos após cada crescimento, analisando as impurezas traços por Espectrometria de Massas com Plasma (ICP-MS). Um decréscimo significativo da concentração de impurezas em função do número de purificações foi observado. Os cristais crescidos apresentaram boa qualidade cristalina de acordo com os resultados de análise por Difração de Raios X (DRX). Para avaliar os cristais a serem usados como detectores de radiação, medidas de suas resistividades e resposta à incidência de radiação gama da fonte de ${ }^{241} \mathrm{Am}(59,5 \mathrm{keV})$ foram realizadas. Essa resposta foi dependente da pureza do cristal. Um modelo compartimental foi proposto para avaliar as concentrações de impurezas no cristal de $\mathrm{TlBr}$ e suas segregações em função do número de crescimentos pelo método de Bridgman. Este modelo compartimental definido por equações diferenciais pode ser usado para calcular o coeficiente de migração das impurezas e mostrou ser útil para prever o número necessário de repetições de crescimento Bridgman para atingir nível de pureza adequado para assegurar a qualidade do cristal como detector de radiação. A diferença dos valores dos coeficientes de migração das impurezas nos cristais entre os sais, de duas procedências diferentes, utilizados foi significativa. Portanto, a escolha do sal de partida deve ser realizada experimentalmente, independente da declaração nominal da sua pureza. 


\title{
METHODOLOGY OPTIMIZATION OF THE THALLIUM BROMIDE CRYSTAL PREPARATION FOR APPLICATION AS A RADIATION DETECTOR.
}

\section{ROBINSON ALVES DOS SANTOS}

\begin{abstract}
In this work, $\mathrm{TlBr}$ crystals have been purified and grown by the Repeated Bridgman method from commercial $\mathrm{TlBr}$ materials and characterized to be used as radiation detectors. To evaluate the purification efficiency, studies on the impurity concentration decrease were performed after each growth, analyzing the trace impurities by inductively coupled plasma mass spectroscopy (ICP-MS). A significant decrease of the concentration of impurities in function of the purification number was observed. The grown crystals presented good crystalline quality according to the results of the x-ray diffraction analysis. To evaluate the crystals to be used as a semiconductor detector, measurements of the resistivity and the pulse height under ${ }^{241} \mathrm{Am}$ gamma rays were carried out. The radiation response was strongly dependent on the crystal purity. The Repeated Bridgman technique showed to be effective to reduce the concentration of impurities and to improve the $\mathrm{TlBr}$ crystal quality to be used as a radiation semiconductor detector. A compartmental model was proposed to fit the concentration/segregation of impurities in function of the Bridgman growth step number. This compartmental model is defined by differential equations and can be used to calculate the rate of migration of impurities. It proved to be a useful tool in predicting the number of Bridgman growth repetitions necessary to achieve the desired impurity concentration. The difference of the impurity migration rates between the crystals grown, using salts from different origins, was significant. Therefore, the choice of the starting salt should be performed experimentally, regardless of the statement nominal purity.
\end{abstract}




\section{Sumário}

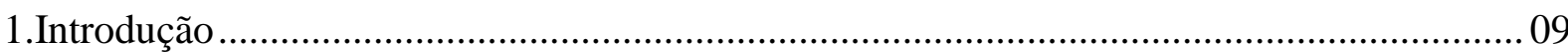

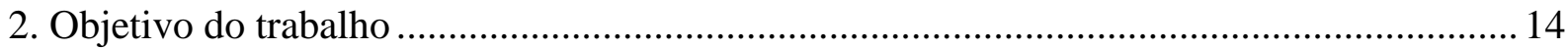

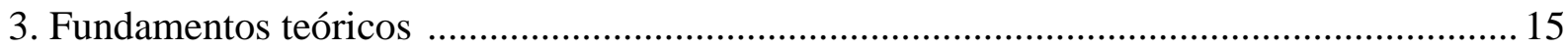

3.1. Principais interações da radiação com a matéria ................................................................. 15

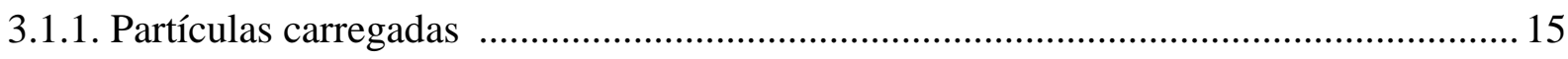

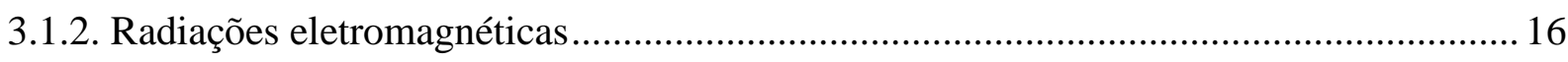

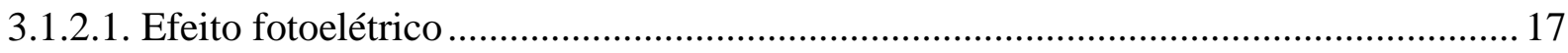

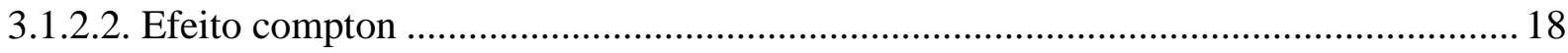

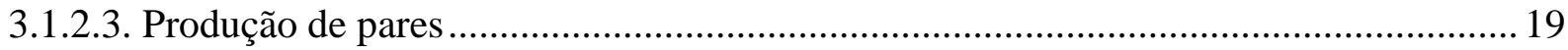

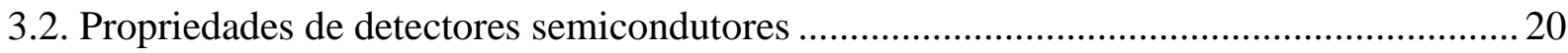

3.3. Cristais utilizados como detectores semicondutores de radiação ...................................... 22

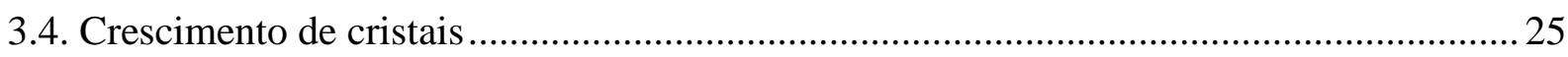

3.4.1. Purificação e crescimento de cristais pelo método de Bridgman .................................. 26

3.5. Métodos de caracterização físico -química de materiais cristalinos ................................. 27

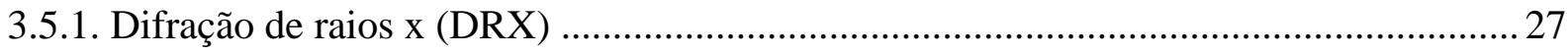

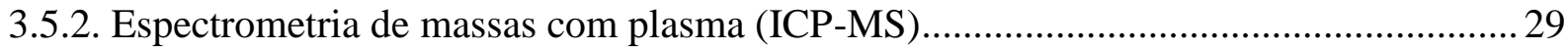

3.5.3. Microscopia eletrônica de varredura (MEV) ................................................................. 32

3.5.4. Formulação de modelos - análise compartimental..................................................... 32

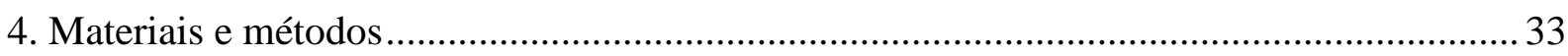

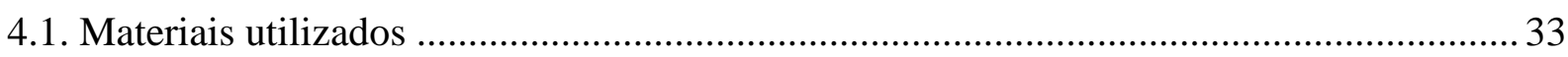

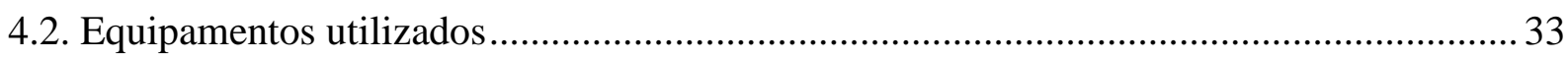

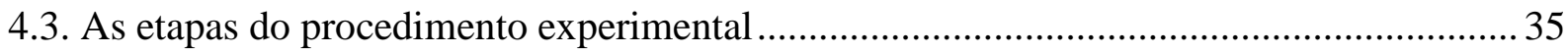

4.3.1. Levantamento do perfil térmico do forno utilizado no método de Bridgman ................ 35

4.3.2. Tratamento químico e desumidificação dos tubos de quartzo e desumidificação do sal

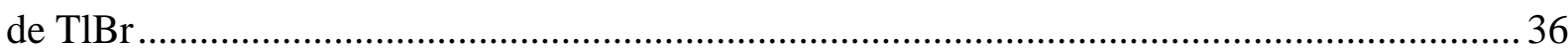

4.3.3. Crescimento de cristais de tlbr pelo método de Bridgamn e purificação por Bridgam

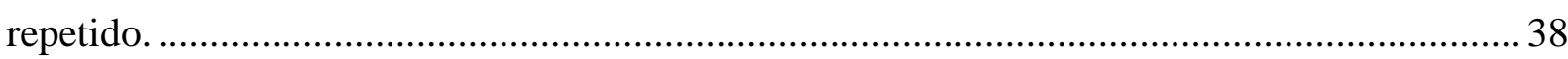

4.3.4. Corte e polimento dos cristais de TlBr para aplicação dos contatos eletrônicos............ 39

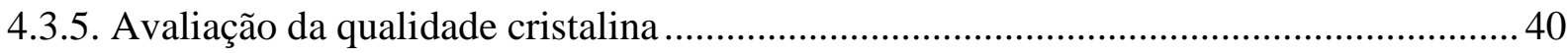

4.3.6. Análise morfológica e verificação estequiométrica: microscopia eletrônica de varredura

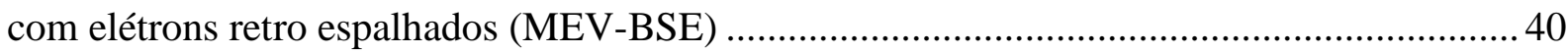

4.3.7. Caracterização do cristal semicondutor de TlBr como detector de radiação ................. 41

4.3.8. Preparação das amostras de TlBr para análises química das impurezas e do modelo 
compartimental 43

4.3.9. Análise quantitativa das de impurezas presentes por ICP-MS ...................................... 44

4.3.10. Análise de segregação de impurezas presentes (modelo compartimental).................. 45

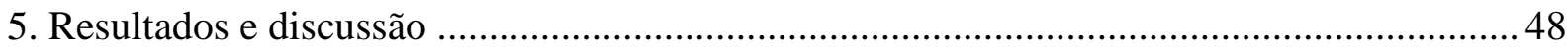

5.1. Levantamento do perfil térmico do forno utilizado no método de Bridgman ................... 48

5.2. Tratamento químico e desumidificação dos tubos de quartzo e desumidificação do sal de $\mathrm{TlBr}$ 49

5.3. Crescimento de cristais de TlBr pelo método de Bridgman e purificação por Bridgman

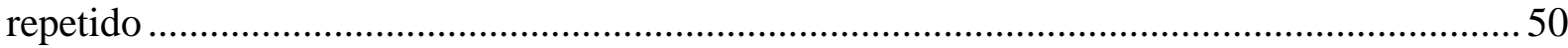

5.4. Corte e polimento dos cristais de $\mathrm{TlBr}$ e aplicação dos contatos eletrônicos .....................52

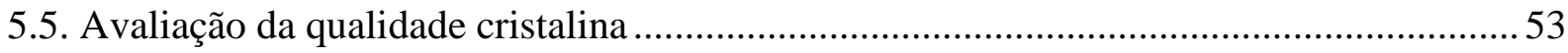

5.6. Análise morfológica: microscopia eletrônica de varredura com elétrons retro espalhados

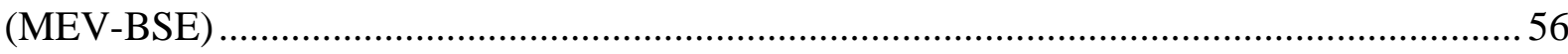

5.7. Análise estequiométrica: microscopia eletrônica de varredura com elétrons retro

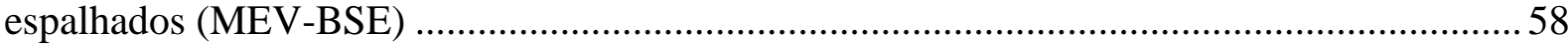

5.8. Caracterização do cristal semicondutor de $\mathrm{TlBr}$ como detector de radiação .....................59

5.8.1. Preparação do cristal como detectores de radiação ......................................................... 59

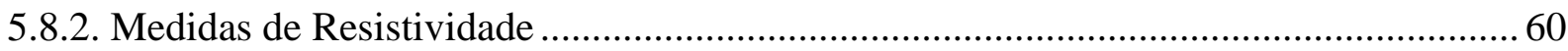

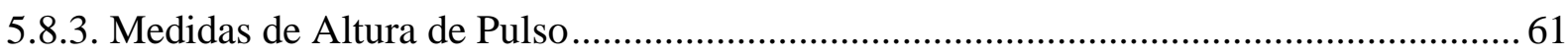

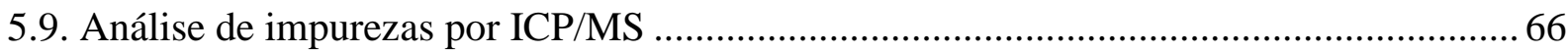

5.10. Segregação de impurezas (modelo compartimental) ..................................................... 67

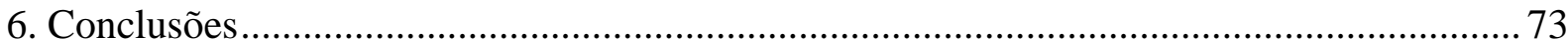

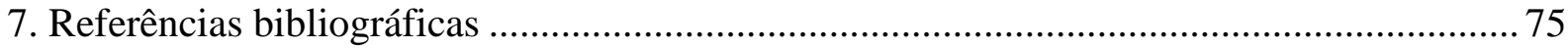




\section{INTRODUÇÃO}

A grande maioria dos detectores semicondutores de radiação em freqüente uso é fabricada a partir de matrizes de silício e germânio. A popularidade destes materiais é atribuída a excelente propriedade de transporte de carga, a qual permite o uso de cristais com espessuras de até $10 \mathrm{~cm}$ sem excessiva perda de portadores de carga devido ao armadilhamento ou recombinação das cargas produzidas ${ }^{(1,2)}$. Na última década, além do Si e $\mathrm{Ge}$, foi disponibilizado comercialmente o cristal de telureto de cádmio $(\mathrm{CdTe})$ como detector de radiação. Destes materiais somente o Si e CdTe podem ser usados à temperatura ambiente. O Si é um material semicondutor freqüentemente usado para medidas de raios-X de baixa energia e partículas ionizantes. No entanto, quando são necessárias medidas espectrométricas de alta resolução, o material adequado é o Ge, mas este apresenta o inconveniente de requerer refrigeração para reduzir a corrente de fuga gerada termicamente ${ }^{(1,2)}$. Normalmente o nitrogênio líquido é utilizado para essa finalidade. Em aplicações de baixo ruído, como espectroscopia de raios-X, o detector de Si também deve ser refrigerado pela mesma razão. Atualmente, para aplicações onde é desejada operação à temperatura ambiente e reduzidas dimensões é utilizado o CdTe. No entanto, o efeito de polarização é observado neste detector, no decorrer do tempo. Apesar das excelentes propriedades do Si e Ge, é observado na literatura um considerável interesse no desenvolvimento de outros materiais que apresentem a vantagem de não operar sob refrigeração, tais como: arseneto de gálio (GaAs), iodeto de mercúrio $\left(\mathrm{HgI}_{2}\right)$, iodeto de chumbo $\left(\mathrm{PbI}_{2}\right)$, telureto de cádmio e zinco $(\mathrm{CdZnTe})$ e brometo de tálio (TlBr), para utilização como detectores de radiação ${ }^{(1,3,5,6,7,8)}$.

Em princípio, um material semicondutor com energia de banda proibida larga (acima de $1,35 \mathrm{eV}$ ) apresenta um valor de corrente de fuga baixo suficiente para operar à temperatura ambiente $^{(1)}$, que somada a outras características pode viabilizar o material como um detector de radiação semicondutor à temperatura ambiente. O conjunto de propriedades requerido para atuar como um detector semicondutor para raios-X e gama e operar à temperatura ambiente é composto de: (a) elevado número atômico [Z], (b) larga energia de banda proibida [Eg]: entre 1,35 e $2,7 \mathrm{eV}$ e (c) alto produto de mobilidade dos portadores por tempo de vida $[\mu \tau]$, com o intuito de obter uma completa coleção de cargas, indispensável para boa resolução energética $^{(1,2,3,4)}$. 
$\mathrm{O}$ denominador comum dos materiais semicondutores, que operam à temperatura ambiente, é a dificuldade em crescer cristais com alta perfeição cristalográfica, tendo alta pureza química e estequiometria adequadas. Estes requisitos básicos devem ser satisfeitos em vários estágios na fabricação do detector. Esse processo envolve a purificação dos materiais de partida, crescimento do cristal, fabricação do detector, deposição dos eletrodos, montagem sobre um substrato rígido, encapsulamento e seu acoplamento a uma eletrônica associada. Cada uma dessas etapas podem introduzir defeitos que podem deteriorar a resposta do detector à radiação incidente ${ }^{(1,2,3)}$.

Os compostos semicondutores com alto número atômico e energia de banda proibida larga, como CdTe, CdZnTe, $\mathrm{HgI}_{2}, \mathrm{PbI}_{2}$ e $\mathrm{TlBr}$ vêm sendo pesquisados como detectores de radiação gama, encontrando-se em diferentes estágios de desenvolvimento para alcançar boas resoluções em energia à temperatura ambiente. Destes, o brometo de tálio ( $\mathrm{TlBr}$ ) vem sendo estudado, em particular, por apresentar características superiores ou comparáveis a esses semicondutores, apresentando potencialidade para confecção de detectores de radiação ionizante $^{(1,3,5,6,7,8,9)}$.

$\mathrm{O} \mathrm{TlBr}$ tem um número atômico médio alto $\left(\mathrm{Z}_{\mathrm{Tl}}=81\right.$ e $\left.\mathrm{Z}_{\mathrm{Br}}=35\right)$, densidade alta $(7,5$ $\left.\mathrm{g} / \mathrm{cm}^{3}\right)$, resistividade alta $\left(10^{12} \Omega \mathrm{cm}\right)$ e energia de banda proibida de $2,7 \mathrm{eV}$. Cristaliza em uma estrutura cristalina cúbica simples, apresentando parâmetro de rede de 3,97 angstrons, e funde congruentemente à $480{ }^{\circ} \mathrm{C}$. A energia da banda proibida relativamente larga tem permitido que detectores de $\mathrm{TlBr}$ operem em temperatura ambiente com baixa corrente de fuga $^{(9)}$ e baixo ruído eletrônico ${ }^{(3,8,9)}$ apresentando alta resolução para raios $-X$ e gama.

Uma das desvantagens do TlBr é a baixa mobilidade de seus portadores de carga, 6 $\mathrm{cm}^{2} /$ Vs para elétrons e $2 \mathrm{~cm}^{2} / \mathrm{Vs}$ para lacunas ${ }^{(9)}$. Entretanto, o transporte de cargas é regido pelo produto da mobilidade pelo tempo de armadilhamento $(\mu \tau)$, podendo ser suficientemente grande para materiais de alta pureza e perfeição cristalina ${ }^{(4,8,9,11,12)}$. Isto pode ser alcançado com prévia purificação dos sais por refinamento zonal antes do crescimento dos cristais, bem como pelo método de Bridgman repetido para os cristais já $\operatorname{crescidos}^{(2,5,7,9,10,13,18,19,20)}$.

O desempenho e a utilização de compostos semicondutores para aplicação como detectores de radiação é geralmente limitado pela qualidade do material usado para a fabricação destes detectores. Em particular, a alta concentração de níveis profundos de 
armadilhas dos portadores de carga é a mais freqüente causa da baixa eficiência em materiais semicondutores com energia de banda proibida larga. As armadilhas para elétrons e lacunas provém de duas origens: impurezas extrínsecas e defeitos na estrutura cristalina ${ }^{(3,4,6,12,23,24)}$.

$\mathrm{Na}$ literatura observa-se um crescente interesse no desenvolvimento de detectores de radiação de $\operatorname{TlBr}^{(1,2,3,7,8,13-22)}$. As dificuldades relacionadas com a purificação, o crescimento e a caracterização destes cristais são ainda objetos de estudo em diversos centros de pesquisa.

Uma apresentação sucinta sobre os trabalhos realizados até a atualidade sobre os cristais de $\mathrm{TlBr}$ referente à sua purificação, crescimento, caracterização e sua aplicação na área nuclear é descrita a seguir.

$\mathrm{O} \mathrm{TlBr}$ foi citado pela primeira vez, como um promissor material para ser aplicado como detector de radiação, por Hofstadter ${ }^{(6)}$ em 1949. Nesse trabalho, a pureza do material foi apontada como um possível fator limitante para o desempenho do detector. No entanto, desde esta descoberta até o final de década dos 80 , os trabalhos encontrados na literatura sobre $\mathrm{TlBr}$ eram referentes às suas características físico-químicas, térmicas e cristalinas. Nenhum trabalho sobre sua aplicação e desempenho como detector radiação foi encontrada.

Em 1965 Lefkowitz e col. ${ }^{(25)}$ fizeram um estudo comparativo dos espectros de absorção do $\mathrm{TlBr}$ e do $\mathrm{TlCl}$ à temperaturas de $77 \mathrm{~K}$ e $4 \mathrm{~K}$. Foram atingidos avanços significativos, sobretudo no estudo das propriedades físicas dos cristais, especialmente quanto a estrutura e orientação dos planos cristalinos. Estudos sobre a dependência entre pressão e dilatação térmica do $\mathrm{TlBr}$ entre as temperaturas de $78 \mathrm{~K}$ e $673 \mathrm{~K}$ foram realizados por Garth e col., em $1967^{(26)}$. Overhof e Treusch ${ }^{(27)}$, em 1971, calcularam relativisticamente as bandas de energia do $\mathrm{TlBr}$ ao longo dos planos cristalinos com as orientações (100), (110) e (111). Estes trabalhos foram muito significativos para a caracterização dos cristais de TlBr. Análises feitas por meio de espectrometria de massas possibilitaram o conhecimento de diversos íons formados a partir do $\mathrm{TlBr}^{(28)}$, da energia livre de Gibbs e da pressão de vapor do $\mathrm{TlBr}^{(29)}$.

Somente a partir do final da década de 80 , com o interesse por detectores semicondutores de radiação que operam à temperatura ambiente, foram apresentados estudos sobre preparação e caracterização de cristais de $\mathrm{TlBr}$ aplicados como detector de radiação. Em 1987, Rahman e col. ${ }^{(30)}$ analisaram os espectro de altura de pulso do TlBr obtido com 
partículas alfa do ${ }^{241} \mathrm{Am}$ à temperatura de $-80{ }^{\circ} \mathrm{C}$ e com radiação gama do ${ }^{60} \mathrm{Co}$, do ${ }^{207} \mathrm{Bi}$ e do ${ }^{137} \mathrm{Cs}$, nas temperaturas de $-29{ }^{\circ} \mathrm{C}$ e $0{ }^{\circ} \mathrm{C}$. Os autores apresentaram conclusões referentes apenas aos experimentos realizados a baixa temperatura e é mencionado apenas o valor de resolução FWHM de $20 \%$ obtido a partir das partículas alfa. Os valores obtidos para radiação gama não foram expostos.

De Luca e col. ${ }^{(31)}$ pesquisaram os espectros de emissão e absorção de TlBr em solução alcoólica para diferentes concentrações de sal. Os autores fizeram ensaios para diferentes temperaturas e concluíram que diferentes estequiometrias de $\mathrm{TlBr}$ apresentam solubilidades similares e maiores em álcool, quando comparadas com a água.

Em 1990 K.S. Shah e col. ${ }^{(7)}$ fabricaram cristais de TlBr por meio da purificação do material de partida por refino zonal em um forno de duas zonas e crescimento do cristal pelo método de Bridgman. O número de passos e maiores detalhes do processo de purificação e crescimento não foram revelados neste trabalho. Os cristais detectores obtidos foram irradiados com fontes de ${ }^{55} \mathrm{Fe}$, operando a $60 \mathrm{~V}$, e ${ }^{241} \mathrm{Am}$, operando a $110 \mathrm{~V}$, ambos à temperatura ambiente. $\mathrm{O}$ trabalho sugere que a melhor desempenho do detector de $\mathrm{TlBr}$ pode ser obtido com maior purificação do mesmo, além de apontar o cristal de $\mathrm{TlBr}$ como um material promissor para a construção de detectores de raios X e radiação gama.

A partir de 1990, um aumento significativo de estudos sobre diferentes aspectos e características dos cristais de $\mathrm{TlBr}$ para atingir a qualidade requerida para sua atuação como detectores de radiação que operam à temperatura ambiente são encontrados na literatura ${ }^{(3,4,5-}$ 7,10,11,13-15,18). Dentre eles, podemos destacar alguns trabalhos, como o do Hitomi e col. ${ }^{(32)}$ que utilizaram o método de refino zonal para crescer cristais de $\mathrm{TlBr}$ e conseguiram resolução energética de $29.8 \mathrm{keV}$ (5.8\%) FWHM para fontes de raios gama de $511 \mathrm{keV}$. Sellin ${ }^{(13)}$ destacou o $\mathrm{TlBr}$ como um dos mais promissores materiais a serem pesquisados e utilizados como semicondutores detectores de radiação à temperatura ambiente. Gostilo e col. ${ }^{(33)}$ realizaram um estudo comparativo entre o desempenho de cristais de $\mathrm{TlBr}$ crescidos pelo método de Bridgman e pelo método de refino zonal. Mais recentemente, têm-se observado, na literatura, um aumento significativo de estudos para obtenção de cristais de $\mathrm{TlBr}$ com melhor desempenho como detector de radiação, aprimorando diferentes parâmetros, tais como: eletrônica associada ${ }^{(34,35)}$, características físico-químicas do cristal $^{(36,37,38)}$, elétricas ${ }^{(39)}$ e impurezas ${ }^{(19,40-42)}$. Adicionalmente, pesquisas sobre a degradação do sinal no decorrer do 
tempo (polarização), inerente a cristais semicondutores que operam à temperatura ambiente, também, tem aumentado ${ }^{(43-47)}$. Embora tenham sido obtidos resultados expressivos para todos os casos, não foram expostos maiores detalhes sobre como realizar de forma mais eficiente cada uma das etapas de desenvolvimento de detectores semicondutores de TlBr. Estes exemplos destacam a relevância e empenho no desenvolvimento dos detectores de $\mathrm{TlBr}$, tanto no Brasil, quanto num panorama internacional. A Figura 1 mostra a quantidade de artigos sobre TlBr publicados ao longo dos anos ${ }^{(4-7,9-11,14,15,18-20,23-70)}$.

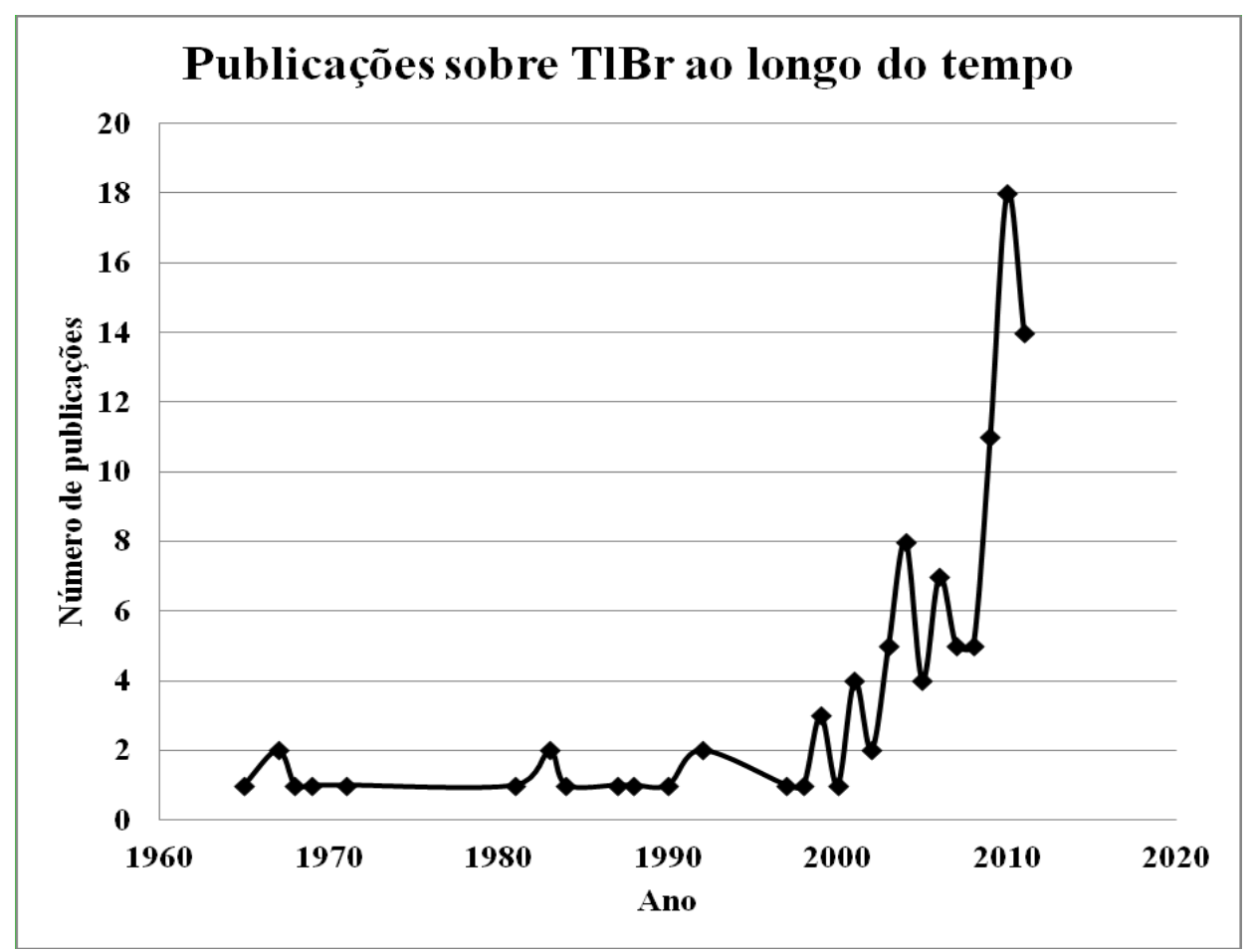

Figura 1: Publicações sobre $\mathrm{TlBr}$ ao longo dos anos.

Apesar das pesquisas com os cristais semicondutores de TlBr para detecção de radiação à temperatura ambiente ter avançado progressivamente nos últimos anos, a busca pela melhoria na coleção de carga e na estabilidade de longo prazo, ainda deve ser prosseguida. Dessa forma, em 2006 foi realizada uma tese de doutoramento ${ }^{(4)}$ no IPEN/CNEN - CTR cujo objetivo foi desenvolver e caracterizar cristais de $\mathrm{TlBr}$ como detectores de radiação à temperatura ambiente. $\mathrm{O}$ trabalho apresentou uma metodologia detalhada de purificação e crescimento dos cristais por meio da combinação das técnicas de refino zonal e de Bridgman. Os resultados obtidos com a purificação prévia do material pela técnica de refino zonal foram bastante satisfatórios e os cristais crescidos por Bridgman apresentaram boa qualidade cristalina e resposta à radiação. Estes cristais foram utilizados para o desenvolvimento de uma 
sonda cirúrgica para operações radioguiadas, também chamado de mapeamento linfático intra-operatório com linfadenectomia seletiva, possibilitando a retirada do tumor cancerígeno com mais acurácia e menor morbidade ${ }^{(18,49)}$. No entanto, embora os cristais de $\mathrm{TlBr}$ desenvolvidos apresentassem características adequadas para aplicações onde não requerem o uso contínuo de operação do detector como a sonda cirúrgica, uma progressiva degradação dos detectores foi observada devido ao efeito de polarização ${ }^{(4)}$ ao longo do tempo. O efeito é uma redução na eficiência de coleta de cargas devido ao armadilhamento de cargas na estrutura interna do cristal que produzem um campo elétrico contrário ao sentido desejado de coleta das cargas. É observado na literatura um grande esforço para compreensão deste efeito com o intuito de alcançar estabilidade a longo prazo para os detectores que operam à temperatura ambiente ${ }^{(18,46,48,54,60)}$. Contudo, o efeito de polarização em detectores que operam à temperatura ambiente e conseqüente falta de estabilidade continua sendo um grande desafio. No presente trabalho a metodologia de preparação dos cristais semicondutores de TlBr foi otimizada para melhorar a estabilidade do cristal detector de TlBr. Nesse sentido, os processos de purificação e análise de segregação de impurezas dos cristais têm sido fundamentais para avaliar suas qualidades como detectores de radiação que operam à temperatura ambiente e sua estabilidade ao longo do tempo.

\section{OBJETIVO DO TRABALHO}

Este trabalho tem como objetivo a análise e otimização da metodologia de crescimento e purificação dos cristais semicondutores de TlBr com o intuito de utilizá-los como detectores de radiação à temperatura ambiente.

Para tanto, foram realizados estudos para conhecimentos teóricos e práticos dos métodos de crescimento, purificação e caracterização de cristais de $\mathrm{TlBr}$, bem como para o conhecimento das possíveis causas que influenciam no desempenho dos mesmos na aplicação como detectores de radiação à temperatura ambiente, especialmente as relacionadas à presença de impurezas nos mesmos. Sais de diferentes procedências foram utilizados para avaliar e comparar o desempenho do cristal em função da matéria prima. 


\section{FUNDAMENTOS TEÓRICOS}

\subsection{PRINCIPAIS INTERAÇÕES DA RADIAÇÃO COM A MATÉRIA}

Os diferentes tipos de radiação podem ser agrupados conforme suas características da seguinte forma:

- partículas carregadas pesadas (massas maiores que a massa de repouso do elétron): alfa, dêuterons, trítions, prótons e fragmentos de fissão;

- partículas carregadas leves: elétrons, pósitrons e partículas beta;

- partículas sem carga e com massa: nêutrons, neutrinos;

- radiação eletromagnética: fótons gama e X.

Em função destas características, tem-se determinado tipo de interação da radiação com a matéria, conforme descrito a seguir ${ }^{(2,6,12)}$.

\subsubsection{PARTÍCULAS CARREGADAS}

As interações com a matéria para partículas carregadas pesadas (PCP) e partículas carregadas leves (PCL) podem ocorrer das seguintes formas ${ }^{(2,6,12)}$ :

a) espalhamento elástico pelo campo coulombiano do núcleo dos átomos que compõem o meio material: esta interação não causa perdas da energia da radiação incidente, mas determina alteração em sua trajetória.

- para PCP: devido a sua massa apresentam ângulos de espalhamento próximos de 1 grau. Logo, trata-se de um processo desprezível;

- para PCL: apresenta intenso espalhamento e, conseqüentemente, trajetória tortuosa no meio material;

b) espalhamento elástico com elétrons dos átomos que compõem o meio material:

- para PCP: efeito desprezível;

- para PCL: pode ocorrer para partículas com energias próximas de $100 \mathrm{keV}$ e constitui um processo que não causa perdas de energia da radiação incidente;

c) espalhamento inelástico com núcleos dos átomos do meio material: processo que determina perda de energia da radiação incidente por emissão de radiação de freamento / bremstrahllung (diminuição contínua) e ocorre sempre que uma partícula carregada sofre 
variação de velocidade. Tal processo faz com que a partícula carregada emita radiação eletromagnética com espectro contínuo.

\subsubsection{RADIAÇÕES ELETROMAGNÉTICAS}

As radiações eletromagnéticas podem penetrar grandes espessuras de determinados materiais antes de perderem parte de sua energia através de interações. A capacidade de penetração da radiação em determinado meio depende da probabilidade de interação (seção de choque) para espalhamento ou absorção da radiação incidente, bem como de sua energia inicial $^{(2,6,71)}$.

As principais formas de interação da radiação eletromagnética com um meio material são: efeito fotoelétrico, efeito Compton e produção de pares, conforme Figura 2.

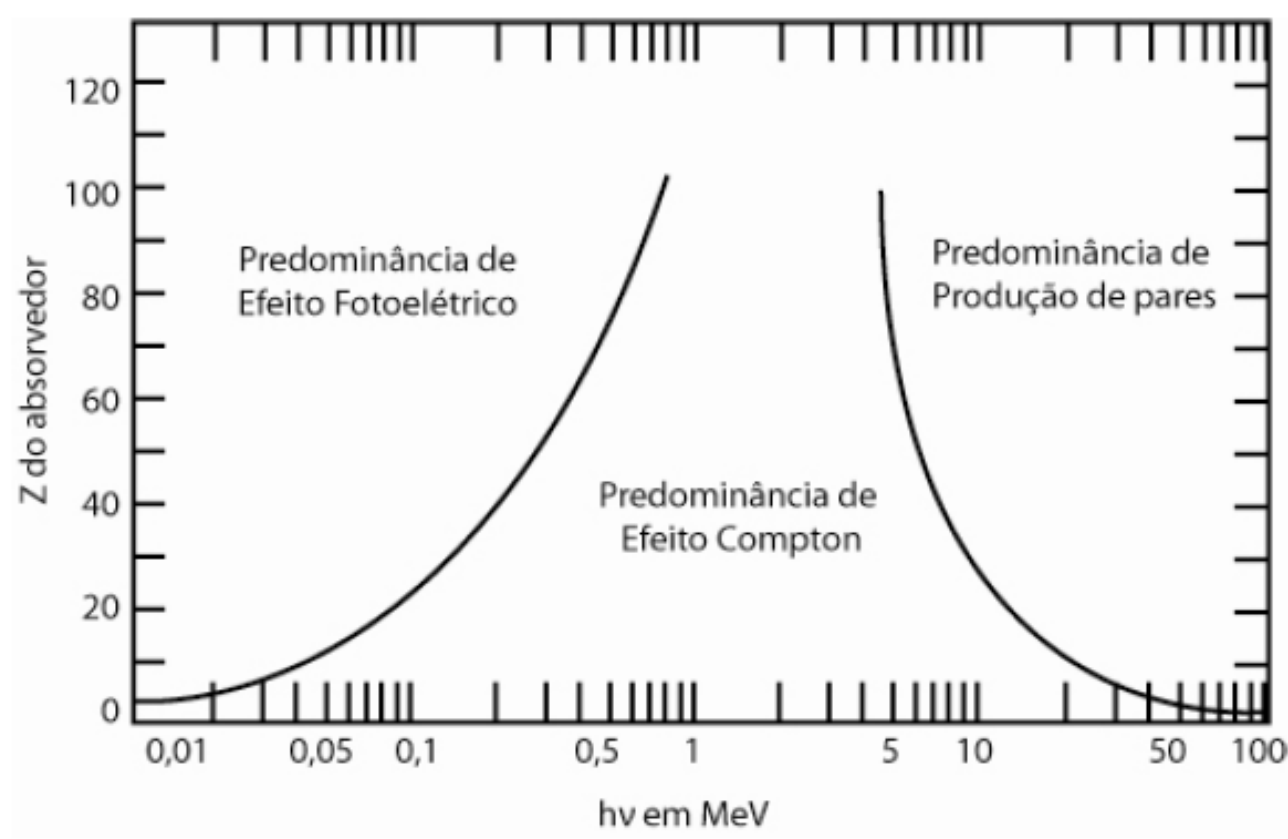

Figura 2: Regiões de predominância de ocorrência dos efeitos de interação da radiação em função da energia do fóton incidente ( hv ) e do número atômico (Z) do material absorvedor ${ }^{(2)}$. 
A probabilidade de interação da radiação eletromagnética (fótons de raios-X ou gama) com um determinado material detector, é função do número atômico $\mathrm{Z}$ em suas respectivas faixas de energias, com as seguintes dependências aproximadas:

a) $Z^{\mathrm{n}}(4<\mathrm{n}<5)$ para ocorrer efeito fotoelétrico;

b) Z para ocorrer espalhamento Compton;

c) $Z^{2}$ para produção de pares.

\subsubsection{EFEITO FOTOELÉTRICO}

Efeito Fotoelétrico consiste no fenômeno em que um fóton de energia igual a $h . v$ (produto entre a constante de Planck e a frequência da radiação) interage com um átomo de determinado material, transferindo toda sua energia a um dos elétrons das órbitas mais internas do mesmo, como mostrado na Figura 3. Se a energia do fóton incidente for maior que a energia de ligação $E_{l}$ dos elétrons da camada mais interna do átomo, o fóton desaparece e o átomo emite um fotoelétron (na maior parte das vezes da camada $\mathrm{K}$ ) com energia cinética $E_{c}$, que é a diferença entre a energia do fóton incidente $(h . v)$ e a energia de ligação do elétron a sua órbita de origem $\left(E_{l}\right)$ :

$$
E_{c}(e V)=h . v-E_{l}
$$

As lacunas criadas pela emissão do fotoelétron fazem com que as camadas eletrônicas do átomo se recomponham, causando emissão de raios-X característicos. $\mathrm{O}$ fotoelétron emitido, por apresentar baixa energia, é rapidamente reabsorvido, causando emissão de raios-X característicos, que originam outro efeito fotoelétrico em outro átomo. Tem-se, assim, uma cadeia de criação de pares elétron - lacuna que é diretamente proporcional a energia do fóton incidente ${ }^{(2,6,72)}$. 


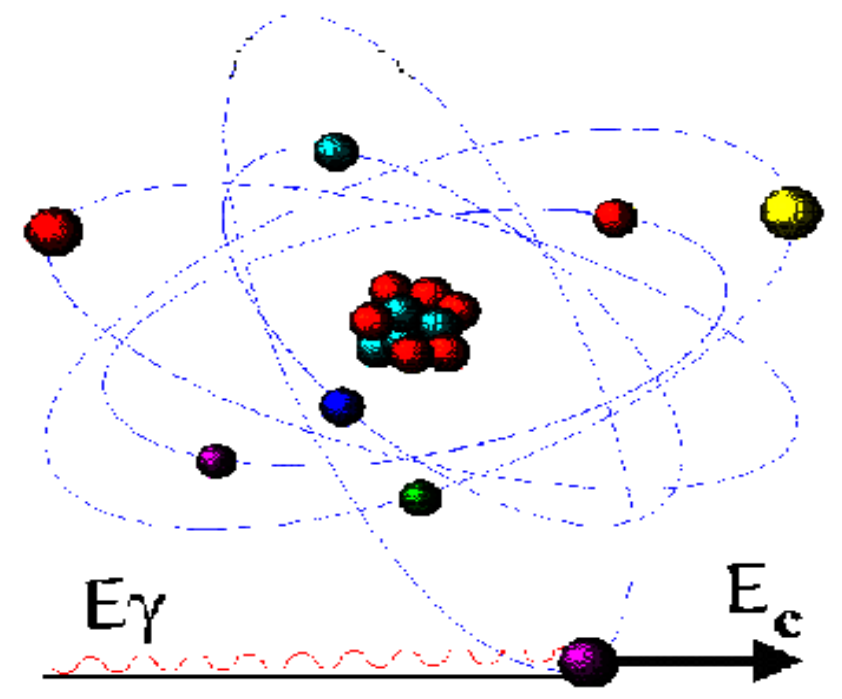

Figura 3: Ilustração do efeito fotoelétrico ${ }^{(8)}$.

\subsubsection{EFEITO COMPTON}

Efeito Compton consiste na interação de um fóton com um elétron da camada mais externa dos átomos de determinado material na qual ocorre colisão entre um fóton e um destes elétrons. Em tal colisão, o elétron absorve parte da energia do fóton, que passa a ter uma freqüência menor em relação à anterior e, assim, um comprimento de onda maior em relação ao anterior. O elétron é arrancado da estrutura atômica sob um ângulo $\theta$ e o fóton incidente é espalhado em uma direção distinta da direção de incidência, como mostrado na Figura $4^{(2,6,72)}$.

Partindo-se das conservações da quantidade de movimento e de energia, chega-se a equação do espalhamento de Compton $^{(2,6)}$.

$$
\begin{gathered}
\lambda_{2}=\frac{h}{m_{e} c}(1-\cos \theta)+\lambda_{1} \\
h v_{2}=\frac{h v_{1}}{1+\frac{h v_{1}}{m_{e} c^{2}}(1-\cos \theta)}
\end{gathered}
$$

onde

$\lambda_{1}$ é o comprimento de onda do fóton antes do espalhamento; $\lambda_{2}$ é o comprimento de onda do fóton depois do espalhamento; $\mathrm{m}_{\mathrm{e}}$ é a massa de repouso do elétron; 
$\mathrm{h} /\left(\mathrm{m}_{\mathrm{e}} \mathrm{c}\right)$ é conhecido como comprimento de onda de Compton;

$\theta$ é o ângulo pelo qual a direção do fóton é mudada;

h é a constante de Planck;

c é a velocidade da luz no vácuo;

$h v_{2}$ é a energia do fóton espalhado;

$h v_{1}$ é a energia do fóton incidente.

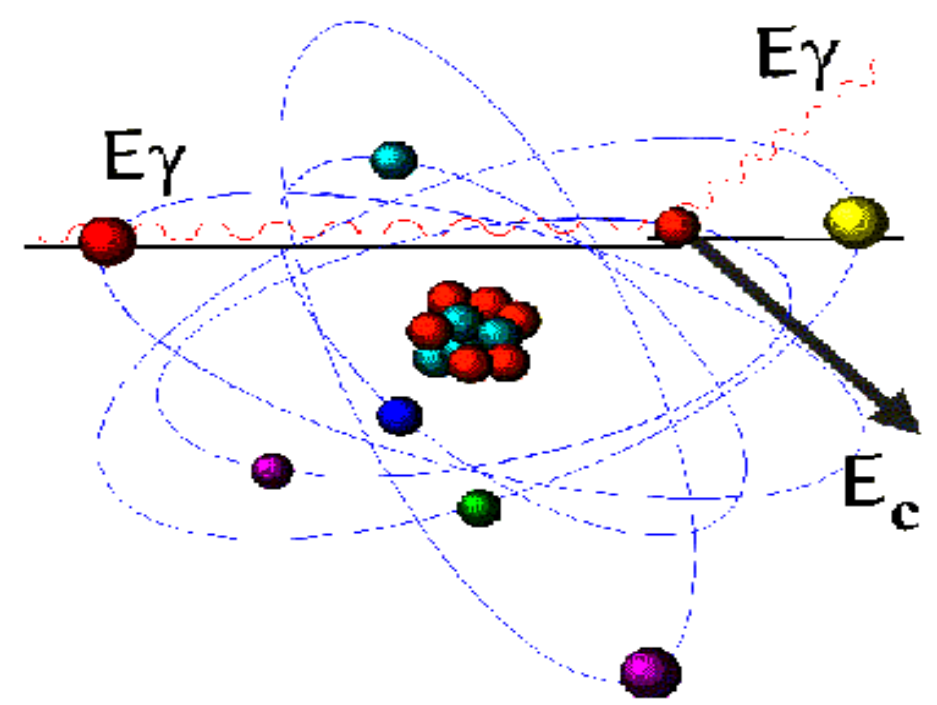

Figura 4: Ilustração do efeito Compton ${ }^{(8)}$.

\subsubsection{PRODUÇÃO DE PARES}

Produção de pares consiste no fenômeno em que um fóton (radiação eletromagnética) interage com o campo coulombiano próximo do núcleo atômico e desaparece, dando origem a um par elétron-pósitron. A energia mínima necessária para se produzir um elétron $\left(e^{-}\right)$e um pósitron $\left(e^{+}\right)$é fornecida conforme a relação relativística entre massa e energia dada pela seguinte equação ${ }^{(2,6,72)}$ :

$$
E=2 . m_{o} \cdot c^{2}(4)
$$

Na qual $m_{o}$ é a massa de repouso do elétron e $c$ é a velocidade da luz no vácuo.

Isso corresponde a um foton incidente com energia mínima de $1,02 \mathrm{MeV}$. 
O pósitron transmite sua energia cinética aos átomos do meio e em seguida volta a se combinar com um elétron, originando dois fótons, cada um com energia de $0,511 \mathrm{MeV}$, como mostrado na Figura 5.

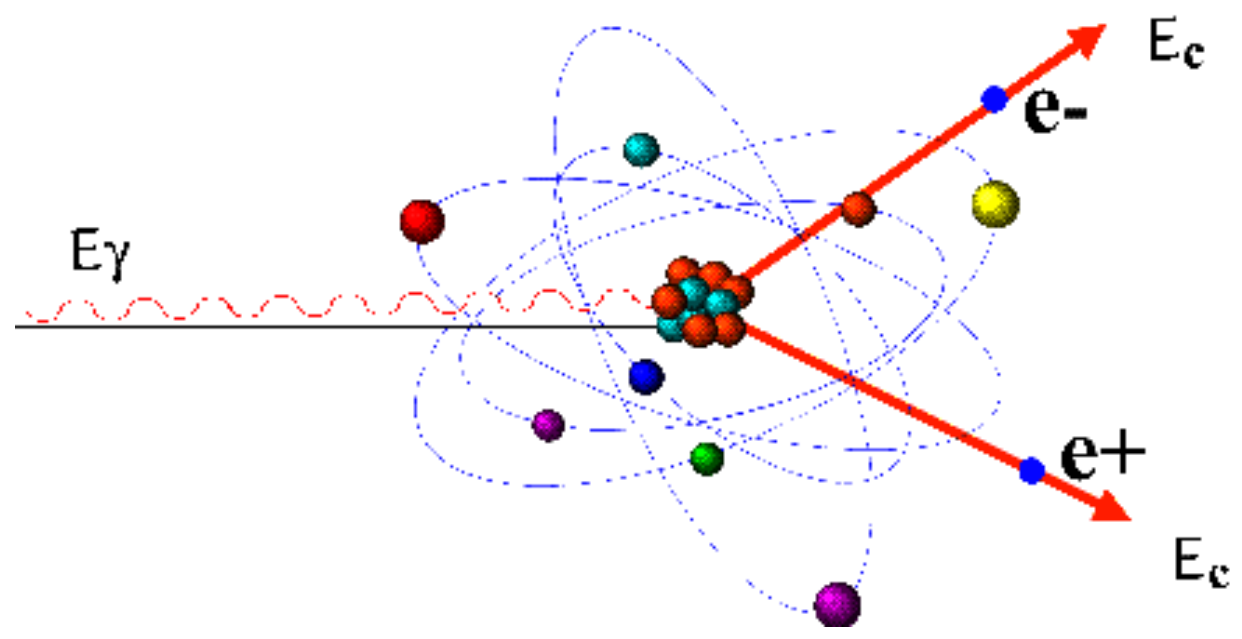

Figura 5: Ilustração do processo de produção de pares ${ }^{(8)}$.

\subsection{PROPRIEDADES DE DETECTORES SEMICONDUTORES}

Detectores de radiação são materiais capazes de indicar a presença de determinada radiação quando expostos a ela ${ }^{(2,6)}$. A partir de tal evento, tem-se diversos processos que podem evidenciar a radiação incidente, tais como produção de luz, produção de cargas elétricas, geração de calor, geração de traços no material, entre outros. Um detector é constituído de um material sensível à radiação e um sistema associado que transforme determinadas grandezas da radiação incidente em valores mensuráveis para serem analisados para diversas finalidades ${ }^{(2,6,72)}$.

O funcionamento de materiais detectores semicondutores é regido pelo princípio excitação dos elétrons, que passam da banda de valência para a banda de condução. Isso permite a coleção destes elétrons e a detecção da radiação ${ }^{(2,4,6,21)}$.

O grande interesse no uso de detectores semicondutores deve-se a propriedades superiores em comparação aos detectores cintiladores e gasosos: 
a) elevado número atômico [Z], o que possibilita um aumento da probabilidade de interação contribuindo para uma melhor resolução energética;

b) a quantidade de energia necessária para produzir um par elétron-lacuna nos semicondutores é de aproximadamente $3,5 \mathrm{eV}$; nos detectores gasosos é de $30 \mathrm{eV}$ e nos cintiladores é de $350 \mathrm{eV}$. Portanto, o número de portadores de carga gerados em um material semicondutor mediante perda da radiação incidente é muito superior. Isso contribui para uma melhor resolução energética ${ }^{(2,4,6,21)}$;

c) o pulso de saída nos detectores semicondutores é diretamente proporcional à quantidade de pares elétron - lacuna produzidos. Assim, esses detectores fornecem um pulso proporcional à energia do fóton incidente. Dessa forma, é possível identificar a energia da partícula incidente ${ }^{(2,4,6,21)}$.

O conjunto de propriedades requerido para atuar como um detector semicondutor para raios-X e gama e operar à temperatura ambiente é composto de:

(a) elevado número atômico [Z] para aumentar a probabilidade de interação;

(b) larga energia de banda proibida [Eg - entre 1,35 e 2,7eV], de modo a minimizar a corrente de fuga gerada termicamente [efeito termoiônico];

(c) alto produto de mobilidade dos portadores por tempo de vida $[\mu \tau]$, com o intuito de obter uma completa coleção de cargas, indispensável para boa resolução energética $^{(1,2,3,4)}$.

A Tabela 1 apresenta os principais materiais semicondutores e suas características, que são adequadas para sua aplicação como detectores de radiação ${ }^{(1,2,4,6)}$. 
Tabela 1: Propriedades de diversos semicondutores com características adequadas para aplicação como detectores de radiação.

\begin{tabular}{|c|c|c|c|c|c|c|}
\hline Material & $\mathrm{Z}$ médio & $\begin{array}{c}\text { Densidade } \\
\left(\mathrm{g} / \mathrm{cm}^{3}\right)\end{array}$ & $\begin{array}{c}\text { Energia } \\
\text { da banda } \\
\text { proibida }(\mathbf{e V})\end{array}$ & $\begin{array}{c}\text { Mobilidade de } \\
\text { elétrons (e) e } \\
\text { lacunas (l) } \\
\left(\mathrm{cm}^{2} / \mathrm{V} . \mathbf{s}\right)\end{array}$ & $\begin{array}{l}\text { Resistividade } \\
\qquad(\Omega \mathrm{cm})\end{array}$ & 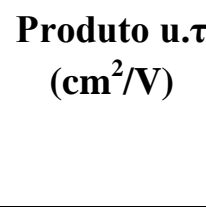 \\
\hline \multirow[t]{2}{*}{ TIBr } & \multirow[t]{2}{*}{58} & \multirow[t]{2}{*}{7,5} & \multirow[t]{2}{*}{2,70} & e: 6 & \multirow[t]{2}{*}{$10^{12}$} & e: $1,3.10^{-5}$ \\
\hline & & & & $1: 2$ & & $1: 1,5 \cdot 10^{-6}$ \\
\hline \multirow[t]{2}{*}{$\mathbf{P b I}_{2}$} & \multirow[t]{2}{*}{67} & \multirow[t]{2}{*}{6,2} & \multirow[t]{2}{*}{2,55} & $\mathrm{e}: 8$ & \multirow[t]{2}{*}{$10^{13}$} & e: $8.10^{-3}$ \\
\hline & & & & $1: 2$ & & $1: 9.10^{-7}$ \\
\hline \multirow[t]{2}{*}{$\mathbf{H g I}_{2}$} & \multirow[t]{2}{*}{62} & \multirow[t]{2}{*}{6,4} & \multirow[t]{2}{*}{2,13} & $\mathrm{e}: 10$ & \multirow[t]{2}{*}{$10^{14}$} & e: $1.10^{-3}$ \\
\hline & & & & $1: 4$ & & $1: 8.10^{-5}$ \\
\hline \multirow[t]{2}{*}{ CdTe } & \multirow[t]{2}{*}{50} & \multirow[t]{2}{*}{6,06} & \multirow[t]{2}{*}{1,52} & e: 1050 & \multirow[t]{2}{*}{$10^{9}$} & e: $8.10^{-4}$ \\
\hline & & & & $1: 100$ & & 1: $2.10^{-4}$ \\
\hline \multirow[t]{2}{*}{ CdZnTe } & \multirow[t]{2}{*}{39} & \multirow[t]{2}{*}{6} & \multirow[t]{2}{*}{1,6} & e:1120 & \multirow[t]{2}{*}{$10^{11}$} & $\mathrm{e}: 1.10^{-5}$ \\
\hline & & & & $1: 200$ & & $1: 1.10^{-6}$ \\
\hline \multirow[t]{2}{*}{ GaAs } & \multirow[t]{2}{*}{32} & \multirow[t]{2}{*}{5,3} & \multirow[t]{2}{*}{1,42} & e:8500 & \multirow[t]{2}{*}{$10^{8}$} & - \\
\hline & & & & $1: 400$ & & \\
\hline \multirow[t]{2}{*}{$\mathbf{S i}$} & \multirow[t]{2}{*}{12} & \multirow[t]{2}{*}{2,33} & \multirow[t]{2}{*}{1,12} & e: 1300 & \multirow[t]{2}{*}{$2,3 \times 10^{5}$} & $\mathrm{e}: 0,4$ \\
\hline & & & & 1: 500 & & $1: 0,2$ \\
\hline \multirow[t]{2}{*}{ Ge } & \multirow[t]{2}{*}{32} & 5,33 & 0,72 & e: 3800 & 47 & $\mathrm{e}: 0,8$ \\
\hline & & & & 1: 1800 & & $1: 0,8$ \\
\hline
\end{tabular}

\subsection{CRISTAIS UTILIZADOS COMO DETECTORES SEMICONDUTORES DE RADIAÇÃO}

Um cristal é constituído por um conjunto de átomos ou moléculas constituído por uma repetição regular em três dimensões de uma determinada unidade fundamental chamada de célula unitária do cristal $^{(71,73)}$. A estrutura cristalina é composta de uma rede (estrutura geométrica regular) e uma base (distribuição dos átomos do material em cada ponto da rede). A menor célula cristalina capaz de gerar a rede é chamada de célula primitiva. Com isso, uma célula primitiva que é transladada múltiplas vezes nas direções x, y e z gera a rede cristalina inteira $^{(71,73)}$.

A formação de núcleos sólidos de determinado material a partir de uma fase líquida ocorre pelo processo de nucleação. Este processo pode ser definido como a formação de uma nova fase a partir de outra em posição específica. A nucleação é caracterizada por contornos 
bem definidos que a separam do meio que a gerou. No caso da solidificação, a nucleação envolve a formação de partículas de sólido envolvidas pelo material líquido. As condições que favorecem a ocorrência de nucleação dependem dos aspectos termodinâmicos e das condições cinéticas da transformação. Quando o sólido é formado dentro do próprio líquido sem o auxílio de nenhum tipo de estimulante energético externo, diz-se que a nucleação é homogênea. Todavia, o processo pode sofrer uma ação catalisadora por meio da presença de partículas sólidas em suspensão no líquido, ou elementos/compostos inseridos propositalmente. Sob tais condições, o processo de nucleação tem início exatamente nessas partículas diferentes do sistema e é denominado de nucleação heterogênea ${ }^{(74)}$.

Os átomos que formam um determinado cristal são unidos por ligações covalentes entre os elétrons de suas camadas mais externas. Nestas ligações, tais elétrons são compartilhados entre os átomos dos elementos que formam o cristal, conforme Figura 6.

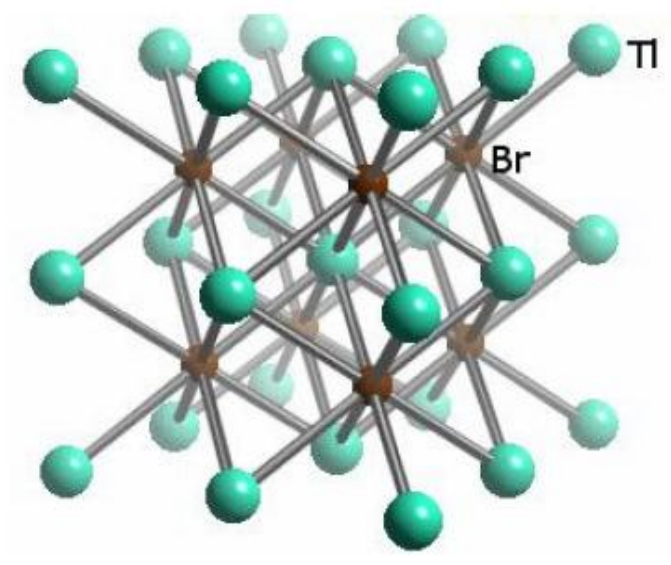

Figura 6: Estrutura cúbica simples do cristal semicondutor de $\mathrm{TlBr}^{(2)}$.

Devido ao processo de quantização de energia, somente determinadas dimensões de órbitas (níveis de energia) são permitidas aos elétrons dos átomos. Quanto maior for a órbita do elétron, maior será seu nível de energia potencial em relação ao núcleo. Se um determinado átomo sofre incidência de energia externa, na forma de radiação, por exemplo, um de seus elétrons pode ser elevado a um nível mais energético em relação ao inicial, constituindo o chamado estado excitado do átomo ${ }^{(72)}$. 
Os níveis energéticos de elétrons de camadas mais internas dos átomos não sofrem influência significativa de átomos vizinhos, mas os níveis energéticos de elétrons da camada mais externa são influenciados, uma vez que tais elétrons são compartilhados por mais um átomo na estrutura cristalina devido a ligações covalentes. Segundo a Mecânica Quântica tais compartilhamentos geram uma banda de estados de energias muito próximos, níveis discretos de energia, em vez de níveis de energia separados presentes no átomo isolado ${ }^{(2,72)}$.

Uma representação ilustrativa das bandas de energia é mostrada na Figura 7. A banda mais baixa, representada pelo nível de energia inferior, consiste na banda de valência, que corresponde aos elétrons que estão ligados a níveis específicos na estrutura cristalina. A banda mais alta, representada pelo nível de energia superior, consiste na banda de condução e corresponde aos elétrons que estão livres para migrar pelo cristal. Assim, os elétrons que estão na banda de condução contribuem para a condutividade elétrica de determinado material.

A principal diferença entre os materiais sólidos é a chamada banda proibida, isto é, a energia necessária para um elétrons migrar da banda de valência para a banda de condução. Ela define se o material é isolante, condutor ou semicondutor. Os condutores possuem as bandas parcialmente preenchidas, fazendo com que haja uma intersecção entre estas bandas que acaba permitindo que um elétron migre de uma a outra. Com a aplicação de um campo elétrico, estes elétrons adquirem uma energia adicional e vão para estados de maior energia constituindo a corrente ${ }^{(72)}$. Quanto menor a banda proibida, mais fácil é a possibilidade de um elétron migrar de uma banda para a outra e, assim, aumentar a condução do material ${ }^{(2,72)}$. Já os semicondutores, possuem uma banda proibida grande em relação aos metais, de forma que a condução nesses materias fica condicionada à energia de excitação dos elétrons, isto é, quanto maior a temperatura maior será a energia térmica dos elétrons e com isso mais elétrons serão transferidos à banda de condução, aumentando assim a condutividade do material. Cada um dos tipos conhecidos de semicondutores possui uma energia de banda proibida específica, como mostrado na Figura 7. 


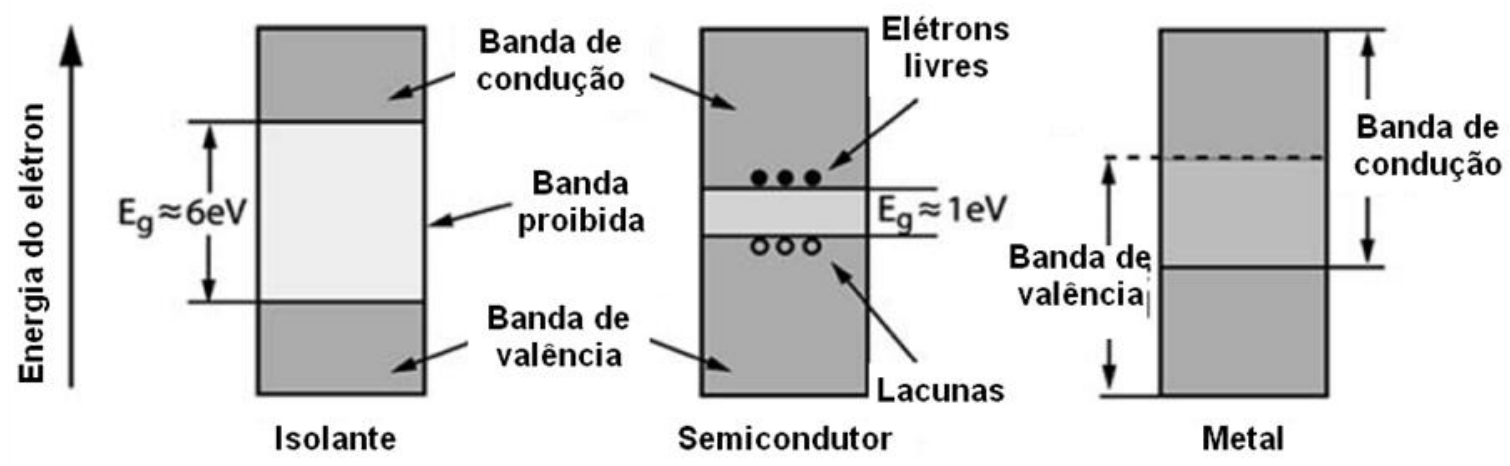

Figura 7: Ilustração dos níveis de energia para materiais isolantes, condutores e semicondutores(72).

Quando elétrons migram de uma banda para outra, deixam um espaço de carga positiva, uma lacuna. Estas lacunas referem-se a estados da banda de valência vazios, não preenchidos por elétrons com carga negativa. Na realidade a lacuna não existe como partícula ou como entidade isolada, mas ela é uma conseqüência do movimento de elétrons. Com isso, tem-se um movimento de cargas negativas associadas aos elétrons e um movimento de cargas positivas associado às lacunas ${ }^{(4,44)}$.

Quando um feixe de radiação externa colide com elétrons dos átomos de determinado material, os elétrons têm suas direções mudadas. A distância média entre tais colisões é denominada de livre percurso médio ${ }^{(72)}$. Com a aplicação de um campo elétrico constante os elétrons dos átomos do material são acelerados até o instante de sua colisão, na qual perdem energia e atingem um novo valor de velocidade de deriva. Sendo v a velocidade de deriva dos elétrons e $\varepsilon$ a permissividade elétrica, a mobilidade $\mu\left(\mathrm{m}^{2} / \mathrm{V} . \mathrm{s}\right)$ é definida por:

$$
\mu=v / \varepsilon
$$

\subsection{CRESCIMENTO DE CRISTAIS}

Crescimento de cristais consiste na modificação estrutural atômica de um determinado material de partida seguida de sua organização em uma estrutura cristalina com orientação bem definida, sendo um processo diretamente ligado ao fenômeno de nucleação. Para ocorrer, é preciso de uma fonte de aquecimento, que fornecerá a energia cinética necessária para que os átomos do material de partida se depreendam, e uma fonte de resfriamento, que diminuirá a 
energia cinética dos átomos, fornecendo o gradiente de temperatura necessário para a formação cristalina.

A produção industrial de cristais foi iniciada em 1902, quando Verneuil pioneiramente controlou o processo de nucleação no crescimento de cristais de rubi e safira ${ }^{(75)}$.

O crescimento de cristais pode ser realizado por meio das técnicas de fusão, de epitaxia e de solução saturada. O presente trabalho foi focado prioritariamente na técnica de fusão, que foi empregada por meio do método de Bridgman ${ }^{(4,21,41,42,75)}$.

\subsubsection{PURIFICAÇÃO E CRESCIMENTO DE CRISTAIS PELO MÉTODO DE BRIDGMAN}

Em 1925 P.W. Bridgman desenvolveu o método de crescimento de cristais que leva o seu nome. Este método consiste prioritariamente na fusão completa de um determinado material de partida em um molde que lhe dará a geometria desejada. Posteriormente o material é submetido a um gradiente de temperatura adequado para seu resfriamento e formação da estrutura cristalina ${ }^{(4,6,7,75,83)}$.

Para a obtenção de monocristais sem a utilização de semente, pode ser utilizado como mecanismo adicional um molde (tubo) de quartzo afinado/afunilado em sua extremidade inferior onde se inicia o crescimento. Com isso, tem-se o preenchimento da secção reta do tubo de quartzo com um pequeno monocristal, que servirá de semente para o crescimento

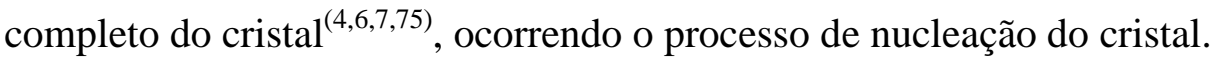

O gradiente de temperatura da região de crescimento deve ser alto o suficiente de modo que apenas um pequeno volume do material fundido seja super resfriado. Já o gradiente de temperatura na região em que o material já está cristalizado deve ser baixo de modo que tensões térmicas no cristal não sejam introduzidas. A taxa de resfriamento do cristal é fundamental para sua qualidade de modo que não ocorram trincas e deformações. A taxa recomendada para o cristal de $\mathrm{TlBr}$ é de $20^{\circ} \mathrm{C} / \mathrm{h}^{(4)}$. 
A purificação do cristal de $\mathrm{TlBr}$ pode ser feita por repetições de processo de crescimento, método de Bridgman repetido ${ }^{(4,42,75)}$. A cada crescimento as impurezas tendem a migrar nas extremidades do cristal, dependendo do coeficiente de segregação $k$ de cada impureza: (a) para $k$ menor do que a unidade a região inicial do material solidificado será mais pura, porque o soluto será rejeitado pelo sólido e se acumulará no líquido, (b) para $k$ maior do que a unidade, a região final do material solidificado será mais pura. Para $k$ igual a um, a impureza será distribuída homogeneamente ao longo do cristal $^{(4,74)}$.

Um esquema de um forno vertical de Bridgman é mostrado na Figura 8.

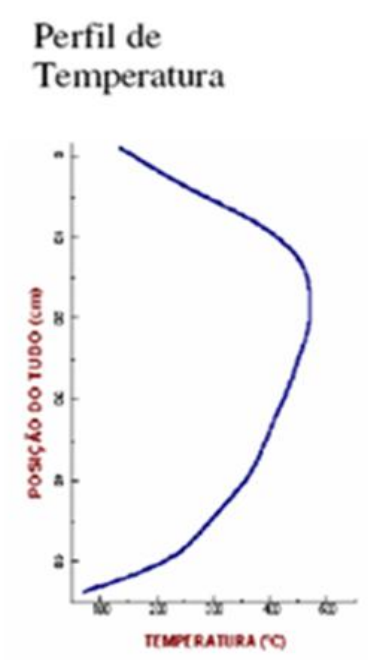

Figura 8: Perfil térmico interno do forno vertical utilizado na técnica de Bridgman ${ }^{(4)}$

\subsection{MÉTODOS DE CARACTERIZAÇÃo FÍSICO -QUÍMICA DE MATERIAIS CRISTALINOS}

\subsubsection{DIFRAÇÃO DE RAIOS-X (DRX)}

Uma técnica para se obter as dimensões e a composição da célula cristalina, isto é, fazer uma análise microestrutural, é incidir radiação de comprimentos de onda adequados sobre o 
cristal. Este é o princípio fundamental da técnica de difração de raios-X. Os primeiros estudos dessa técnica foram feitos em 1912 pelo físico alemão Max Von Laue. Ele considerou que , se os cristais eram compostos de átomos regularmente espaçados que podem atuar como centros de dispersão para raios- $\mathrm{X}$, e se os raios-X eram ondas eletromagnéticas de comprimento de onda igual à distância interatômica nos cristais, então seria possível difratar raios-X por meio de cristais $^{(71)}$.

Quando o comprimento de onda da radiação incidente é da mesma ordem de grandeza que a distância interatômica da rede cristalina, o feixe é difratado em relação de fase (interação construtiva - formação de picos de difração) pelos átomos do cristal. Com este feixe difratado, pode-se calcular as posições dos átomos no cristal, planos cristalinos, por meio da Lei de Bragg ${ }^{(71,73)}$, como mostrado na Figura 9 e na equação 6:
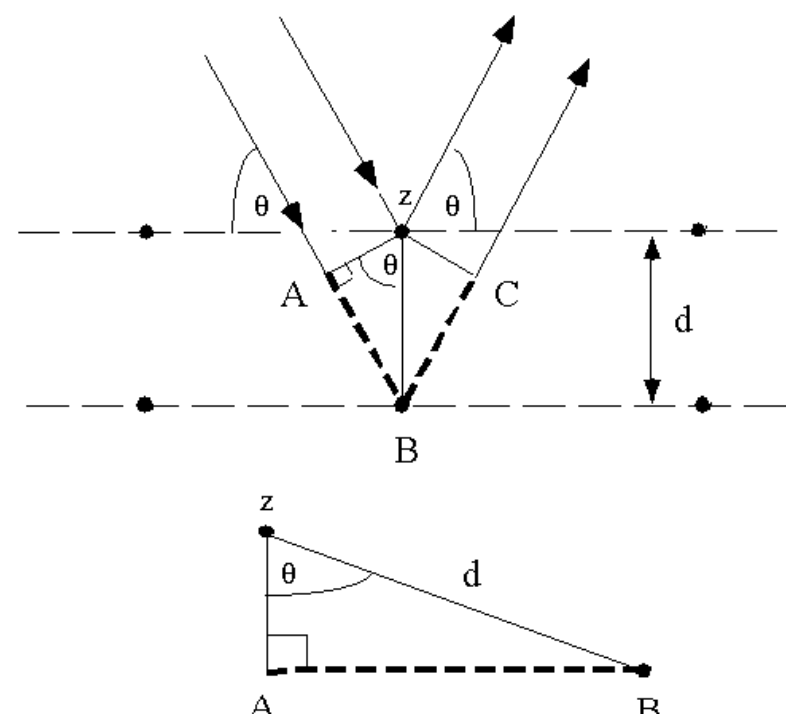

Figura 9: Feixe incidindo em planos cristalinos

Sendo $\theta$ o ângulo da radiação incidente no plano de átomos em análise, $d$ a distância entre os planos cristalinos, $A B C$ a trajetória extra que a radiação difratada pelo átomo $\mathrm{B}$ tem de percorrer, tem-se:

$$
\begin{gathered}
A B=d \sin \theta \\
\text { como } A B=B C,
\end{gathered}
$$




$$
\begin{aligned}
& n \lambda=2 A B, \text { ou seja: } \\
& n \lambda=2 d \sin \theta
\end{aligned}
$$

Considerando-se uma estrutura cúbica simples e sendo $a$ a distância interatômica, parâmetro de rede, e $h, k, l$ os índices de Miller, que fornecem a orientação do plano cristalino ${ }^{(71,73)}$, temse a relação:

$$
d=\frac{a}{\sqrt{h^{2}+k^{2}+l^{2}}}
$$

Com isso, variando-se o ângulo de incidência, pode-se obter informações relacionadas a diversas famílias de planos cristalinos, bem como suas orientações em relação ao feixe de radiação incidente. Esta técnica permite, assim, estudar os planos cristalinos, as distâncias interplanares e densidades nos planos específicos e comparação entre padrões difratométricos.

Quando os átomos de um determinado material sofrem empilhamentos dando origem a planos bem definidos no espaço, apresentando uma mesma orientação (índices de Miller), tem-se a formação de monocristais. Uma vez que a obtenção de monocristais é tecnologicamente complexa, o emprego da técnica de DRX faz necessária a pulverização do cristal a ser analisado. Isso possibilita que os planos de difração do material, com orientação específica, sejam distribuídos em todas as direções, aumentando a probabilidade de ocorrer a difração ${ }^{(71,73)}$.

\subsubsection{ESPECTROMETRIA DE MASSAS COM PLASMA (ICP-MS)}

Um dado composto químico pode ser identificado por meio da técnica de espectroscopia de massas com plasma.

Nesta técnica, o espectrômetro de massas bombardeia uma determinada substância com um feixe de plasma de modo a ionizar seus átomos ou deixá-los eletricamente carregados. Estes íons passam por um campo magnético que curva suas trajetórias de formas diferentes, de acordo com as características intrínsecas de seus espectros de massas. Com isso, tem-se 
uma relação específica entre massa e carga para os íons de cada material e sua posição no espectro.

Deve-se manter baixas pressões no espectrômetro a fim de evitar colisões entre os íons a serem analisados e outras moléculas no interior do espectrômetro, pois essas possíveis colisões podem causar reações químicas, transformação de energia e alteração na trajetória dos íons de interesse, comprometendo os resultados finais ${ }^{(76)}$.

O espectrômetro de massas é fundamentalmente composto das seguintes partes ${ }^{(76)}$ :

a) Fonte de plasma: converte os átomos dos elementos de determinada amostra em íons gasosos. A saída da fonte é um feixe de íons gasosos que são acelerados para o analisador de massa. Alguns elementos podem ser utilizados na fonte de plasma, dentre eles o argônio, conforme o equipamento e a necessidade de se quantificar uma amostra específica;

c) Analisador de massa/separador de íons: é a parte do equipamento responsável pela discriminação dos íons produzidos, que têm suas trajetórias controladas com o emprego de campos eletromagnéticos e são selecionados de acordo com sua relação m/Z (massa / carga);

d) Detector e sistema de análise: são responsáveis por detectar os íons e convertê-los em sinais elétricos que são amplificados, processados e analisados.

Portanto, de forma simplificada tem-se o seguinte procedimento:

a) Introdução da amostra / analito a ser analisada no espectrômetro de massas;

b) Argônio (Ar) é semeado com elétrons livres oriundos de uma faísca de alta tensão;

c) Campos elétricos e magnéticos são produzidos por um gerador de ondas de rádio geradas dentro de uma bobina de carga. Ocorre a aceleração e colisões de elétron de modo a produzir plasma (tocha de plasma). O material da amostra é ionizado por meio do bombardeamento com plasma; 
d) Plasma com alto estado de energia: as moléculas injetadas na tocha são quebradas em seus constituintes químicos, que são ionizados. Ocorre a separação e quantificação dos íons conforme sua relação de carga/massa e sua posição no espectro de massas;

e) Coleta de íons através de um orifício diminuto de dois cones metálicos (skimmer localizados na interface). Esse feixe focalizado de íons é transferido para o separador/analisador de massa (ion lens $-10^{-5}$ torr);

f) Razão $\mathrm{m} / \mathrm{Z}$ dos íons: os íons seguem trajetória homogênea e conseguem atravessar o quadrupolo magnético, cujos valores de interesse são pré-selecionados. Com isso, tem-se a formação de pulsos elétricos de curtíssima duração, que são detectados e medidos;

g) Processamento dos sinais e construção da curva de intensidade iônica x relação massa / carga para identificação dos materiais da amostra inicial.

A configuração de um espectrômetro pode ser visto na Figura 10.

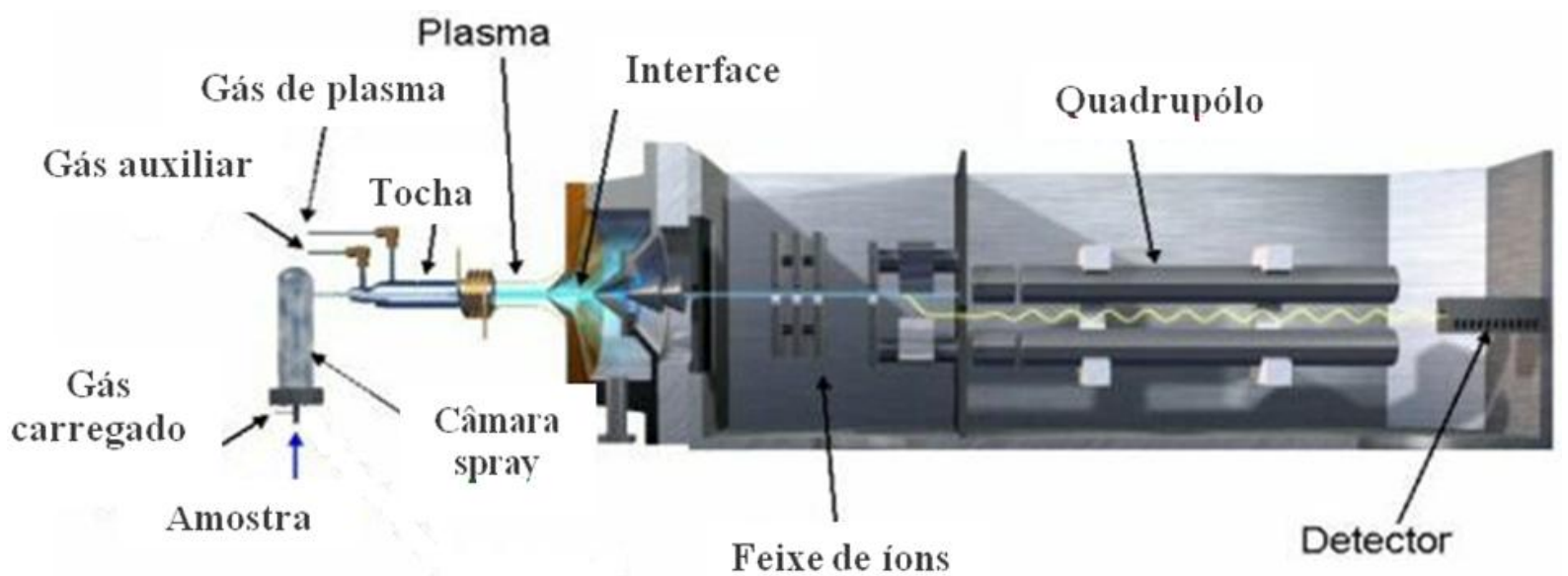

Figura 10: Funcionamento de um equipamento de ICP-MS ${ }^{(76)}$. 


\subsubsection{MICROSCOPIA ELETRÔNICA DE VARREDURA (MEV)}

A técnica de microscopia eletrônica de varredura permite a obtenção de informações químicas e estruturais de amostras de diversos materiais, possibilitando correlacionar sua microestrutura com propriedades químicas, mecânicas e processos de fabricação relacionados. Possui alta resolução $(0,2$ a $5 \mathrm{~nm})$, grande profundidade de foco, imagem com aparência tridimensional e relativa facilidade de preparação das amostras. Essa técnica possibilita que um feixe de elétrons de alta energia incida na superfície de determinada amostra com a probabilidade de ocorrer os seguintes fenômenos: (a) parte do feixe é refletida e coletada por um sistema detector que converte este sinal em uma imagem de elétrons retroespalhados (BSE); (b) parte do feixe incide no material provocando a emissão de elétrons, produzindo a chamada imagem de elétrons secundários (ES) e (c) ocorre a emissão de raios-X que permite conhecer a composição química de um ponto ou região específicos da superfície da amostra e identificar os elementos químicos presentes na mesma ${ }^{(21,77)}$.

\subsubsection{FORMULAÇÃO DE MODELOS - ANÁLISE COMPARTIMENTAL}

A teoria dos compartimentos é uma ferramenta poderosa para a análise de fenômenos cinéticos, de migração e transporte de moléculas e suas transformações químicas. Esta forma de análise determinista envolve a divisão do sistema utilizado em uma série de compartimentos interligados, onde um compartimento é definido como qualquer subdivisão estrutural, química, funcional ou física de um sistema. A suposição básica é que o analito é uniformemente distribuído em todo o compartimento ${ }^{(78)}$. A partir de tais definições, pode-se utilizar ferramentas algébricas para relizar ajustes de aproximações, de modo a descrever quantitativamente as grandezas desejadas ${ }^{(79.80)}$.

A teoria dos compartimentos foi usada como modelo matemático para explicar e ajustar os dados da concentração de impurezas como função do número de repetições do crescimento do cristal. Na teoria de análise compartimental, assume-se que a variação no conteúdo do i-ésimo compartimento $\mathrm{Ci}$ (onde Ci é a concentração de impurezas no compartimento i), como função da variável $\mathrm{x}$ (onde $\mathrm{x}$ é o número de repetições do processo de crescimento), pode ser equacionada como: 


$$
\frac{d C_{i}(x)}{d x}=-\sum_{i=1 ; i \neq j}^{N} k_{i, j} \cdot C_{i}(x)+\sum_{j=1 ; j \neq i}^{N} k_{j, i} \cdot C_{j}(x)
$$

Onde kij é o coeficiente/constante de migração de impureza do compartimento (região do cristal) i para o compartimento j e $\mathrm{N}$ é o número total de compartimentos.

\section{MATERIAIS E MÉTODOS}

\subsection{MATERIAIS UTILIZADOS}

* Sais comerciais de brometo de tálio (TlBr) com os seguintes índices nominais de pureza: 99,99\% (Merck) e 99,99\% (Sigma-Aldrich);

* Tubos de quartzo de diâmetro:1,8 cm / comprimento: $40 \mathrm{~cm}$ ) ( Hipperquimica e Vidrolex )

* Ácido Fluorídrico (HF ) P.A. ( Merck )

* Detergente neutro, Extran MA-02 ( Merck )

* Acetona P.A. (Merck )

* Argônio 6.0 (White Martins)

* Acetileno e oxigênio (White Martins)

* Tecido de algodão (100\%) e papel Sontara

* Abrasivos: lixas de $\mathrm{Al}_{2} \mathrm{O}_{3}$ com granulometria variando de 3 a $30 \mu \mathrm{m}$

* Pinturas de grafite (Electron Microscopy Sciences)

* Mistura de ácido nítrico (65\%, Merck) e peróxido de hidrogênio (30\%, Merck)

* Fita condutiva de carbono (modelo: double sided carbon tape, da Eletron Microscopy Sciences)

\subsection{EQUIPAMENTOS UTILIZADOS}

a) Tratamento químico / térmico dos tubos de quartzo e desumidificação do sal de brometo de tálio

* Bomba mecânica de vácuo, modelo A65401906, motor RV8 1 ph (Edwards)

* Controlador de temperatura com microprocessador, modelo JD13A (Dhacel ) 
* Termopar cromel-alumel tipo $\mathrm{K}$ revestido com aço inox e isolação mineral $\left(\mathrm{Al}_{2} \mathrm{O}_{3}\right)$ e com condutores de $0,2 \mathrm{~mm}$ de diâmetro cada

* Balança eletrônica (Marte - AS 5000C)

\section{b) Crescimento do cristal de brometo de tálio}

* Forno de crescimento de cristal por método de Bridgman, nas dimensões de $250 \mathrm{~mm}$ de largura e altura de 600 mm, modelo LEO110 (Jung)

* Controlador de temperatura com microprocessador, modelo E5T (Omron)

* Controlador de temperatura com microprocessador, modelo N1100 ( Novus )

* Termopar cromel-alumel tipo K com condutores de 0,3 mm de diâmetro cada

c) Corte e polimento do cristal de brometo de tálio

* Serra de diamante Isomet, modelo 11-1180 (Buehler Ltd.)

d) Caracterização de detecção à radiação dos cristais

* Multímetro modelo DM-25 (Beckman Indl.)

* Amperímetro modelo 619 (Keithey)

* Pré-amplificador sensível à carga de baixo ruído, modelo A250F (Amptek )

* Amplificador modelo 450 EG\&G (Ortec)

* Analisador Multicanal 918A EG\&G (Ortec)

* Fonte de tensão modelo 556 EG\&G (Ortec)

* Osciloscópio modelo TDS 3032B (Tektronix)

\section{d) Difração de Raios-X}

* Difratômetro de Raios X modelo D5005 (Siemens)

e) Microscopia eletrônica de varredura (MEV)

* Microscópio eletrônico de varredura modelo LX 30, Philips

* Evaporadora (modelo SCD 040, Balzers Union).

\section{f) Espectrometria de massas com plasma (ICP-MS)}

* Espectrômetro de massas com plasma (Elan 6100, Perkin Elmer, USA)

* Forno digestor com microondas (modelo DGT 100 Plus, Provecto Analítica). 


\subsection{AS ETAPAS DO PROCEDIMENTO EXPERIMENTAL}

O Trabalho realizado constituiu, basicamente, de três etapas experimentais distintas:

1- Purificação e crescimento dos cristais.

a) Levantamento do perfil térmico do forno utilizado no método de Bridgman;

b) Tratamento químico e térmico dos tubos de quartzo utilizados e desumidificação do sal de TlBr para o crescimento do cristal;

c) Crescimento de cristais pelo método de Bridgman repetidas vezes para purificação.

2- Tratamento das superfícies.

a) Corte do cristal usando serra de diamante e polimento das amostras;

3- Caracterização físico-química e de detecção à radiação dos cristais.

a) Análise da estrutura cristalina: difração de raios-X (DRX);

b) Análise morfológica e verificação estequiométrica: microscopia eletrônica de varredura com elétrons retro espalhados (MEV-BSE);

c) Caracterização do cristal semicondutor de TIBr como detector de radiação;

d) Preparação das amostras de TlBr para análises química das impurezas e do modelo compartimental;

e) Análise quantitativa das impurezas presentes: espectrometria de massas com plasma (ICP-MS);

f) Análise de segregação das impurezas presentes: análise compartimental (modelagem matemática).

\subsubsection{LEVANTAMENTO DO PERFIL TÉRMICO DO FORNO UTILIZADO NO MÉTODO DE BRIDGMAN}

O levantamento do perfil térmico do forno utilizado no método de Bridgman, mostrado na Figura 11, consiste em um procedimento fundamental para se mapear o gradiente térmico ao qual o material de partida será submetido no processo de crescimento e purificação do cristal de TlBr. Esse procedimento é necessário para verificar a simetria do gradiente de temperatura antes e depois da região de temperatura máxima do forno. É a partir desta região que se inicia o crescimento do cristal. $\mathrm{O}$ forno foi programado para atingir a temperatura máxima de $560{ }^{\circ} \mathrm{C}$. Assim, foi obtida uma curva de temperatura em função da posição do 
termopar no interior do forno vertical utilizado. A posição do termopar foi deslocada de 0,5 em $0,5 \mathrm{~cm}$ no interior do forno, registrando a sua temperatura a cada $0,5 \mathrm{~cm}$.
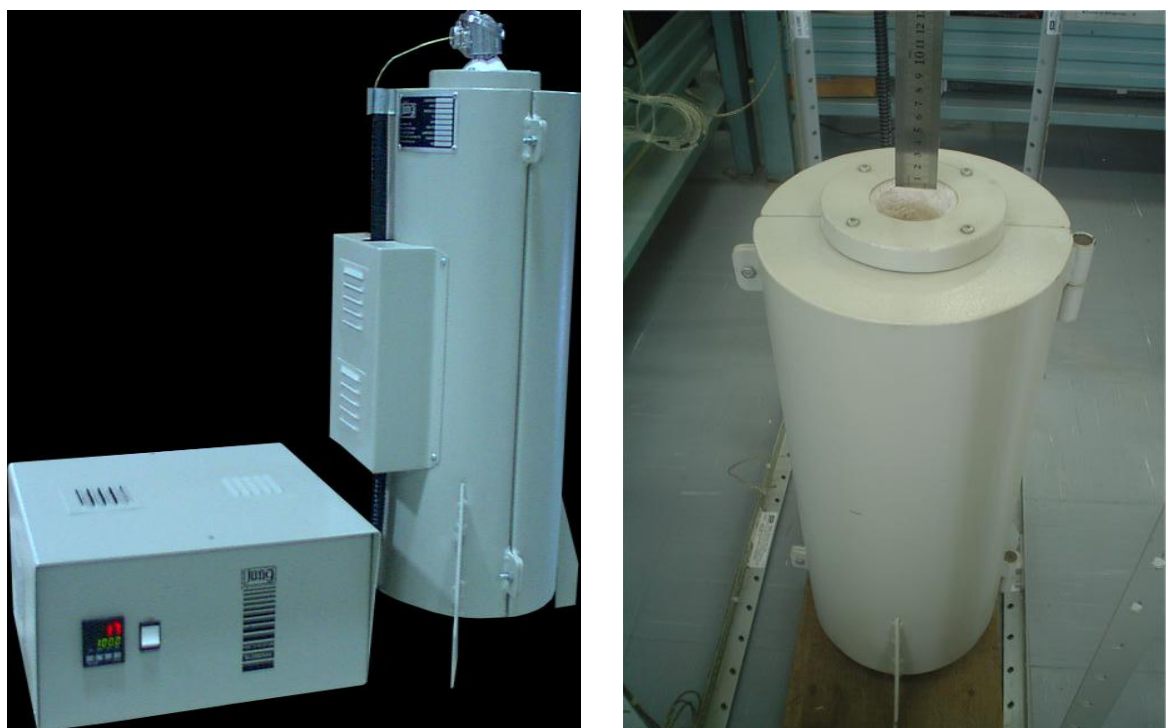

Figura 11: Forno vertical utilizado na técnica de Bridgaman.

\subsubsection{TRATAMENTO QUÍMICO E DESUMIDIFICAÇÃO DOS TUBOS DE QUARTZO E DESUMIDIFICAÇÃO DO SAL DE TIBr}

$\mathrm{Na}$ fase inicial do trabalho, os tubos de quartzo foram tratados, previamente, imergindoos em solução de EXTRAM $^{\mathrm{R}}(1 \% \mathrm{v} / \mathrm{v})$ durante $24 \mathrm{~h}$. A quantidade de sal utilizada foi definida de modo que a extensão final do tubo selado a vácuo, que deve apresentar 50\% de volume livre para expansão gasosa durante a fusão, não seja maior que a extensão do forno. Em seguida foi lavado com água deionizada repetidas vezes. Posteriormente foram submetidos ao tratamento químico com solução de ácido fluorídrico (HF - 5\% v/v) durante 20 minutos. Em seguida os tubos foram lavados com água desmineralizada repetidas vezes. Após esse processo, os tubos foram armazenados em uma estufa para secagem enquanto o forno de desumidificação tinha sua temperatura estabilizada a $250^{\circ} \mathrm{C}$ (tempo médio de 15 minutos). Posteriormente, um tubo foi acoplado à bomba de vácuo e ao forno para desumidificação durante um período de 2 horas. O controlador de temperatura foi programado para manter o forno a temperatura de $250{ }^{\circ} \mathrm{C}$. Na fase final do trabalho, ocorreu uma mudança no procedimento do tratamento dos tubos, na qual o uso do EXTRAM $^{\mathrm{R}}$ e HF foram substituídos, imergindo o tubo em solução de ácido nítrico $\left(\mathrm{HNO}_{3}-10 \%\right.$ v/v) durante 20 minutos. 
Em seguida $45 \mathrm{~g}$ de sal de $\mathrm{TlBr}$ foi adicionado ao tubo e realizou-se uma nova desumidificação durante um período de 1 hora sob a temperatura de $160{ }^{\circ} \mathrm{C}$.

Durante todo o processo um tubo de metal com curva em forma de "u" (trapping) é conectado entre o tubo que sai do registro e o tubo de saída da bomba de vácuo, conforme mostrado na Figura 12, permanecendo mergulhado em um suporte térmico (dewar) contendo nitrogênio líquido. Tal sistema faz com que os possíveis gases e impurezas que saem do tubo do material, ou da bomba, não retornem, ficando retidas no "trapping" imerso em nitrogênio líquido.

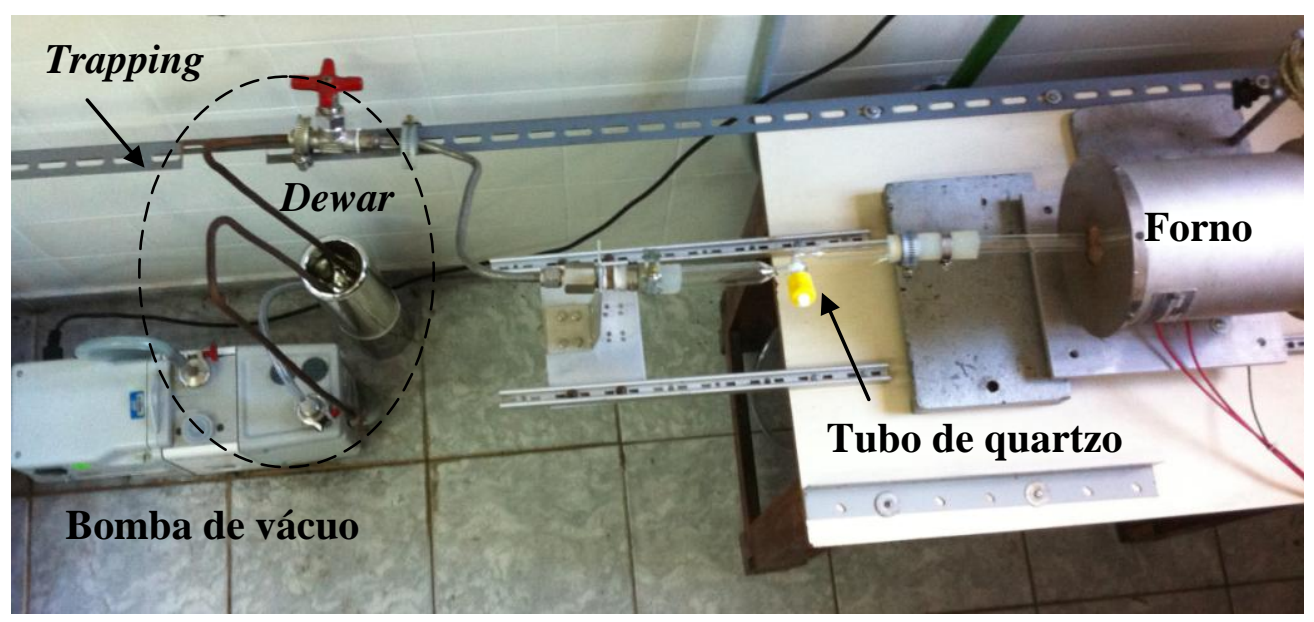

Figura 12: Montagem do sistema de desumidificação dos tubos de quartzo e do sal de TlBr:: forno para desumidificação acoplado a bomba de vácuo, com o trapping de cobre acoplado entre o forno e a bomba de vácuo.

Após a desumidificação o tubo contendo o sal de TlBr foi selado a vácuo e utilizado para o crescimento do cristal, como mostrado na Figura 13. 

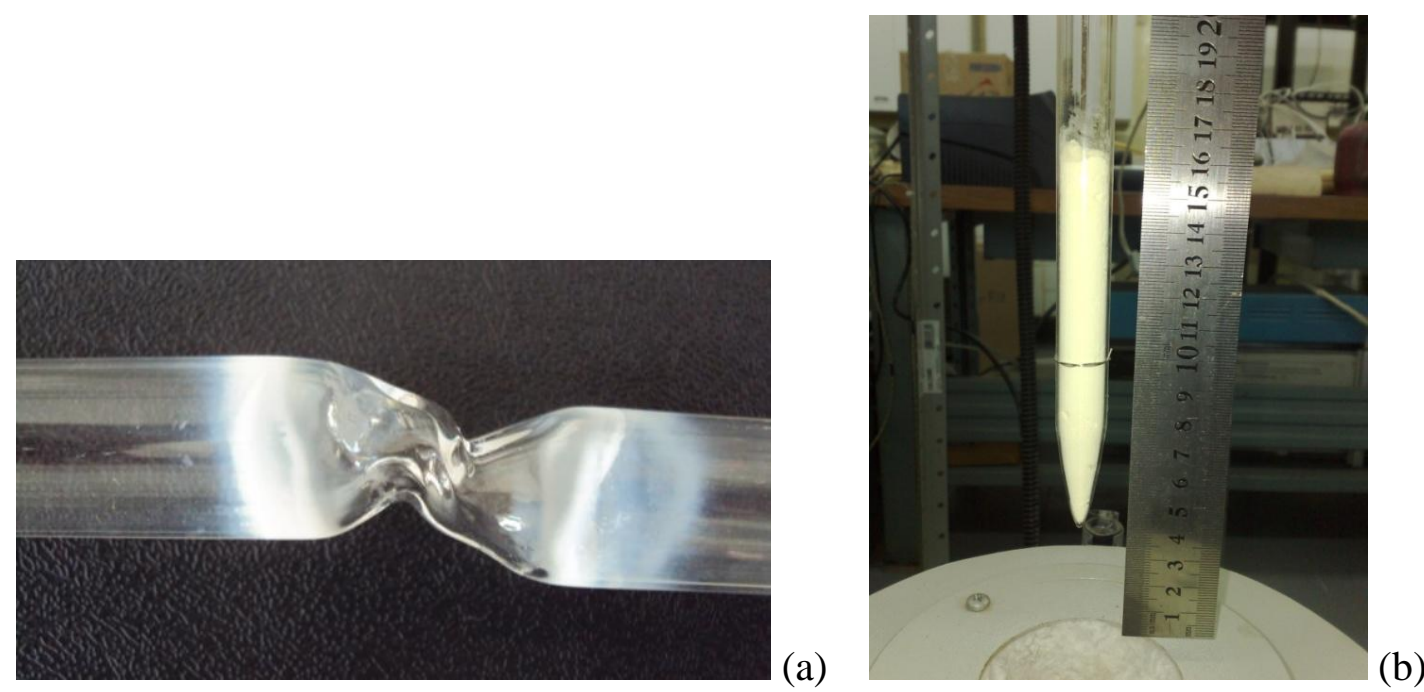

Figura 13: Selamento do tubo de quartzo a vácuo (a) e o tubo selado contendo o sal de $\mathrm{TlBr}$ (b).

\subsubsection{CRESCIMENTO DE CRISTAIS DE TIBr PELO MÉTODO DE BRIDGAMN E PURIFICAÇÃO POR BRIDGAM REPETIDO.}

$\mathrm{Na}$ região de temperatura máxima do forno foi posicionado o tubo de quartzo contendo $45 \mathrm{~g}$ do sal de $\mathrm{TlBr}$ previamente desumidificado e selado a vácuo. A seguir o sal de $\mathrm{TlBr}$ foi fundido. A partir desse ponto o tubo contendo o sal de $\mathrm{TlBr}$ é deslocado verticalmente para baixo a uma velocidade de $1 \mathrm{~mm} / \mathrm{h}$. O forno foi programado para atingir a temperatura máxima de $560{ }^{\circ} \mathrm{C}$ a $10^{-6}$ Torr e manter esta temperatura constante por 50 horas. Após este intervalo de tempo, a temperatura foi programada para resfriar vagarosamente, $20^{\circ} \mathrm{C} / \mathrm{h}$, até a temperatura ambiente. Tais condições permitem o crescimento de cristais com menores desordens estruturais e baixa tensão térmica ${ }^{(4)}$.

Após cada crescimento, o tubo de quartzo foi aberto e amostras da região superior e do meio do cristal foram retiradas para análise. A região restante da amostra é submetida a um novo processo de crescimento, Bridgman repetido. Este método tem como finalidade a purificação do cristal, onde as impurezas segregam para as extremidades do cristal. Com isso, espera-se encontrar maior pureza na região do meio do cristal, que é utilizada para o recrescimento. Foram utilizadas como materiais de partida sais de $\mathrm{TlBr}$ de duas procedências diferentes. Neste trabalho, referenciamos estes materiais como sal 1 e sal 2. 


\subsubsection{CORTE E POLIMENTO DOS CRISTAIS DE TIBr E APLICAÇÃO DOS CONTATOS ELETRÔNICOS}

A extremidade do cristal crescido (região de maior concentração de impurezas) foi cortada utilizando uma serra de diamante lubrificada com etileno glicol, como mostrado na Figura 14. O processo foi realizado lentamente durante o intervalo de $40 \mathrm{~min}$. Por este procedimento, três fatias de 1,0 mm de espessura da região central do cristal (região mais pura devido à segregação de impurezas para as extremidades) foram cortadas do cristal. Duas foram lapidadas, polidas e preparadas como detectores de radiação aplicando-se tinta de carbono coloidal (VIATRONIX M.R.) para constituir os contatos elétricos do detector. Da terceira amostra, $50 \mathrm{mg}$ foi utilizado para determinação das impurezas presentes pela técnica de ICP-MS e o restante para análise de difração de raios X. O polimento foi realizado utilizando abrasivos de lixas de $\mathrm{Al}_{2} \mathrm{O}_{3}$ com granulometria variando de 3 a $30 \mu \mathrm{m}$.

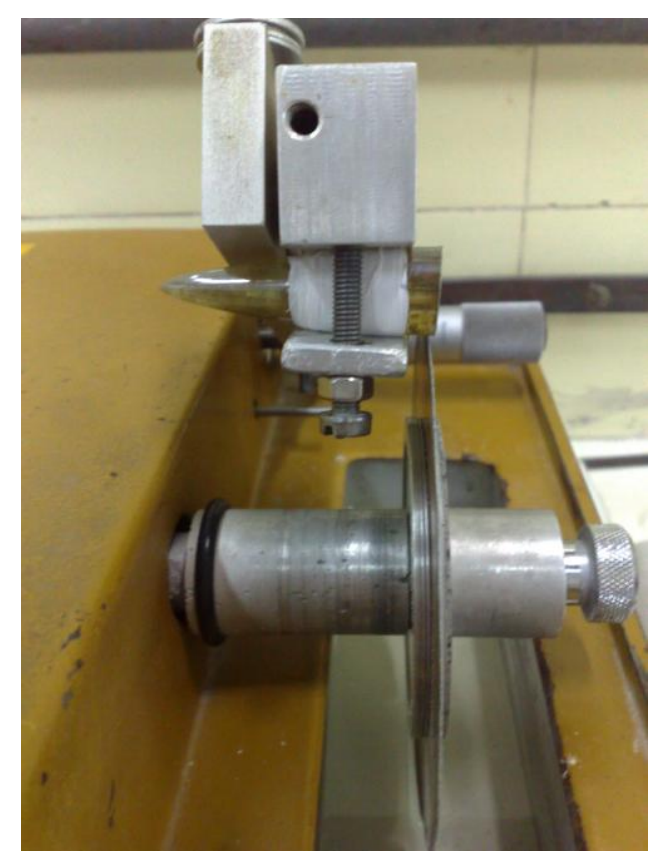

Figura 14: Corte do cristal de $\mathrm{TlBr}$ com serra de diamante. 


\subsubsection{AVALIAÇÃO DA QUALIDADE CRISTALINA}

A avaliação da qualidade cristalina das amostras de $\mathrm{TlBr}$ foi realizada utilizando o Difratômetro de Raio-X modelo D5005 (Siemens), do Laboratório de Difração de Raios-X do CCTM-IPEN/CNEN-SP. Neste processo são identificadas as direções nas quais os planos do cristal crescido são preferencialmente orientados (índices de Miller).

\subsubsection{ANÁLISE MORFOLÓGICA E VERIFICAÇÃO ESTEQUIOMÉTRICA: MICROSCOPIA ELETRÔNICA DE VARREDURA COM ELÉTRONS RETRO ESPALHADOS (MEV-BSE)}

Posteriormente, a análise morfológica e verificação estequiométrica dos cristais de TlBr por meio de microscopia eletrônica de varredura com elétrons retro espalhados (MEV-BSE) foi realizada com microscópio eletrônico de varredura modelo LX 30, da Philips, Figura 15, em colaboração com o Laboratório de Microscopia Eletrônica de Varredura da Escola Politécnica da Universidade de São Paulo.

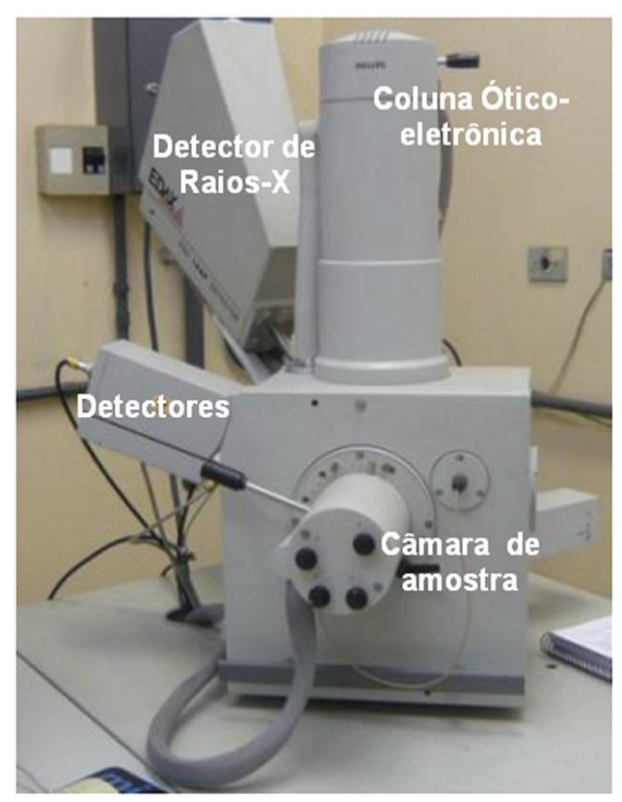

Figura 15: Microscópio eletrônico de varredura modelo LX 30, da Philips. 
As amostras para a análise por MEV foram preparadas da seguinte forma:

a) as amostras do cristal de $\mathrm{TlBr}$ foram submetidas a pressão de $10^{-6} \mathrm{mmHg}$ e temperatura de $90^{\circ} \mathrm{C}$, durante 15 minutos, a fim de remover previamente toda água e voláteis da superfície. Estes poderiam comprometer os resultados finais, uma vez que a análise de MEV é realizada sob vácuo;

b) as amostras foram preparadas usando fita condutiva de carbono para montagem correta da fatia do cristal de TlBr no porta amostra;

c) evaporar um filamento de carbono na superfície, utilizando uma evaporadora modelo SCD 040, da Balzers Union, Figura 16, para tornar o cristal condutivo.

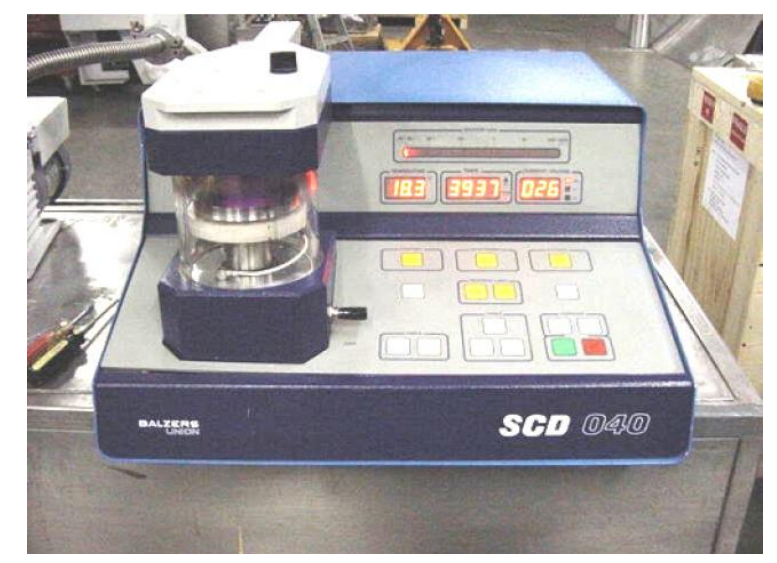

Figura 16: Evaporadora utilizada para evaporar um filamento de carbono na superfície do cristal para torná-lo condutivo.

\subsubsection{CARACTERIZAÇÃO DO CRISTAL SEMICONDUTOR DE TIBr COMO DETECTOR DE RADIAÇÃO}

Para sua aplicação como detectores de radiação, os cristais de $\mathrm{TlBr}$ foram preparados com a colocação de contatos elétricos nas suas fatias para tornar possível coletar os portadores de carga produzidos pela radiação. Foram aplicados contatos em lados opostos das fatias, utilizando pintura de grafite condutiva, Viatronix. As Figuras 17 (a, b e c) apresentam a seqüência da sua preparação como detectores de radiação. 


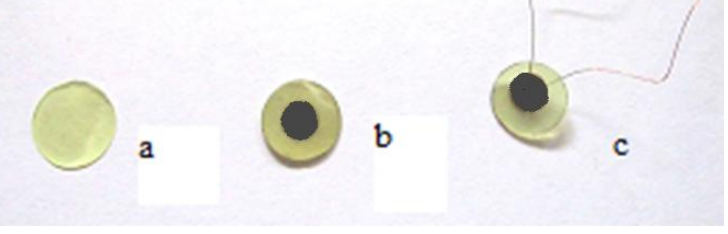

Figura 17: Fatias do cristal de TlBr após: tratamento na superfície por meio de polimento (a), aplicação dos contatos com pintura de grafite condutiva (b) e aplicação de fio de cobre (c).

A montagem eletrônica utilizada para as medidas de radiação é mostrada na Figura 18. Para a caracterização do cristal como detector, inicialmente é avaliada a medida de corrente de fuga em função da voltagem aplicada. As medidas de corrente de fuga foram realizadas utilizando o multímetro Keithey, modelo 619 e fonte de alta tensão Ortec, modelo 459, e desconectando o pré-amplificador A250F. Dos valores encontrados dessa medida foi determinada a resistividade apresentada pelos detectores, utilizando-se a equação 9.

$$
\rho=\frac{V A}{I_{d} l}
$$

onde $\rho$ é a resistividade no escuro, $\mathrm{V}$ é a tensão aplicada em volts, A é área do contato em $\mathrm{cm}^{2}, \mathrm{I}_{\mathrm{d}}$ é a corrente no escuro em ampére e $l$ é a espessura da amostra em $\mathrm{cm}$.

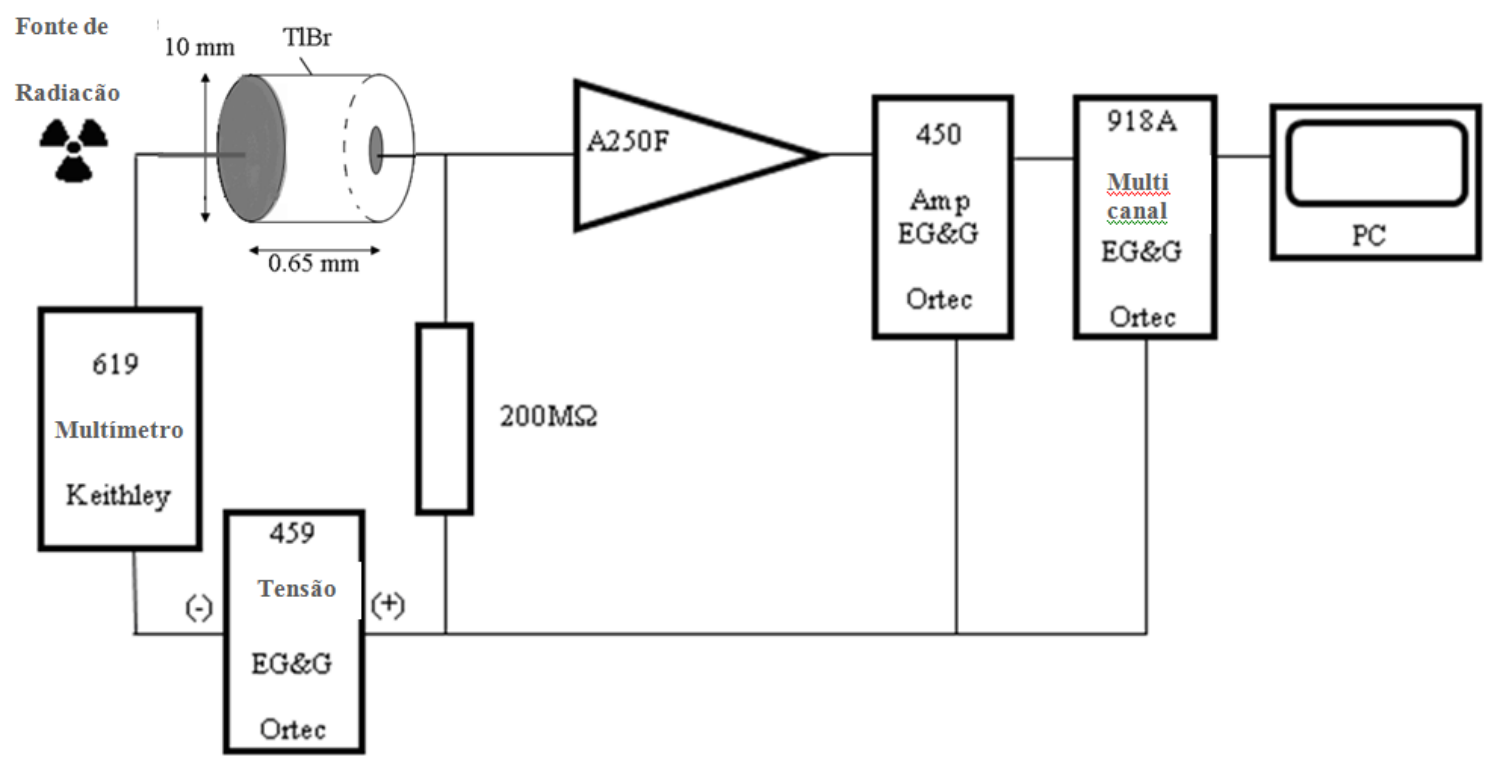

Figuta 18: Montagem eletrônica utilizada para as medidas de radiação e análise de dados. 
O comportamento (desempenho) da coleta de cargas foi avaliada por inferência das medidas de altura de pulso, utilizando fontes de raios gamas da fonte de ${ }^{241} \mathrm{Am}(59 \mathrm{keV})$. Para medidas de altura de pulso, o sinal do pré-amplificador sensível à carga $\mathrm{A}$ 250F, da Amptek, foi conectado ao amplificador $450 \mathrm{EG} \& \mathrm{G}$, da Ortec, e ao analisador multicanal 918A EG\&G, da Ortec.

Para medidas de radiação gama foi utilizada uma fonte selada de radiação gama de ${ }^{241} \mathrm{Am}$, com energia preferencial de 59,5 keV, com atividade ao redor de $398 \mathrm{kBq}$ (10 uCi) para a excitação de cristal. A tensão utilizada foi $400 \mathrm{~V}$ e o espectro foi contado por $3000 \mathrm{~s}$, à temperatura ambiente em torno de $24^{\circ} \mathrm{C}$.

O tempo de estabilidade do detector é avaliado pela verificação da mudança temporal da posição do pico e da resolução energética.

\subsubsection{PREPARAÇÃO DAS AMOSTRAS DE TIBr PARA ANÁLISES QUíMICA DAS IMPUREZAS E DO MODELO COMPARTIMENTAL.}

Para preparação das amostras para estudo da segregação das impurezas e proposição de um modelo compartimental, três amostras foram retiradas do cristal a cada crescimento. Para cada crescimento, o tubo de quartzo foi aberto e o cristal foi dividido em 3 regiões, como mostrado na Figura 19, sendo a região "TOP”, a extremidade superior do cristal de $\sim 5 \mathrm{~mm}$ de espessura (compartimento 3 com volume $V_{\mathrm{C}_{3}}=1571 \mathrm{~mm}^{3}$ ), para onde a maioria das impurezas migram, a qual foi amostrada para análise química. A região do meio, denominada "MIDDLE", foi considerada a região nobre do cristal de $\sim 31 \mathrm{~mm}$ de espessura (compartimento 2 com volume $\mathrm{V}_{\mathrm{C} 2}=4710 \mathrm{~mm}^{3}$ ), assumindo que existe uma boa uniformidade na concentração da região do meio do cristal. Amostras (duas fatias de 0.65 $\mathrm{mm}$ ) foram retiradas, da região chamada de "MIDDLE", para análise química das impurezas e posterior preparação como detectores de radiação. A região "BOTTOM" corresponde a extremidade inferior do cristal de $\sim 20 \mathrm{~mm}$ de espessura, a qual tem o formato cônico (compartimento 1 com volume $\mathrm{V}_{\mathrm{C} 1}=1054 \mathrm{~mm}^{3}$ ). 


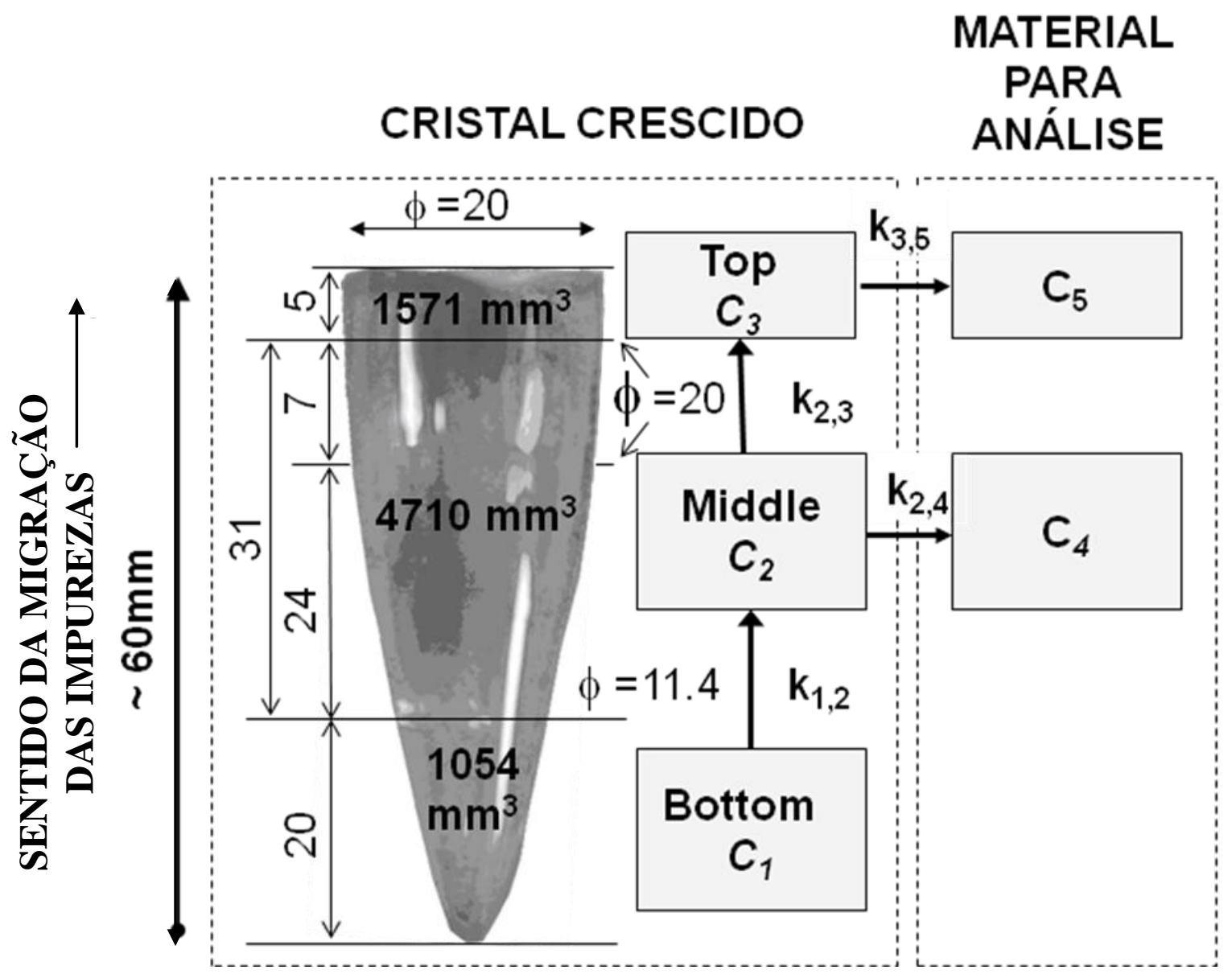

Figura 19: Modelo compartimental proposto para explicar a migração das impurezas no cristal de TlBr. Os valores das constantes $k_{i, j}$ estão na Tabela 5 .

\subsubsection{ANÁLISE QUANTITATIVA DAS IMPUREZAS PRESENTES POR ICP-MS}

A seguir, as amostras retiradas a cada crescimento, como descrito no item anterior (4.3.4.) foram analisadas por ICM-MS. Para a determinação das impurezas presentes, esta análise foi realizada utilizando um espectrômetro de massas Elan 6100, Perkin Elmer, USA, em colaboração com o Laboratório de Cristais Iônicos, Filmes e Datação do IF/USP.

Amostras de $50 \mathrm{mg}$ (valor definido em função do limite de detecção do equipamento) dos cristais de $\mathrm{TlBr}$ foram adicionadas em frascos de teflon em $50 \mathrm{~mL}$ de ácido nítrico, $2 \mathrm{~mL}$ de peróxido de hidrogênio e $3 \mathrm{~mL}$ de ácido clorídrico. Para a solubilização assistida do TlBr por microondas, nesta solução, os frascos de teflon foram aquecidas sob pressão por 40 minutos no forno digestor com microondas, modelo DGT 100 Plus, da Provecto Analítica. 
Posteriormente, as impurezas presentes nas amostras foram analisadas no espectrômetro de massas com plasma. No presente trabalho, foi realizada a análise quantitativa com o intuito de identificar e quantificar as impurezas presentes no $\mathrm{TlBr}$.

\subsubsection{ANÁLISE DE SEGREGAÇÃO DE IMPUREZAS PRESENTES (MODELO COMPARTIMENTAL)}

Para explicar a segregação das impurezas no cristal de TlBr em função do número de crescimentos Bridgman, foi proposto um modelo matemático utilizando a teoria da análise compartimental $^{(78,79,80)}$.

O modelo compartimental, proposto para explicar a migração das impurezas como uma função da enésima repetição do crescimento Bridgman, é mostrado na Figura 19. Os parâmetros $k$ são as constantes de imigração das impurezas da região $i$ para a região $j$. Compartimento $\mathrm{C}_{5}$ representa a quantidade acumulada de impurezas retiradas do topo do cristal $(5 \mathrm{~mm})$. Compartimento $\mathrm{C}_{4}$ representa a quantidade acumulada de impurezas das duas fatias de $0.65 \mathrm{~mm}$ removidas da região de meio do cristal, para serem utilizadas como detector de radiação e para análise química. A hipótese básica aplicada para formulação do modelo descrito na Figura 20 fundamenta-se em (i) o coeficiente de segregação $k>1$, ou seja, as impurezas medidas são mais solúveis na fração fundida do cristal; (ii) inicialmente, as concentrações das impurezas nas três regiões (compartimentos), 1 a 3, são iguais aos sais utilizados como material de partida e as concentrações iniciais nos compartimentos 4 e 5 são ambas iguais a zero; (iii) o coeficiente de migração $\mathrm{k}_{i j}$ é uma constante, independentemente do número de repetições $x$, isto é, a quantidade de impurezas que migra da região $i$ para região $j$ é proporcional a sua concentração na região $i$ e, finalmente, (iv) $k_{1,2}=k_{2,3}$. As constantes $k_{2,4} \mathrm{e}$ $k_{3,5}$ dependem do volume do material fatiado do cristal e foram numericamente estimadas pelo processo algébrico de regressão não linear.

O núcleo deste modelo, ou seja, os compartimentos $\mathrm{C} 1, \mathrm{C} 2$ e $\mathrm{C} 3$, pode ser definido, matematicamente, como o sistema de equações diferenciais de primeira ordem indicado a seguir. 
$\frac{d C_{1}}{d x}=-k_{1,2} \cdot C_{1}$

$C_{1,0}=C_{2,0}=C_{3,0}=$ concentração de impurezas

no material de partida e $C_{4,0}=C_{5,0}=0$

$\frac{d C_{2}}{d x}=+k_{1,2} \cdot C_{1}-\left(k_{2,3}+k_{2,4}\right) \cdot C_{2}$

$\frac{d C_{3}}{d x}=+k_{3,5} \cdot C_{3}$

Reescrevendo o sistema de equações (10) em notação matricial e assumindo o argumento algébrico $\sum_{i=1 ; i \neq j}^{N} k_{i, j}=k_{i, i}$, com a intenção de conseguir a uniformidade nos índices dos elementos da matriz, temos:

$$
\left[\begin{array}{ccc}
-k_{1,1} & 0 & 0 \\
k_{1,2} & -k_{2,2} & 0 \\
0 & k_{2,3} & -k_{3,3}
\end{array}\right] \cdot\left[\begin{array}{l}
C_{1} \\
C_{2} \\
C_{3}
\end{array}\right]=\left[\begin{array}{l}
d C_{1} / d x \\
d C_{2} / d x \\
d C_{3} / d x
\end{array}\right]
$$

Aplicando a tranformada de Laplace ${ }^{(80,81)}$ na equação (11) e invertendo a matriz:

$$
\left[\begin{array}{c}
\overline{C_{1}}(s) \\
\overline{C_{2}}(s) \\
\overline{C_{3}}(s)
\end{array}\right]=\frac{1}{\Delta} \cdot\left[\begin{array}{ccc}
\left(s+k_{2,2}\right) \cdot\left(s+k_{3,3}\right) & 0 & 0 \\
\mathrm{k}_{1,2} \cdot\left(\mathrm{s}+\mathrm{k}_{3,3}\right) & \left(s+k_{1,1}\right) \cdot\left(s+k_{3,3}\right) & 0 \\
k_{1,2} \cdot k_{2,3} & k_{2,3} \cdot\left(s+k_{1,1}\right) & \left(s+k_{1,1}\right) \cdot\left(s+k_{2,2}\right)
\end{array}\right] \cdot\left[\begin{array}{c}
C_{1,0} \\
C_{2,0} \\
C_{3,0}
\end{array}\right]
$$

Onde, $\bar{C}_{i}(s)=\mathrm{L}\left(C_{i}(x)\right)$ é a transformação de Laplace de $\boldsymbol{C}_{\boldsymbol{i}}(\boldsymbol{x})$ pela mudança da variável $x$ para um espaço $s$ e $\Delta=\left(s+k_{1,1}\right) \cdot\left(s+k_{2,2}\right) \cdot\left(s+k_{3,3}\right)$. Assim, obtém-se a seguinte relação:

$$
\left[\begin{array}{c}
\overline{C_{1}}(s) \\
\overline{C_{2}}(s) \\
\overline{C_{3}}(s)
\end{array}\right]=\left[\begin{array}{c}
\frac{\left(s+k_{2,2}\right) \cdot\left(s+k_{3,3}\right)}{\left(s+k_{1,1}\right) \cdot\left(s+k_{2,2}\right) \cdot\left(s+k_{3,3}\right)} \cdot C_{1,0} \\
\frac{k_{1,2} \cdot\left(s+k_{3,3}\right) \cdot C_{1,0}+\left(s+k_{1,1}\right) \cdot\left(s+k_{3,3}\right) \cdot C_{2,0}}{\left(s+k_{11}\right) \cdot\left(s+k_{2,2}\right) \cdot\left(s+k_{3,3}\right)} \\
\frac{k_{1,2} \cdot k_{2,3} \cdot C_{1,0}+k_{2,3} \cdot\left(s+k_{1,1}\right) \cdot C_{2,0}+\left(s+k_{1,1}\right) \cdot\left(s+k_{2,2}\right) \cdot C_{3,0}}{\left(s+k_{11}\right) \cdot\left(s+k_{2,2}\right) \cdot\left(s+k_{3,3}\right)}
\end{array}\right]
$$


Finalmente, aplicou-se a transformada de Laplace de forma inversa: $C_{i}(x)=\mathrm{L}^{-}$ ${ }^{1}\left(C_{i}(s)=\frac{P_{i}(s)}{Q(s)}\right)$, usando o algoritmo de Heaviside ${ }^{(80,81)}$, no qual $Q(s)=\Delta$ e $P_{i}(s)$, os elementos do numerador da matriz produto. Com isso, são obtidas as principais equações utilizadas nesse modelo:

$$
\begin{gathered}
C_{1}(x)=C_{1,0} \cdot e^{-k_{1,1} \cdot x} \\
C_{2}(x)=\frac{k_{1,2} \cdot C_{1,0}}{k_{2,2}-k_{1,1}} \cdot e^{-k_{1,1} \cdot x}+\left(\frac{k_{1,2} \cdot C_{1,0}}{k_{1,1}-k_{2,2}}+C_{2,0}\right) \cdot e^{-k_{2,2} \cdot x} \\
C_{3}(x)=\frac{k_{1,2} \cdot k_{2,3} \cdot C_{1,0}}{\left(k_{2,2}-k_{1,1}\right) \cdot\left(k_{3,3}-k_{1,1}\right)} \cdot e^{-k_{1,1} \cdot x} \\
+\left(\frac{k_{1,2} \cdot k_{2,3} \cdot C_{2,0}}{\left(k_{1,1}-k_{2,2}\right) \cdot\left(k_{3,3}-k_{2,2}\right)}+\frac{k_{2,3} \cdot C_{2,0}}{k_{3,3}-k_{2,2}}\right) \cdot e^{-k_{2,2} \cdot x} \\
+\left(\frac{k_{1,2} \cdot k_{2,3} \cdot C_{3,0}}{\left(k_{1,1}-k_{3,3}\right) \cdot\left(k_{2,2}-k_{3,3}\right)}+\frac{k_{2,3} \cdot C_{2,0}}{k_{2,2}-k_{3,3}}+C_{3,0}\right) \cdot e^{-k_{3,3} \cdot x} \\
C_{4}(x)=k_{2,4} \cdot \int_{x=0}^{x} C_{2}(x) d x \\
C_{5}(x)=k_{3,5} \cdot \int_{x=0}^{x} C_{3}(x) d x
\end{gathered}
$$

Sendo $\mathrm{C}_{1}, \mathrm{C}_{2}, \mathrm{C}_{3}$ e $\mathrm{C}_{4}$ referentes aos compartimentos $1,2,3$ e 4 , respectivamente; $k_{i, j}$ é o coeficiente de segregação das impurezas do compartimento $i$ para o compartimento $j$.

Sumarizando, $\mathrm{C}_{\mathrm{i}}(\mathrm{x})$ é a concentração experimental de impurezas na região $i$ do cristal após a x-ésima repetição do crescimento do cristal, $\mathrm{C}_{\mathrm{i}, 0}$ é a condição inicial medida, experimentalmente, no material de partida e $k_{i, j}$ é o coeficiente de migração da impurezas, que é determinado por ajuste dos mínimos quadrados não linear. Neste trabalho, os cálculos compartimentais foram feitos com o software ANACOMP ${ }^{(82)}$. 


\section{RESULTADOS E DISCUSSÃO}

\subsection{LEVANTAMENTE DO PERFIL TÉRMICO DO FORNO UTILIZADO NO MÉTODO DE BRIDGMAN}

A Figura 20 mostra a curva característica do perfil de temperatura do forno utilizado no método de Bridgman. Esse procedimento foi necessário para se verificar a simetria do gradiente de temperatura antes e depois da região de temperatura máxima do forno.

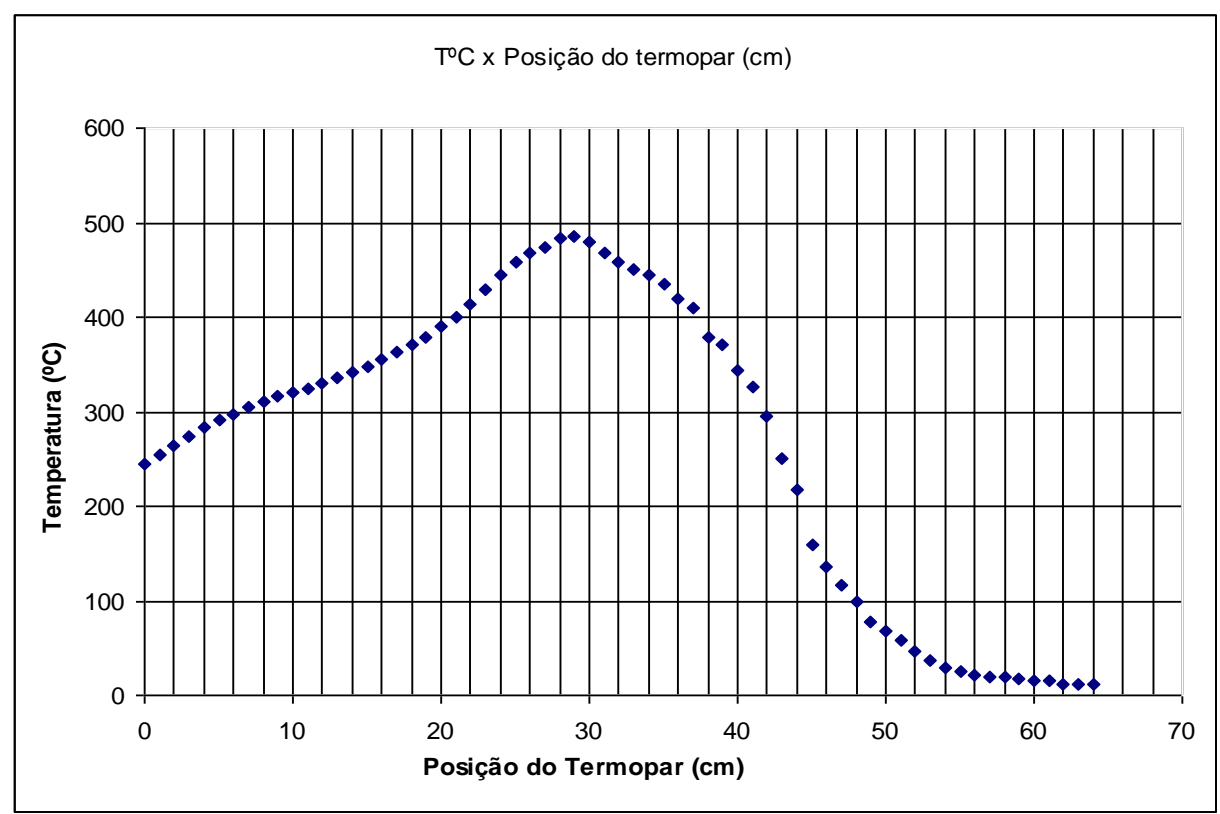

Figura 20: Curva característica do forno vertical de crescimento de cristais: variação da temperatura $\left({ }^{\circ} \mathrm{C}\right) \mathrm{x}$ posição do termopar $(\mathrm{cm})$ no interior do forno de crescimento.

A curva característica de perfil de temperatura do forno (Figura 20) apresentou simetria entre a rampa de subida e decréscimo da temperatura para valores entre $400^{\circ} \mathrm{C}$ e $500^{\circ} \mathrm{C}$. $\mathrm{O}$ termopar, bem como o tubo de quartzo contendo o sal de $\mathrm{TlBr}$, não podem encostar nas paredes no interior do mesmo, fato que pode comprometer a estrutura cristalina do cristal crescido, mas deve ficar sempre centralizado, evitando gradientes de temperatura indesejados ou eventuais impactos mecânicos. Mesmo pequenas oscilações do tubo podem comprometer os aspectos termodinâmicos característicos de todo o processo. 


\subsection{TRATAMENTO QUÍMICO E DESUMIDIFICAÇÃO DOS TUBOS DE QUARTZO E DESUMIDIFICAÇÃO DO SAL DE TIBr}

A Figura 21 apresenta os resultados do tratamento químico (retirada de possíveis impurezas) e térmico (desumidificação do tubo e posteriormente do sal de $\mathrm{TlBr}$ ) dos tubos de quartzo utilizados. A Figura 21 (a) e (b) mostram que o tratamento foi eficiente, visto que os cristais crescidos se desprenderam facilmente dos mesmos ao serem retirados. Este é um parâmetro importante a ser avaliado, pois a presença de possível resquício de oxigênio devido a umidade no interior do tubo pode reagir com o silício presente na constituição do tubo de quartzo, formando ligação Tl-O-Si, o que causa a aderência do cristal nas paredes do tubo. Este evento pode atribuir danos estruturais e mecânicos. A Figura 21 (c) mostra um exemplo de um cristal aderido ao tubo. Fatores como excesso de impurezas no material de partida e ou presença de oxigênio no tubo devido à umidade no tubo e/ou do próprio sal de TlBr, podem justificar a adesão resultante na Figura 21 (c).
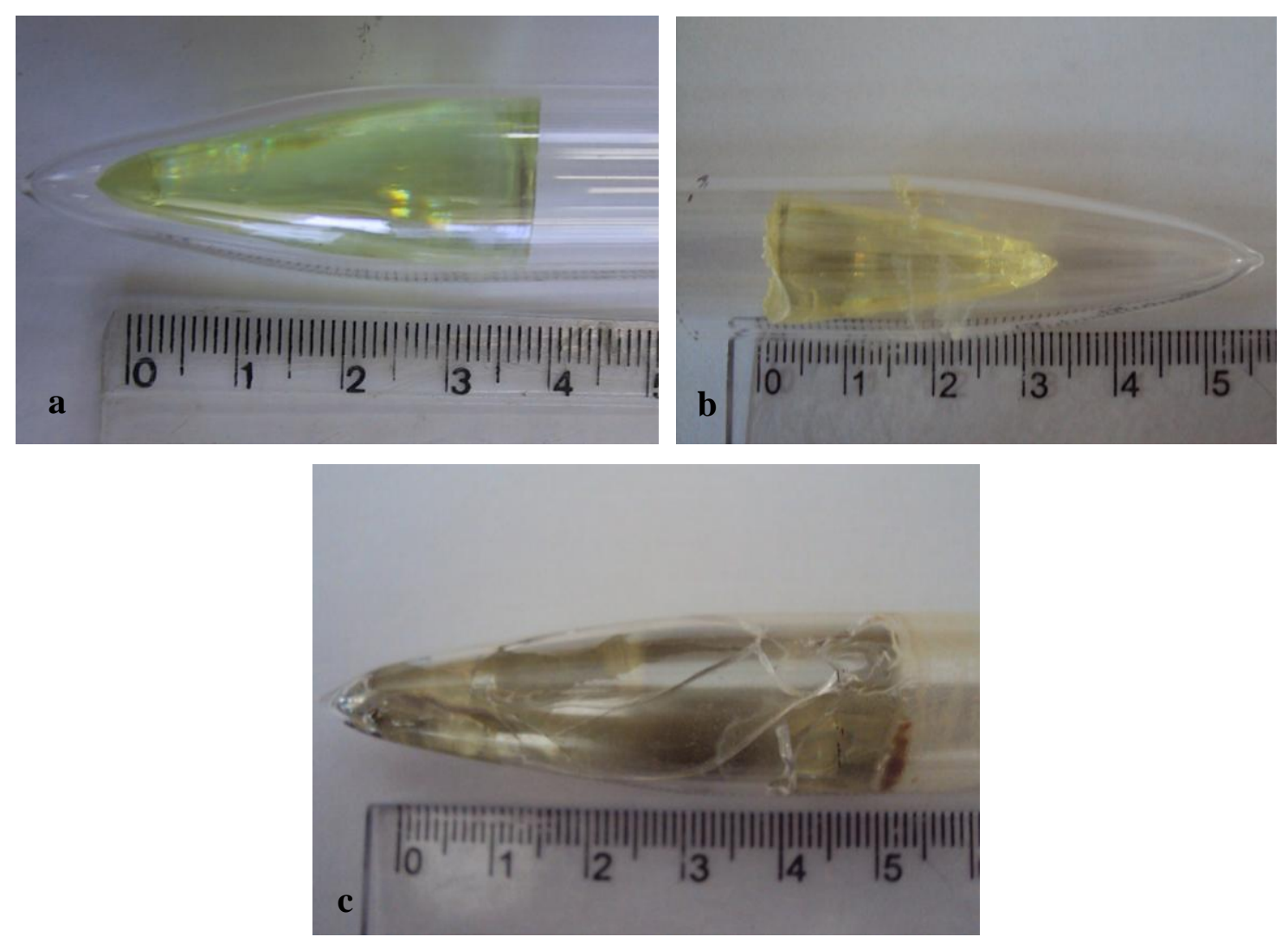

Figura 21: Cristais de TIBr crescidos pelo método de Bridgman desprendidos no interior do tubo de quartzo (a) e (b) e aderido no tubo (c) 


\subsection{CRESCIMENTO DE CRISTAIS DE TIBr PELO MÉTODO DE BRIDGAMN E PURIFICAÇÃO POR BRIDGAM REPETIDO}

As Figuras 22 e 23 mostram diferentes cristais crescidos a partir de $45 \mathrm{~g}$ do sais comerciais de $\mathrm{TlBr}$ pelo método de Bridgman. Sais de $\mathrm{TlBr}$ de duas diferentes procedências, disponível comercialmente (Aldrich-Sigma e da Merck, por ordem alfabética), com pureza nominal de 99,99\%, foram utilizados como material de partida para crescimentos de cristal. Neste trabalho, os cristais foram nomeados de sal 1 e sal 2. Por questões éticas, os resultados apresentados, a seguir, não identificam a sua origem. Os cristais provenientes do sal 1 apresentaram cristais transparentes já no primeiro crescimento, como mostrado na Figura 22 (a). No entanto, apresentaram coloração escura, sendo mais acentuada na parte superior, enquanto os cristais crescidos duas vezes apresentaram uma cor amarela brilhante forte ao longo de todo o comprimento, Figura 22 (b). Os cristais crescidos três vezes foram visualmente os mais transparentes. A Figura 22 (c) mostra o cristal crescido três vezes.
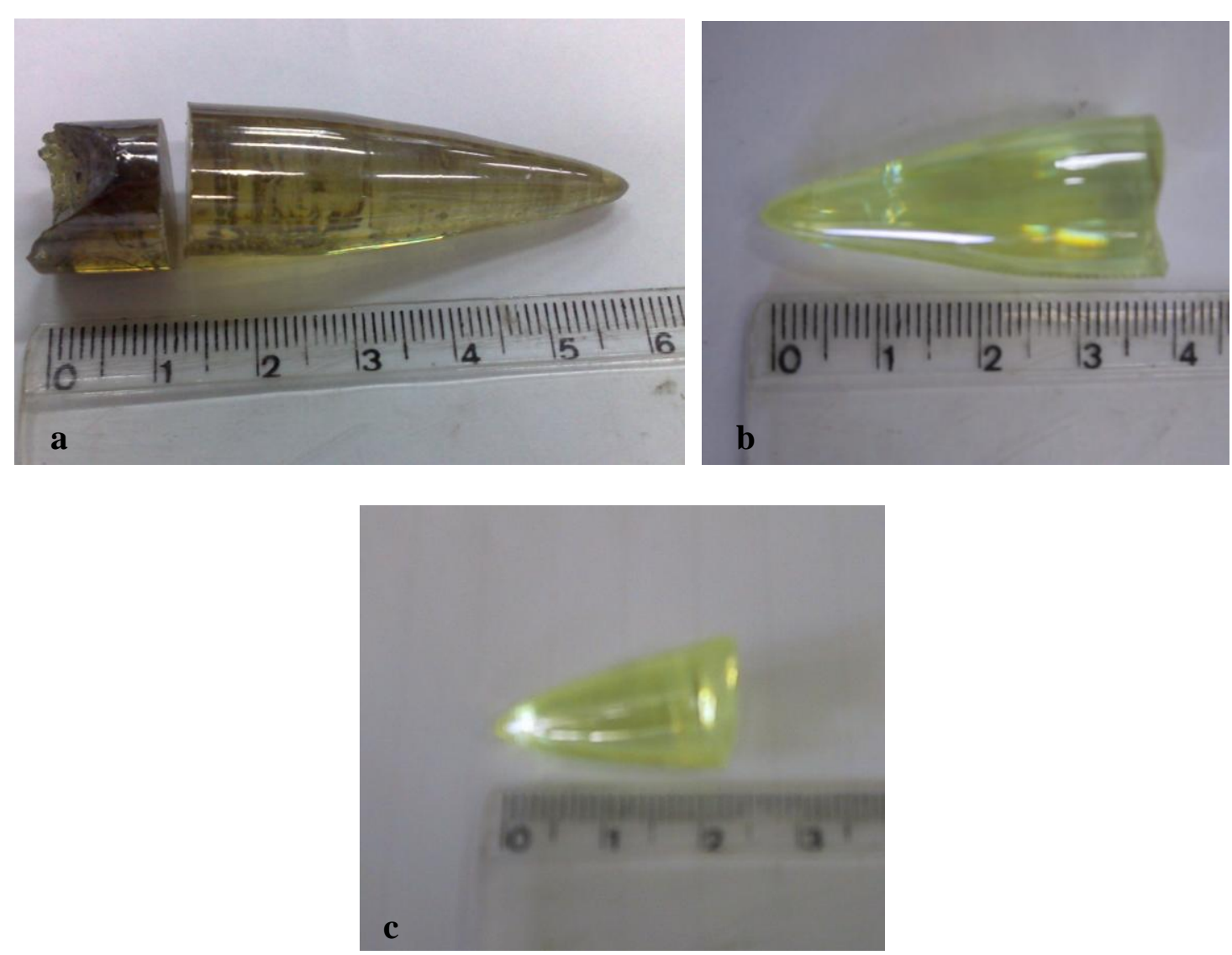

Figura 22: Cristais de $\mathrm{TlBr}$ crescidos pelo método de Bridgman a partir do sal 1: (a) submetido a um crescimento, (b) submetido a dois crescimentos e (c) submetido a três crescimentos. 
Por outro lado, os cristais provenientes de sal 2, submetido a apenas um processo de crescimento sofreram aderências ao tubo de quartzo e tiveram sua estrutura danificada, como mostrado na Figura 23(a). Após amostragem para análises, o cristal foi submetido a um segundo processo de crescimento, obtendo cristal com aparência transparente com alguns pontos enegrecidos e aderidos ao tubo (Figura 23 (b)). O mesmo procedimento de crescimento foi realizado uma terceira vez, quando se obteve cristal transparente e sem aderência ao tubo de quartzo (Figura 23 (c)).

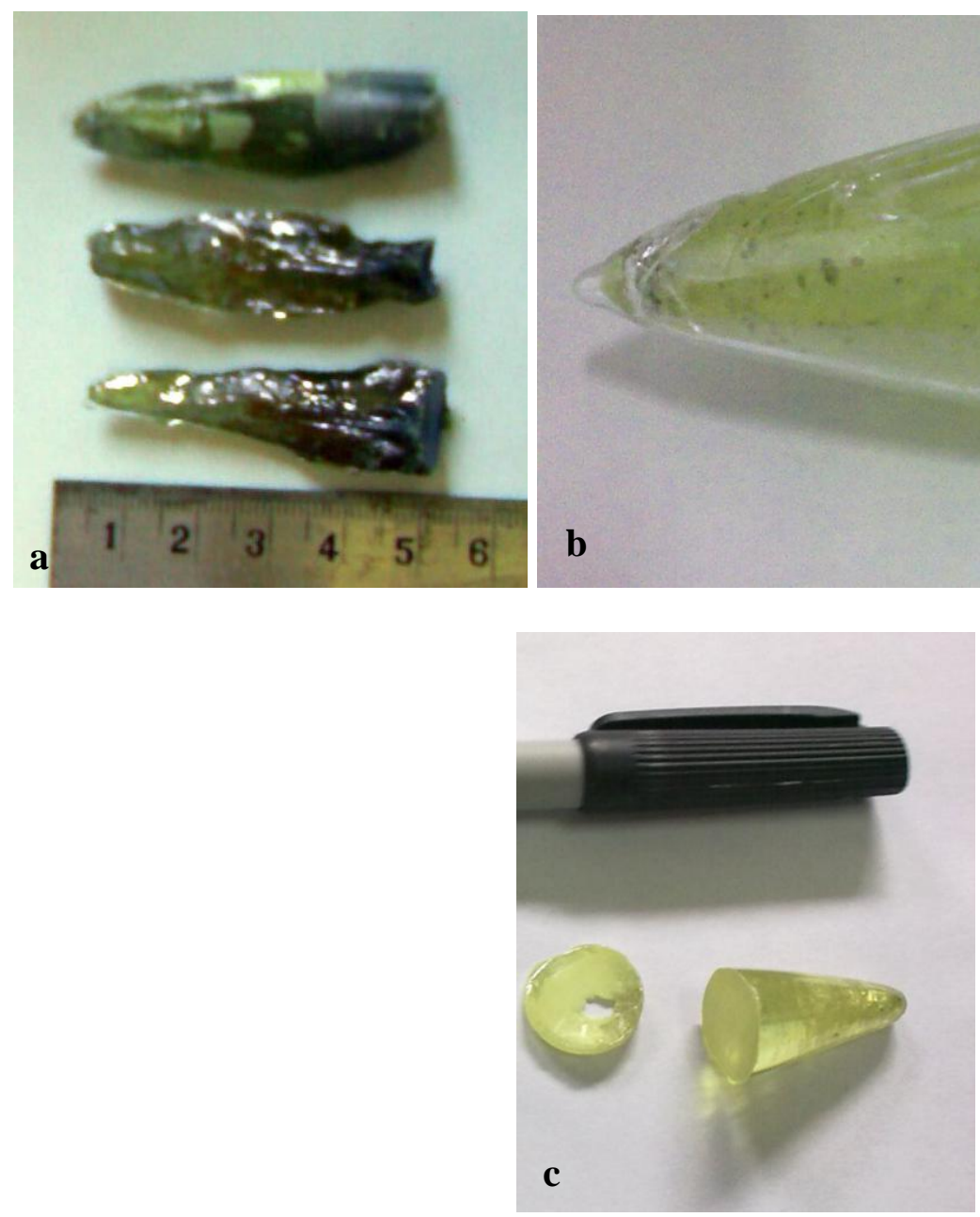

Figura 23: Cristais de $\mathrm{TlBr}$ crescidos pelo método de Bridgman a partir do sal 2: (a) submetido a um crescimento, (b) submetido a dois crescimentos e (c) submetido a três crescimentos. 


\subsection{CORTE E POLIMENTO DOS CRISTAIS DE TIBr PARA APLICAÇÃO DOS CONTATOS ELÉTRICOS}

As Figuras 24 (a) e (b) mostram as fatias cortadas dos cristais de TlBr. Pode-se notar a transparência e cristalinidade da cor característica do material. As fatias foram cortadas usando uma serra diamantada lubrificada com etileno glicol. O processo foi feito lentamente durante o intervalo de 40 minutos. A espessura inicial de cada fatia é de $1 \mathrm{~mm}$. O polimento foi feito utilizando os abrasivos mencionados no item 3 (Materiais Usados) e a espessura final de cada fatia é de $0,65 \mathrm{~mm}$.
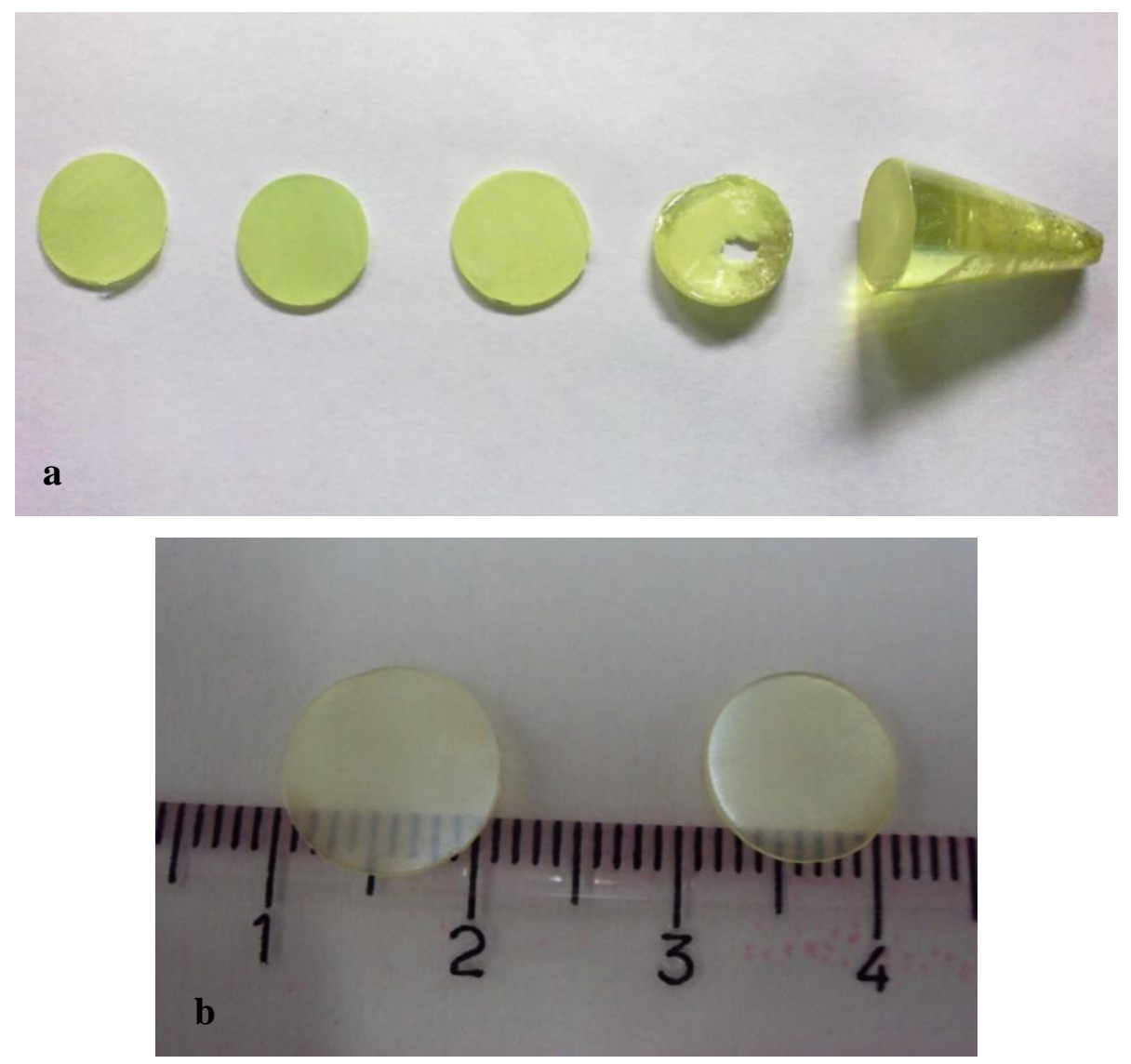

Figura 24: detalhe das fatias cortadas do cristal de TlBr, antes do polimento (a) e depois do polimento(b).

O corte das fatias dos cristais foi realizado de forma lenta para não comprometer a estrutura cristalina e, consequentemente, a qualidade dos cristais. Usualmente, o processo de corte dos cristais é tarefa tecnologicamente difícil porque durante o corte ocorre um grande número de defeitos distribuídos ao longo da profundidade das camadas. Para esse procedimento, a serra foi mantida a uma velocidade baixa e continuamente lubrificada com 
glicerina a fim de reduzir aquecimento e mais danos mecânicos ao cristal. Cabe ressaltar que a dureza do $\mathrm{TlBr}$ é muito baixa comparada a outros materiais (dureza Knoop para o $\mathrm{TlBr}=12$ $\mathrm{kg} \mathrm{mm}^{-2}$ e para o $\mathrm{Si}=1150 \mathrm{~kg} \mathrm{~mm}^{-2}$ ). Assim, durante qualquer tratamento mecânico (corte, lapidação e polimento) de fatias com pequenas espessuras (da ordem de mm), pode ser gerada alta concentração de defeitos estruturais intrínsecos devido à deformação plástica ${ }^{(4,26)}$, podendo danificar a geometria necessária para preparação dos detectores.

Deve ser ressaltado que o tempo médio para conclusão dos procedimentos 4.4.1 ao 4.4.3 é de aproximadamente 114 h, a saber: a desumidificação, purificação, crescimento, corte e polimento.

\subsection{AVALIAÇÃO DA QUALIDADE CRISTALINA}

As Figuras 25 (a), 25 (b) e 25 (c) ilustram os espectros de resposta da análise de difração de raios-X, obtidos do sal de $\mathrm{TlBr}$ e das superfícies dos cristais de $\mathrm{TlBr}$ crescidos uma e duas vezes a partir do sal 1 respectivamente. Os espectros obtidos para todas as medidas foram similares, não foram observadas diferenças significativas nas estruturas dos cristais obtidos sem purificação e purificados (dois e três crescimentos). Os difratogramas indicam que os cristais estão orientados preferencialmente nos planos (110) e (111) com estrutura semelhante ao modelo cúbico cristalino do TlBr. Este resultado está de acordo com a

literatura ${ }^{(1,4,15,23)}$. Comportamento similar foi observado nos difratogramas obtidos para os cristais crescidos a partir do sal 2, como mostrado nas Figuras 26 (a), (b) e (c). 


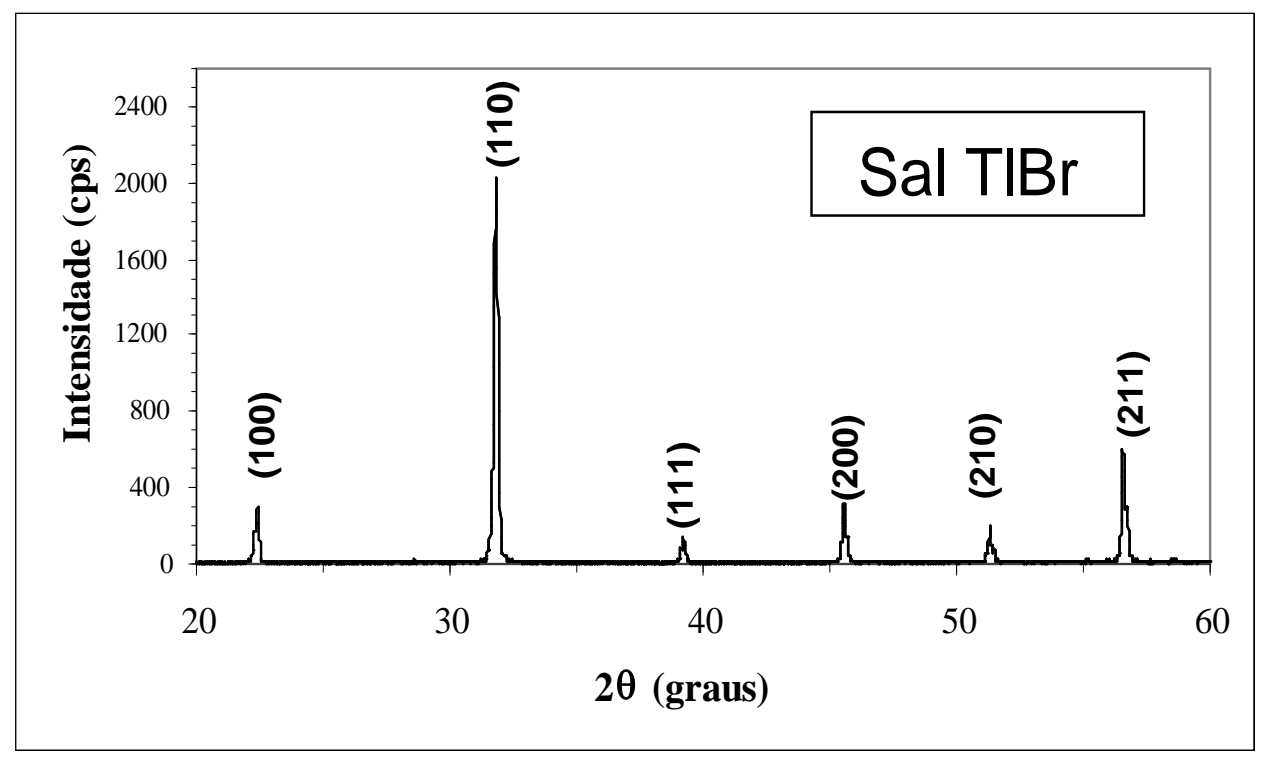

a)

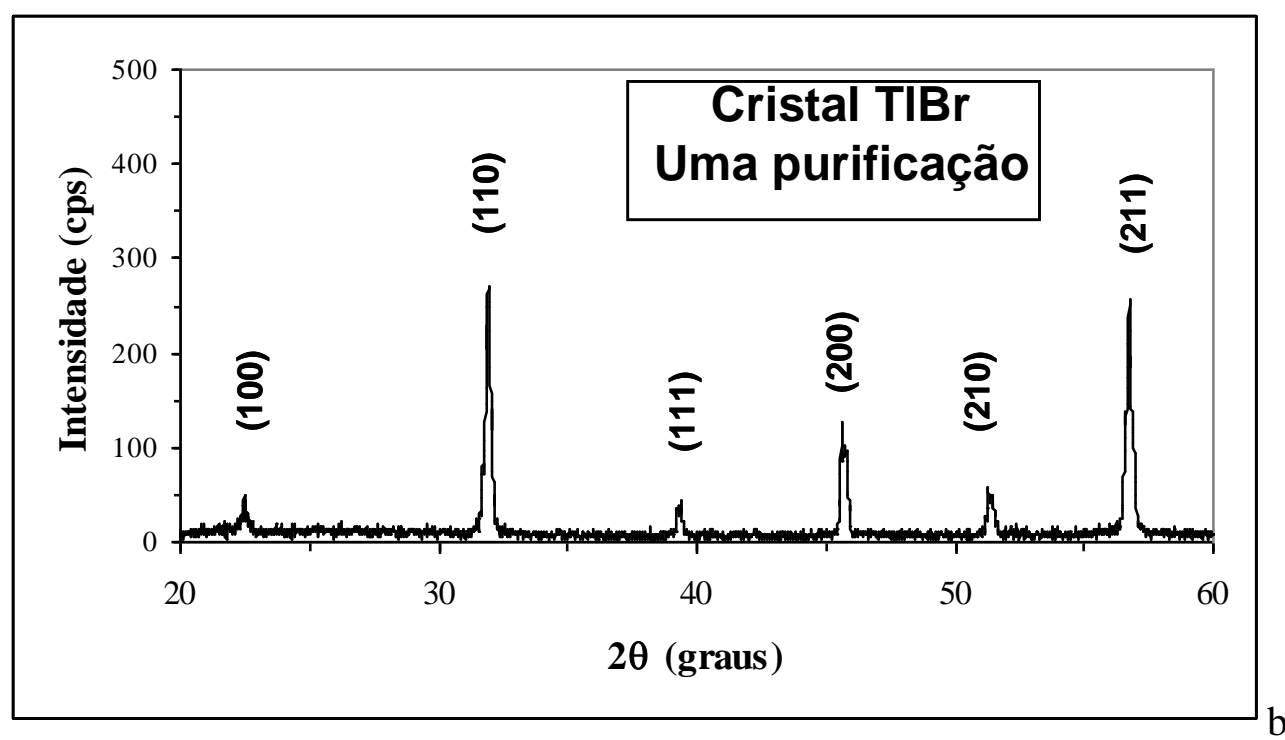

b)

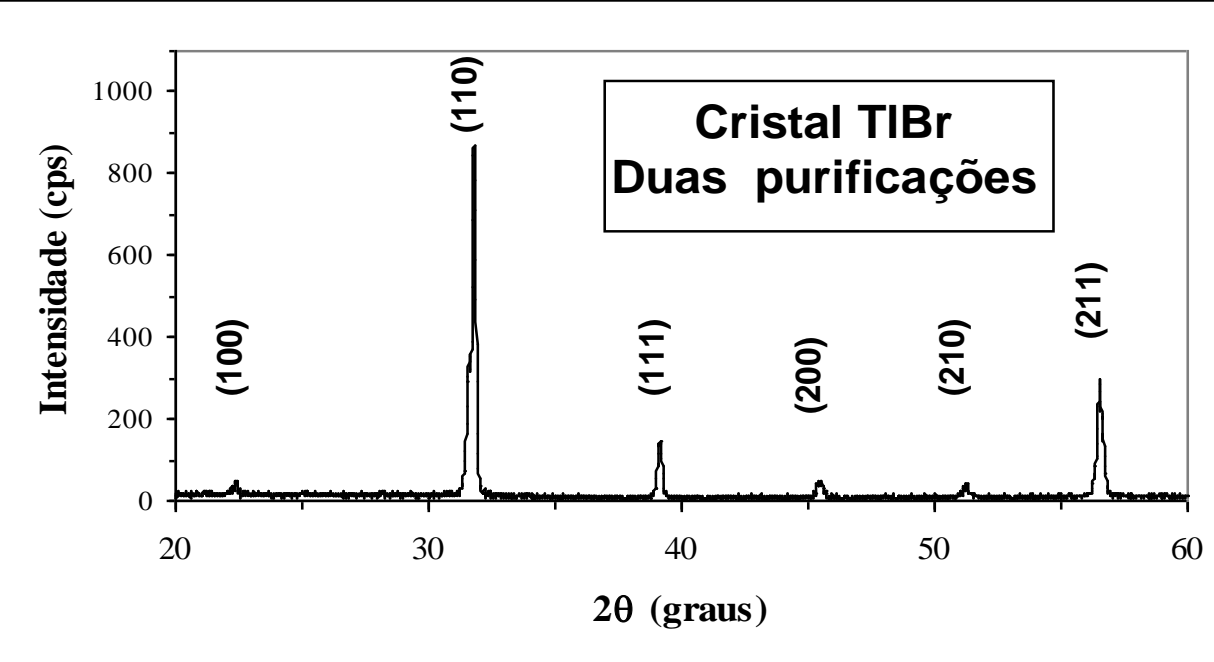

c)

Figura 25: Difratograma típico do cristal de $\mathrm{TlBr}$ crescido a partir do sal 1: a) sal de brometo de tálio; b) cristal de $\mathrm{TlBr}$ submetido a uma purificação e c) cristal de $\mathrm{TlBr}$ submetido a duas purificações. 

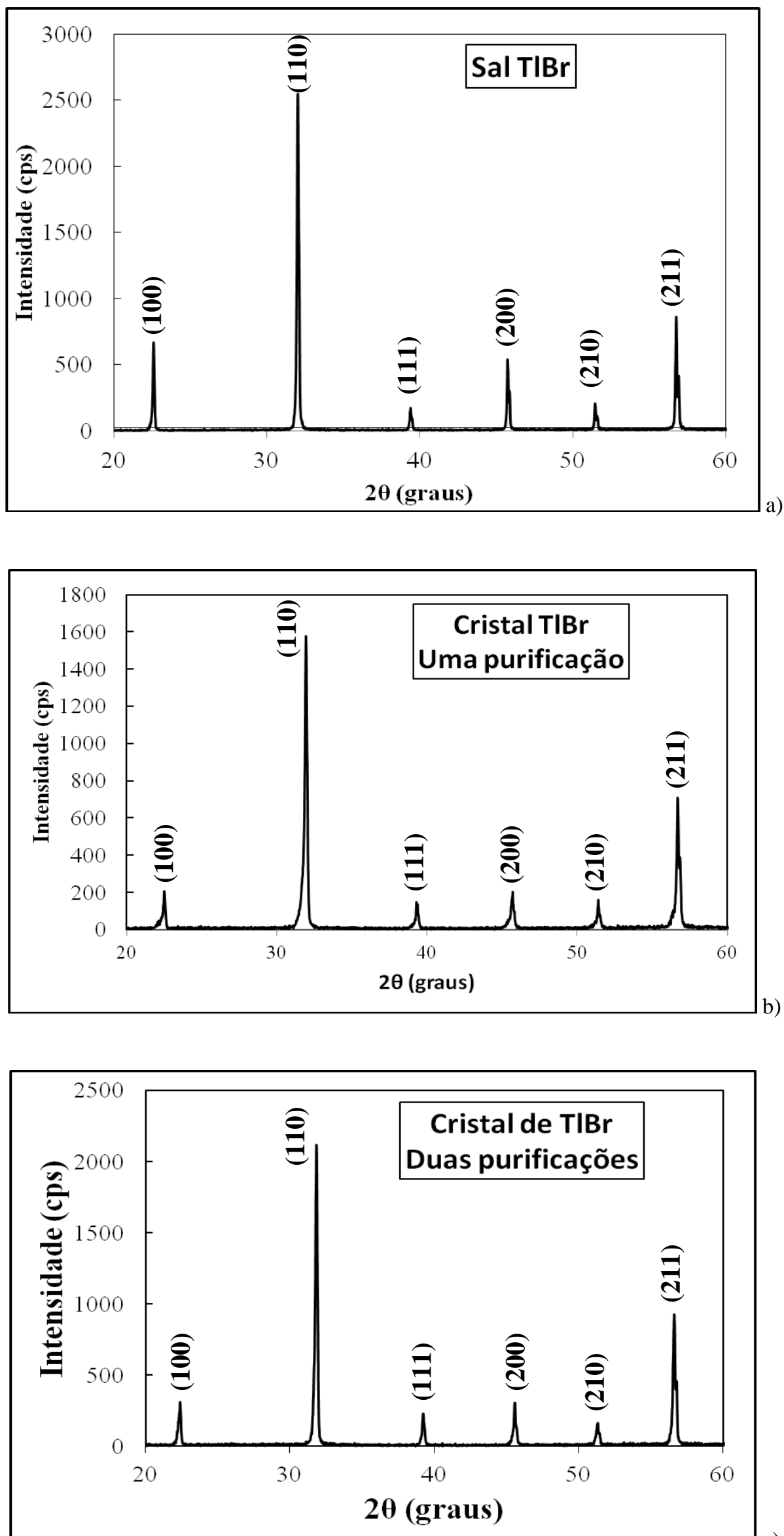

Figura 26: Difratograma típico do cristal de $\mathrm{TlBr}$ crescido a partir do sal 2: a) sal de brometo de tálio; b) cristal de TlBr submetido a uma purificação e c) cristal de TlBr submetido a duas purificações. 


\subsection{ANÁLISE MORFOLÓGICA: MICROSCOPIA ELETRÔNICA DE VARREDURA COM ELÉTRONS RETRO ESPALHADOS (MEV-BSE)}

A Figura 27 apresenta as micrografias realizadas com MEV-BSE em fatias cortadas dos cristais obtidos a partir do sal de $\mathrm{TlBr}$ da marca 1, após primeiro (Figura 27 (a)), segundo (Figura 27 (b)) e terceiro (Figura 27 (c)) crescimentos, ampliada 1000 vezes. Pode ser observado que a rugosidade diminui em função do número de crescimento (Figura 27). Uma superfície bastante uniforme foi encontrada na fatia do cristal crescido três vezes (Figura 27(c)) e, assim, as incrustações dos resíduos tornaram-se mais evidente devido a uniformidade da superfície.
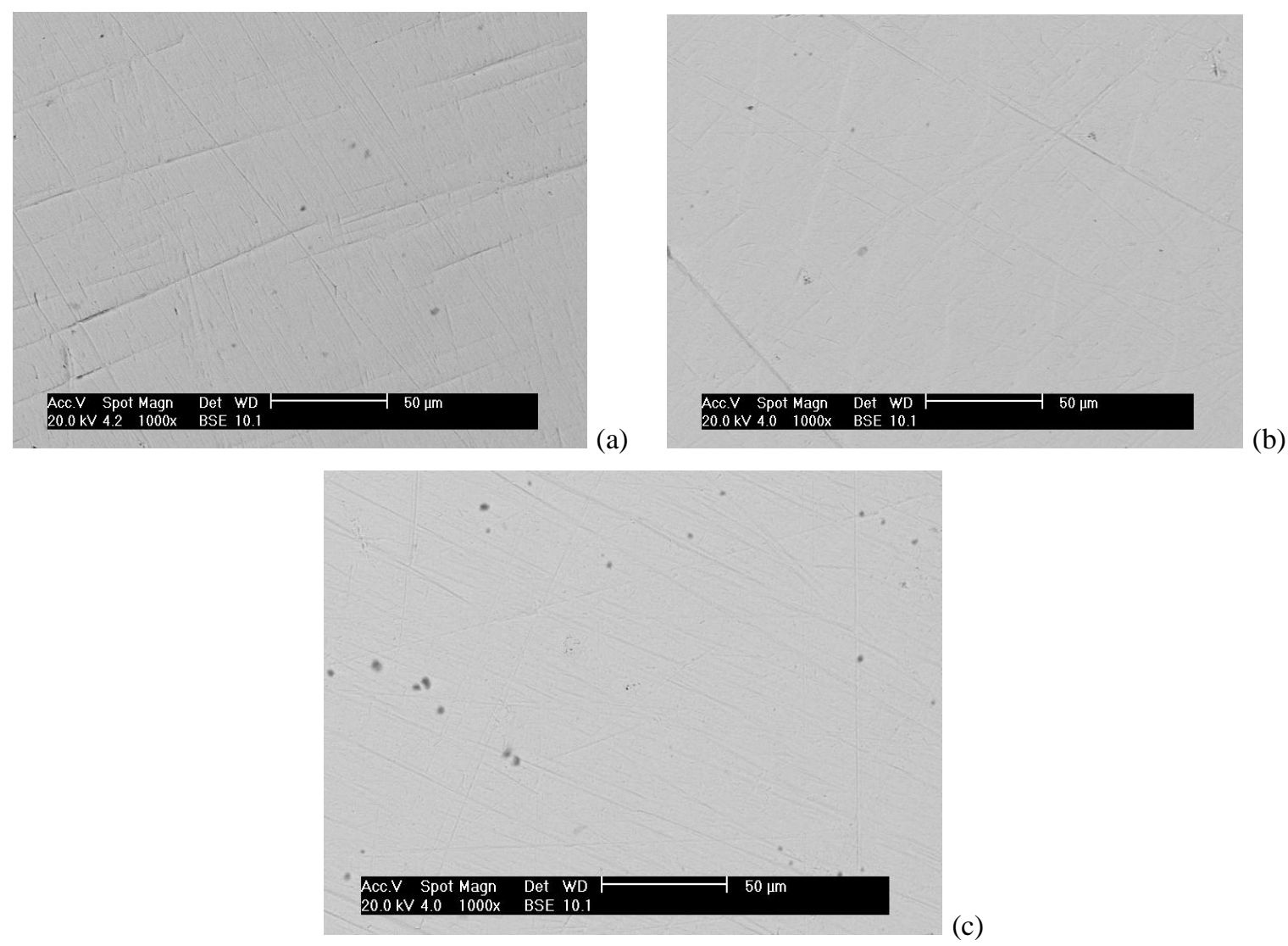

Figura 27: Micrografia das fatias dos cristais obtidos com um crescimento (a), dois crescimentos (b) e com três crescimentos (c) (ampliada 1000 vezes). 
A Figura 28 apresenta as micrografias realizadas com MEV-BSE em fatias cortadas dos cristais obtidos a partir do sal de $\mathrm{TlBr}$ da marca 2, após segundo (Figura 28 (a)) e terceiro (Figura 28 (b)) crescimentos, a fim de avaliar a qualidade da superfície das fatias usadas para preparação como detectores de radiação. Como pode ser observado na Figura 28 (a), a fatia do cristal crescido duas vezes, ampliada 150 vezes, apresenta rugosidade e granulação na superfície que pode ser devido à presença de impurezas e/ou defeitos na superfície, enquanto aquela obtida com o crescido três vezes apresenta uma superfície mais uniforme, apesar de ainda observar-se pequenas rugosidades (Figura 28(b) com ampliação de 150 vezes). Não foi possível realizar o experimento para o cristal crescido uma vez, devido a má formação do cristal, como mostrado na Figura 23(a).
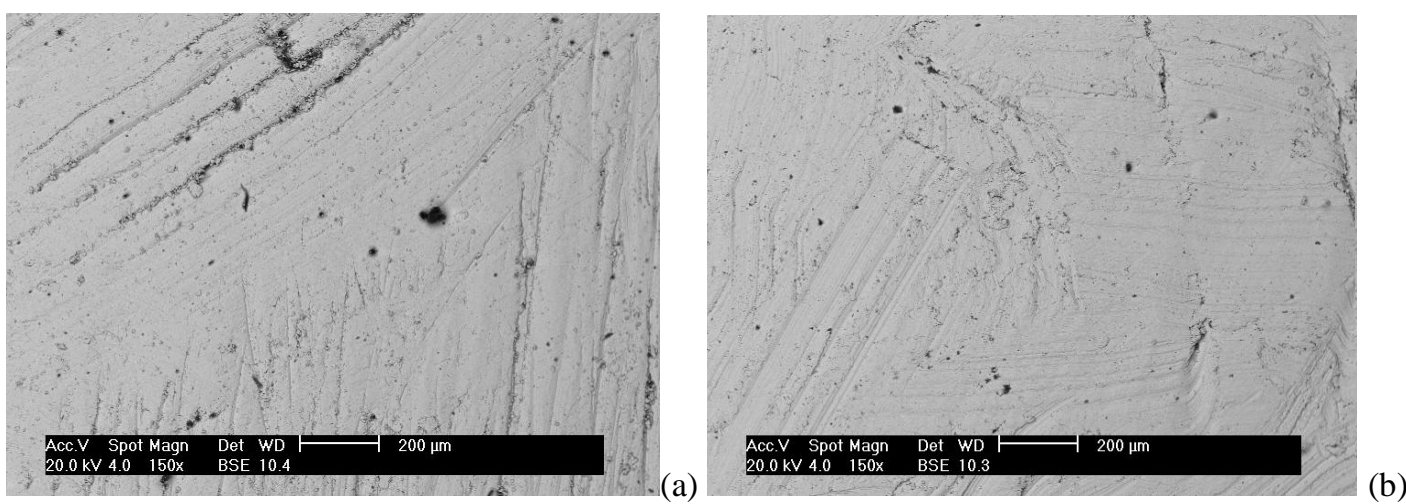

Figura 28: Micrografia das fatias dos cristais obtidos com dois crescimentos (a) e com três crescimentos (b) (ampliada 150 vezes).

Comparando as superfícies das fatias dos cristais obtidos dos sais de $\mathrm{TlBr}$ das marcas 1 e 2 (Figuras 27 e 28), o cristal proveniente do sal 1 apresentou superfícies mais uniformes e limpas (Figura 28). 


\subsection{ANÁLISE ESTEQUIOMÉTRICA: MICROSCOPIA ELETRÔNICA DE VARREDURA COM ELÉTRONS RETRO ESPALHADOS (MEV-BSE)}

Adicionalmente, utilizando-se da técnica de MEV-BSE pode-se realizar uma varredura semi-quantitativa dos elementos presentes na superfície do cristal, indicando a estequiometria do TlBr. A composição elementar da superfície dos cristais obtidos por diferentes números de repetições do processo de crescimento dos cristais obtidos com sal 1 e 2 é mostrada nas Tabelas 2 e 3, respectivamente. Como pode ser observado nessas Tabelas, uma estequiometria adequada foi encontrada em todos os cristais crescidos, a relação estequiométrica do cristal foi praticamente de 1 átomo de Tl para um átomo de Br. Por exemplo, da Tabela 2, pode-se inferir que a porcentagem atômica de $\mathrm{Tl}$ foi 50,73 e de $\mathrm{Br}$ foi de 49,27 para cristais crescidos três vezes. Estes resultados sugerem que as impurezas traços presentes nos cristais não interferiram na qualidade estequiométrica dos cristais.

Tabela 2: Composição elementar da superfície do cristal obtido por três repetições do processo de crescimento dos cristais obtidos com sal 1.

\begin{tabular}{|c|c|c|c|}
\hline $\begin{array}{c}\mathbf{N}^{\circ} \text { de } \\
\text { Purificação }\end{array}$ & Elemento & \% atômica & Desvio Padrão \\
\hline \multirow{2}{*}{1} & $\mathrm{Br}$ & 52,93 & 1,17 \\
\cline { 2 - 4 } & $\mathrm{Tl}$ & 47,07 & 0,96 \\
\hline \multirow{2}{*}{2} & $\mathrm{Br}$ & 52,42 & 1,13 \\
\cline { 2 - 4 } & $\mathrm{Tl}$ & 47,58 & 0,92 \\
\hline \multirow{2}{*}{3} & $\mathrm{Br}$ & 49,27 & 1,84 \\
\cline { 2 - 4 } & $\mathrm{Tl}$ & 50,73 & 1,38 \\
\hline
\end{tabular}

Tabela 3: Composição elementar da superfície do cristal obtido por duas repetições do processo de crescimento dos cristais obtidos com sal 2.

\begin{tabular}{|c|c|c|c|}
\hline $\begin{array}{c}\mathbf{N}^{\circ} \mathbf{d e} \\
\text { Purificação }\end{array}$ & Elemento & \% atômica & Desvio Padrão \\
\hline \multirow{2}{*}{2} & $\mathrm{Br}$ & 52,94 & 1,72 \\
\cline { 2 - 4 } & $\mathrm{Tl}$ & 47,06 & 1,41 \\
\hline \multirow{2}{*}{3} & $\mathrm{Br}$ & 53,09 & 1,63 \\
\cline { 2 - 4 } & $\mathrm{Tl}$ & 46,91 & 1,36 \\
\hline
\end{tabular}




\subsection{CARACTERIZAÇÃO DO CRISTAL SEMICONDUTOR DE TIBr COMO DETECTOR DE RADIAÇÃO}

\subsubsection{Preparação do cristal como detectores de radiação.}

Os detectores foram preparados com a colocação de contatos elétricos nas fatias do cristal de $\mathrm{TlBr}$, para tornar possível mensurar os portadores de carga produzidos pela radiação. Foram aplicados contatos em lados opostos das fatias, utilizando pintura de grafite condutiva, Viatronix. As dimensões finais das fatias dos cristais foram de aproximadamente $10 \mathrm{~mm}$ de diâmetro e $0.65 \mathrm{~mm}$ de espessura. A Figura 29 (a, b, c, d) apresenta a seqüência da sua preparação como detectores de radiação, enquanto a Figura 30 mostra o diagrama esquemático do detector de TIBr e sua conexão com o pré-amplificador.
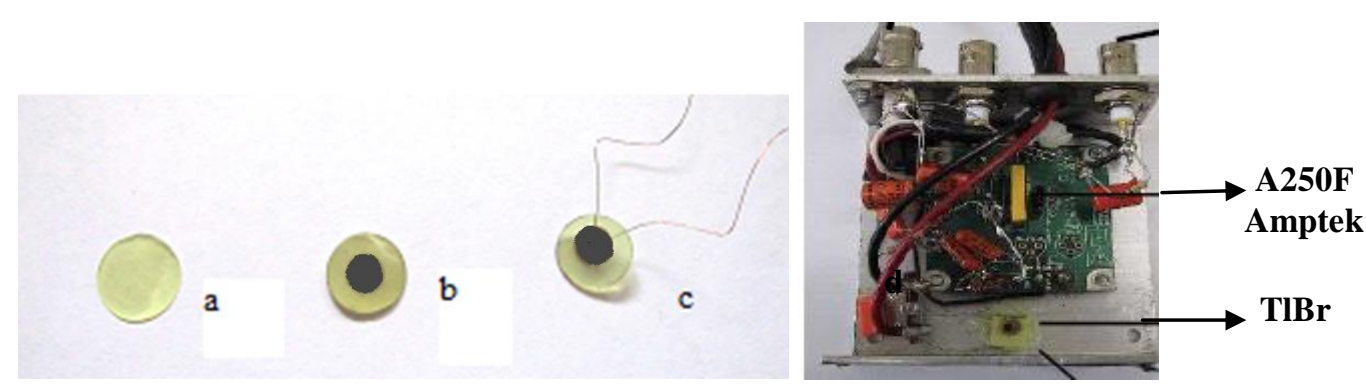

Figura 29: Fatias do cristal de TlBr após: tratamento na superfície por meio de polimento (a), aplicação dos contatos com pintura de gravite condutiva (b), aplicação de fio de estanho (c) e cristal acondicionado na caixa metálica, conectado ao pré-amplificador $(\mathrm{d})$.

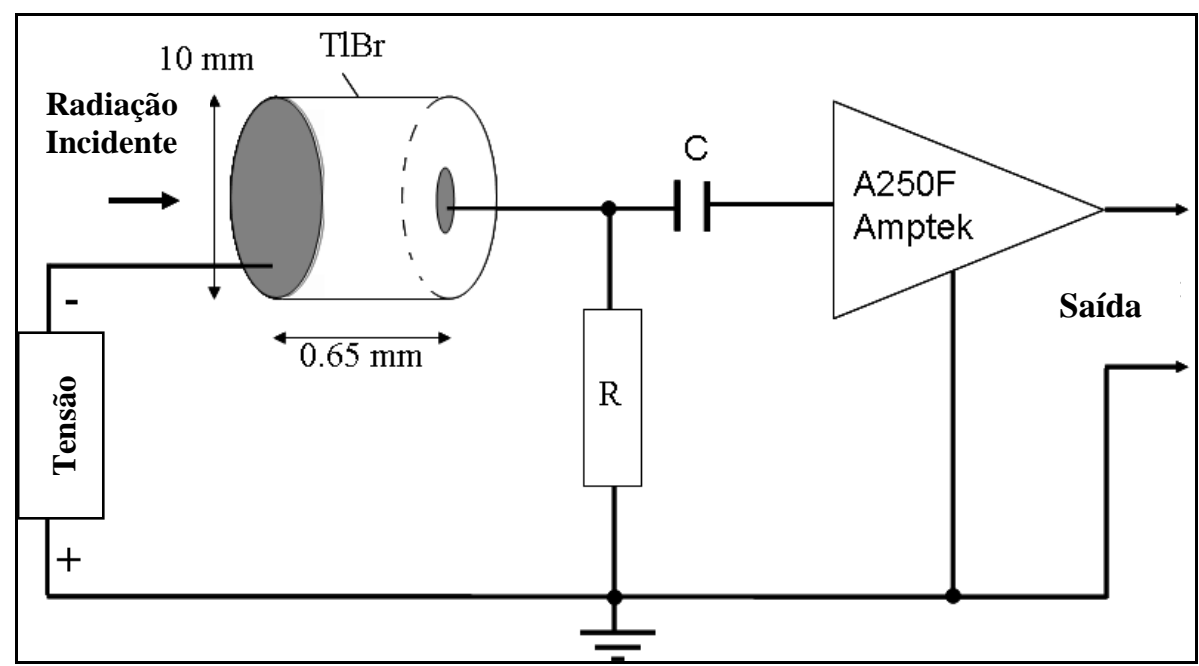

Figura 30: Representação esquemática da eletrônica associada ao detector semicondutor de TlBr. 
Para medidas de radiação gama foi utilizada uma fonte selada de radiação gama de ${ }^{241} \mathrm{Am}$, com energia preferencial de 59,5 keV, com atividade ao redor de $398 \mathrm{kBq}$ (10 uCi) para a excitação de cristal.

\subsubsection{Medidas de Resistividade}

Após a preparação do cristal de $\mathrm{TlBr}$ como um detector de radiação, seu desempenho na resposta à radiação foi avaliada. Inicialmente, foram determinados os valores da resistividade dos cristais de $\mathrm{TlBr}$ obtidos, pelas medidas de corrente de fuga em função da voltagem aplicada. Os valores de resistividades determinados para os cristais crescidos estão sumarizados na Tabela 4, cujos valores estão próximos daqueles descritos por Hitomi e col $(9,23)$

Tabela 4: Valores de resistividade dos detectors de $\mathrm{TlBr}$ preparados com cristais crescidos uma, duas e três vezes, pelo método de Bridgman repetido, utilizando sais de 1 e 2 . As amostras utilizadas foram retiradas do meio do cristal.

\begin{tabular}{lcccc}
\hline Crescimento & \multicolumn{2}{c}{ Resistividade $\left(\mathbf{1 0}^{\mathbf{9}} \mathbf{\Omega . c m}\right)$} & \multicolumn{2}{c}{ Altura de Pulso (canais) } \\
\cline { 2 - 5 } Bridgman & $\mathbf{1}$ & $\mathbf{2}$ & $\mathbf{1}$ & $\mathbf{2}$ \\
\hline \hline Primeiro & $11.3 \pm 9.5$ & $2.17 \pm 0.30$ & sem fotopico & sem fotopico \\
Segundo & $47.5 \pm 13.4$ & $3.45 \pm 0.45$ & 160 & 90 \\
Terceiro & $67.5 \pm 21.9$ & $6.72 \pm 0.43$ & 260 & 200 \\
\hline
\end{tabular}

Na Figura 31 são apresentados os valores de resistividade em função do número de repetições de crescimento Bridgman. 


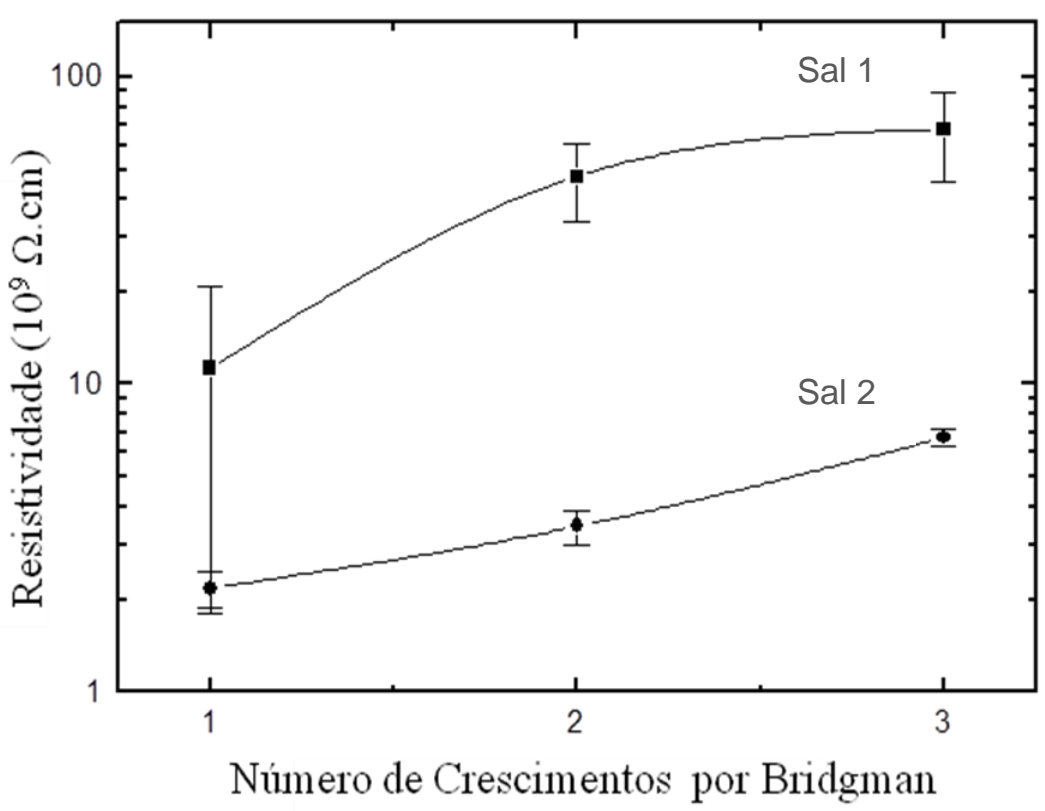

Figura 31: Resistividade dos detectores de TlBr provenientes dos cristais preparados a partir de sal de $\mathrm{TlBr}$ de marcas 1 e 2 em função do número de repetição de crescimento Bridgman. A barra do erro representa um desvio padrão ( $\mathrm{N}=3$ amostras).

A curva de resistividade mostrou uma inclinação positiva (Figura 31). Apesar de ambos os sais terem, nominalmente, a mesma pureza inicial $(99,99 \%)$, os cristais crescidos mostraram diferenças de valores de, aproximadamente, 10 vezes. A resistividade dos cristais provenientes do sal 1 apresentou valores 10 vezes maior que o cristal 2 (Tabela 4 e Figura 31).

\subsubsection{Medidas de Altura de Pulso}

A Figura 32 ilustra os espectros de altura de pulso dos detectores de $\mathrm{TlBr}$ preparados com cristais proveniente de sal 1 e a Figura 33 os espectros dos detectores preparados com sal 2. A tensão utilizada foi $400 \mathrm{~V}$ e o espectro foi contado por 3000s. 

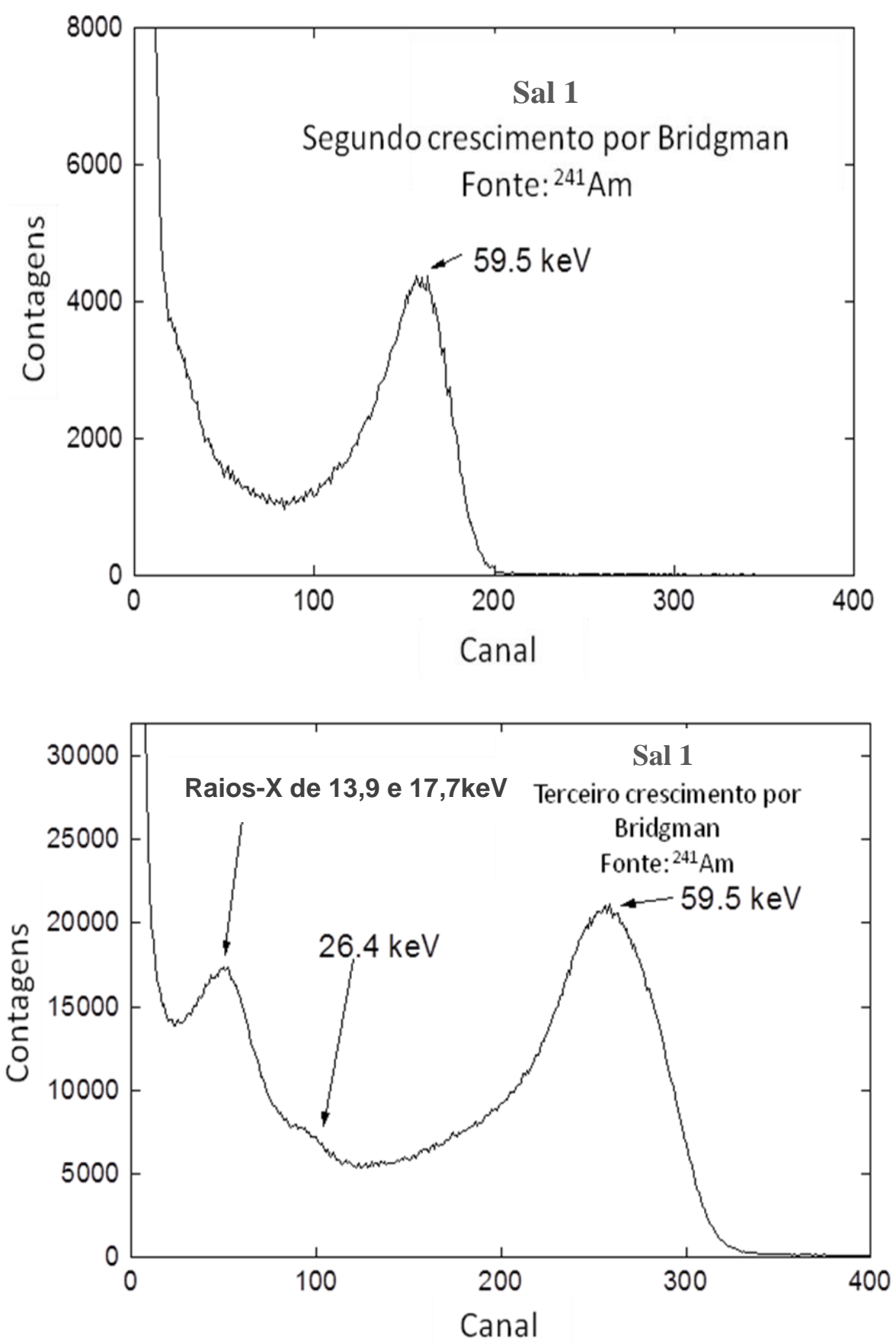

Figura 32: Espectros de altura de pulso dos detectores de TlBr preparados com cristais provenientes do sal 1. 

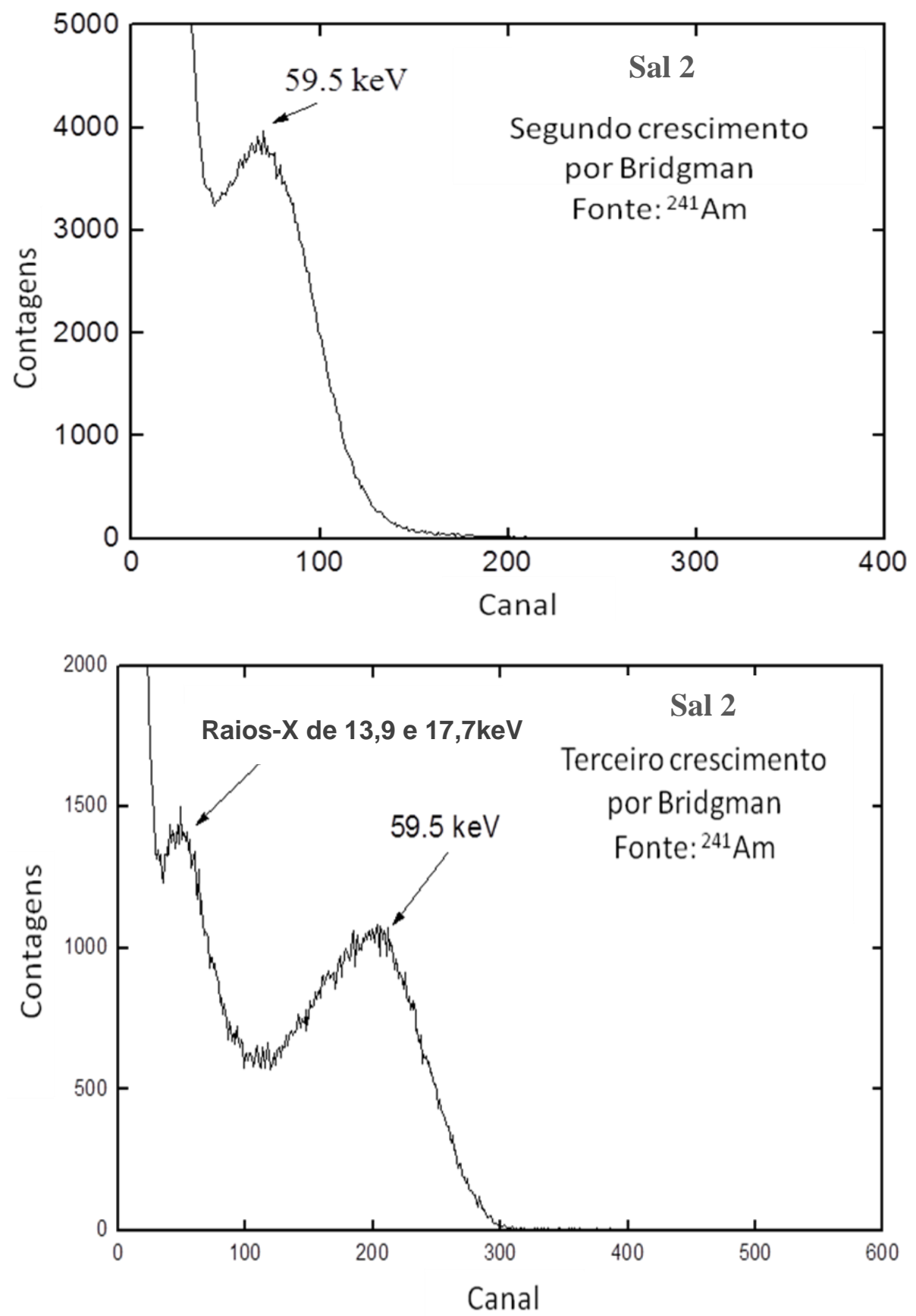

Figura 33: Espectros de altura de pulso dos detectores de TlBr preparados com cristais provenientes do sal 2.

Como pode ser observado nas Figuras 32 e 33, os espectros obtidos sugerem uma melhora significativa nos seus perfis com o aumento do número de purificações. Para o cristal crescido uma vez (sem purificação), não foi possível observar o fotopico devido aos pulsos serem gerados na região do ruído elétrico para ambos os cristais, 1 e 2. Observou-se a resposta à radiação apenas no modo de corrente. Para esses detectores, o modo de pulso não foi observado devido a uma baixa resposta à radiação e um sinal de ruído elevado. Para o cristal de $\mathrm{TlBr}$ crescido duas vezes, pode ser observado somente o fotopico de $59 \mathrm{keV}$ da 
radiação gama de ${ }^{241} \mathrm{Am}$. Para o cristal crescido três vezes, além do fotopico de $59 \mathrm{keV}$, podem ser vistos fotopicos de uma das múltiplas linhas de ${ }^{241} \mathrm{Am}$, abaixo de $59 \mathrm{keV}$, mas sem resolução suficiente para se observar cada uma delas separadamente. Ambos materiais de partida (sais 1 e 2) apresentaram comportamentos espectrométricos similares, ainda que os cristais provenientes do sal 1 mostraram, sistematicamente, resultados melhores, tanto em termos de valores de altura de pulso (Figuras 32 e 33) quanto em valores de resistividade (Figura 31 e Tabela 4).

Existe evidência de que o cristal proveniente do sal 1 apresenta melhor desempenho em todos os parâmetros estudados. Este fato pode ser associado com a resistividade dos cristais. De fato, o desempenho inferior dos cristais produzidos com o sal 2 pode ser correlacionado com a sua resistividade mais baixa. No entanto, comparando o perfil espectrométrico, enquanto o cristal do primeiro crescimento com sal 1 (resistividade alta) não apresentou detalhe espectrométrico (fotopico), em contraste, os cristais do segundo e terceiro crescimentos provenientes do sal 2, apesar de possuirem valores de resistividade mais baixos apresentaram detalhes espectrométricos satisfatórios, com fotopicos (Figura 33). Este fato sugere que a resistividade não parece ter um papel fundamental para caracterizar a qualidade espectrométrica do cristal. Hitomi e col. ${ }^{(23)}$ descreveram observações similares sobre os resultados das medidas de resistividade correlacionando os números de passos de refino zonal realizados para purificação do $\mathrm{TlBr}$.

Como pode ser observado na Figura 31 e Tabela 4, não foi observada diferença significativa nos valores de resistividade, mas a altura de pulso foi melhorada no terceiro crescimento provavelmente devido a uma melhor coleta de cargas, permitindo observar melhor as linhas de baixa energia do ${ }^{241}$ Am (Figuras 32 e 33). Estes detectores mostraram bom desempenho como detectores de radiação, à temperatura ambiente. No entanto, para melhorar a resolução energética é necessário aumentar a coleta de cargas ${ }^{(13,14,32,38)}$. Para atingir esta meta, mais purificações devem ser realizadas a fim de diminuir as impurezas e, consequientemente, reduzir as armadilhas de carga. Novos estudos estão sendo feitos para avaliar a influência e comportamento das impurezas do cristal no desempenho do detector. Para isso, os cristais devem ser crescidos mais vezes pelo método de Bridgman repetido e sua concentração de impurezas, após cada re-crescimento, deve ser determinada. 
A polarização é ainda um fator que tem limitado o uso do cristal $\operatorname{TlBr}^{(18,43-49)}$. Esse fenômeno é descrito na literatura, como uma redução gradual da corrente do detector e de uma progressiva redução da altura do pulso ao longo do tempo. Neste trabalho, a redução nos valores de altura de pulso não foi observada por um período de medição contínua de 8-10 horas. Para as fatias do terceiro crescimento, observou-se que, depois de algumas horas sem aplicação de tensão, a corrente inicial do detector sempre retorna à condição inicial. Este resultado pode ser explicado devido à melhor pureza e estrutura de cristal que propicia um dasarmadilhamento das cargas quando não se aplica tensão. Os detectores do terceiro crescimento têm sido utilizados por três meses, nessa condição, sem mostrar a redução da altura do pulso. Novos estudos deverão ser realizados para entender melhor esse fenômeno.

Estes resultados demonstram a importância da pureza do cristal de $\mathrm{TlBr}$ para sua aplicação como detector de radiação. A resistividade e eficiência do detector são influenciadas pelo armadilhamento dos portadores de cargas devido a impurezas presentes no cristal. Isso sugere que purificações adicionais são efetivas para melhorar o desempenho de um detector.

Para prever o número de purificações necessário, por método Bridgman Repetido, para obter cristal com o grau de pureza adequado para seu bom desempenho como detector de radiação, foram realizadas análises quantitativas das impurezas traços, pela técnica de ICPMS e proposto um modelo compartimental. 


\subsection{ANÁLISE DE IMPUREZAS POR ICP/MS}

A Tabela 5 resume os valores da concentração dos cinco íons mensurados por meio da técnica de ICP/MS, nas amostras dos cristais de ambas as procedências, 1 e 2. Pode-se notar, conforme a Tabela 5, que apenas $\mathrm{Ba}, \mathrm{Ca}$ e $\mathrm{Li}$ apresentaram níveis significativos de concentração. Estes sofreram uma redução percentual, como destacado. Os elementos $\mathrm{Cr}$ e $\mathrm{Cu}$ apresentaram valores abaixo do seu limite de detecção da técnica utilizada.

Tabela 5: Concentrações (ppm) das principais impurezas medidas por ICP/MS para diferentes partes de cada um dos cristais crescidos. Os valores das concentrações do material de partida foram considerados como $100 \%$.

\begin{tabular}{|c|c|c|c|c|c|c|c|c|}
\hline \multirow{2}{*}{$\begin{array}{c}\text { TIBr } \\
\text { ORIGEM }\end{array}$} & & & \multirow{2}{*}{$\begin{array}{l}\text { REGIÃO } \\
\text { DO } \\
\text { CRISTAL }\end{array}$} & \multicolumn{3}{|c|}{$\begin{array}{l}\text { ELEMENTOS IMPUREZAS } \\
(\mathrm{ppm})\end{array}$} & \multirow[b]{2}{*}{$\mathrm{Cr}$} & \multirow[b]{2}{*}{$\mathrm{Cu}$} \\
\hline & & & & $\mathrm{Ba}$ & $\mathrm{Ca}$ & Li & & \\
\hline \multirow{4}{*}{$\bar{\sigma}$} & \multirow{4}{*}{ 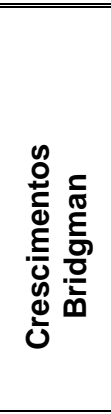 } & & SAL & $\begin{array}{c}5.46 \pm 0.10 \\
(100 \%)\end{array}$ & $\begin{array}{c}8.99 \pm 0.12 \\
(100 \%)\end{array}$ & $\begin{array}{c}2.39 \pm 0.10 \\
(100 \%)\end{array}$ & \multirow{4}{*}{$<0,02$} & \multirow{4}{*}{$<0,04$} \\
\hline & & UM & $\begin{array}{c}\text { TOP } \\
\text { MIDDLE }\end{array}$ & $\begin{array}{l}5.36 \pm 0.12 \\
4.93 \pm 0.12\end{array}$ & $\begin{array}{l}8.58 \pm 0.13 \\
8.28 \pm 0.07\end{array}$ & $\begin{array}{l}2.34 \pm 0.14 \\
2.05 \pm 0.12\end{array}$ & & \\
\hline & & DOIS & $\begin{array}{c}\text { TOP } \\
\text { MIDDLE }\end{array}$ & $\begin{array}{l}6.38 \pm 0.13 \\
6.09 \pm 0.11\end{array}$ & $\begin{array}{l}8.49 \pm 0.10 \\
8.16 \pm 0.13\end{array}$ & $\begin{array}{l}3.00 \pm 0.12 \\
3.04 \pm 0.11\end{array}$ & & \\
\hline & & TRÊS & $\begin{array}{c}\text { TOP } \\
\text { MIDDLE }\end{array}$ & $\begin{array}{c}5.49 \pm 0.11 \\
3.05 \pm 0.15 \\
(44 \%)\end{array}$ & $\begin{array}{c}8.13 \pm 0.09 \\
6.88 \pm 0.12 \\
(23 \%) \\
\end{array}$ & $\begin{array}{c}2.76 \pm 0.11 \\
1.88 \pm 0.12 \\
(21 \%)\end{array}$ & & \\
\hline \multirow{4}{*}{$\frac{N}{\tilde{\Pi}}$} & \multirow{4}{*}{ 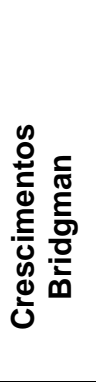 } & & SAL & $\begin{array}{c}9.64 \pm \\
0.11(100 \%)\end{array}$ & $\begin{array}{c}7.69 \pm 0.09 \\
(100 \%)\end{array}$ & $\begin{array}{c}1.92 \pm 0.10 \\
(100 \%)\end{array}$ & \multirow{4}{*}{$<0,02$} & \multirow{4}{*}{$<0,04$} \\
\hline & & UM & $\begin{array}{c}\text { TOP } \\
\text { MIDDLE }\end{array}$ & $\begin{array}{l}9.25 \pm 0.09 \\
9.10 \pm 0.11\end{array}$ & $\begin{array}{l}8.03 \pm 0.09 \\
7.63 \pm 0.10\end{array}$ & $\begin{array}{l}1.61 \pm 0.12 \\
1.60 \pm 0.07\end{array}$ & & \\
\hline & & DOIS & $\begin{array}{c}\text { TOP } \\
\text { MIDDLE }\end{array}$ & $\begin{array}{l}9.11 \pm 0.12 \\
8.96 \pm 0.10\end{array}$ & $\begin{array}{l}7.62 \pm 0.12 \\
7.49 \pm 0.012\end{array}$ & $\begin{array}{l}1.54 \pm 0.11 \\
1.40 \pm 0.06\end{array}$ & & \\
\hline & & TRÊS & $\begin{array}{c}\text { TOP } \\
\text { MIDDLE }\end{array}$ & $\begin{array}{c}9.02 \pm 0.09 \\
8.68 \pm 0.08 \\
(10 \%)\end{array}$ & $\begin{array}{c}7.45 \pm 0.11 \\
6.96 \pm 0.12 \\
(9 \%)\end{array}$ & $\begin{array}{c}1.57 \pm 0.09 \\
1.33 \pm 0.12 \\
(31 \%)\end{array}$ & & \\
\hline
\end{tabular}




\subsection{SEGREGAÇÃO DE IMPUREZAS (MODELO COMPARTIMENTAL)}

Os valores desses resultados de coeficiente de segregação de impurezas são sumarizados na Tabela 6, juntamente com os valores das incertezas dos mesmos, calculados por meio de regressão assintótica. Esses coeficientes foram utilizados para o cálculo das concentrações das impurezas em cada um dos compartimentos com a utilização das equações exponenciais obtidas com o modelo compartimental.

Tabela 6: Valores dos coeficientes de segregação de impurezas para as diferentes regiões dos cristais juntamente com suas incertezas.

\begin{tabular}{|c|c|c|c|}
\hline Impurezas & $\begin{array}{l}\text { Coeficiente de } \\
\text { segregação }\end{array}$ & $\begin{array}{c}\text { Sal de TIBr } 1 \\
\left(\# n^{-1}\right)^{\mathrm{a}}\end{array}$ & $\begin{array}{c}\text { Sal de TlBr } 2 \\
\left(\# n^{-1}\right)^{\mathrm{a}}\end{array}$ \\
\hline Bário & $\begin{array}{c}\mathbf{k}_{\mathbf{2 , 1}}=\mathbf{k}_{\mathbf{3 , 2}} \\
\mathbf{k}_{\mathbf{4 , 2}} \\
\mathbf{k}_{\mathbf{5 , 3}} \\
\end{array}$ & $\begin{array}{c}0.35 \pm 0.01 \\
0.074 \pm 0.013 \\
0.26 \pm 0.01\end{array}$ & $\begin{array}{l}0.057 \pm 0.003 \\
0.037 \pm 0.003 \\
0.083 \pm 0.003 \\
\end{array}$ \\
\hline Cálcio & $\begin{array}{c}\mathbf{k}_{2,1}=\mathbf{k}_{3,2} \\
\mathbf{k}_{4,2} \\
\mathbf{k}_{5,3} \\
\end{array}$ & $\begin{array}{c}0.29 \pm 0.09 \\
0.0076 \pm 0.0463 \\
0.311 \pm 0.086\end{array}$ & $\begin{aligned} 0.17 & \pm 0.02 \\
0.00070 & \pm 0.00887 \\
0.18 & \pm 0.02\end{aligned}$ \\
\hline Lítio & $\begin{array}{c}\mathbf{k}_{2, \mathbf{1}}=\mathbf{k}_{\mathbf{3}, 2} \\
\mathbf{k}_{4,2} \\
\mathbf{k}_{5,3}\end{array}$ & $\begin{array}{c}0.21 \pm 0.51 \\
0.004 \pm 0.200 \\
0.12 \pm 0.45\end{array}$ & $\begin{array}{c}0.056 \pm 0.356 \\
0.14 \pm 0.02 \\
0.15 \pm 0.34 \\
\end{array}$ \\
\hline \multirow[b]{2}{*}{ Média } & $\mathbf{k}_{2,1}=\mathbf{k}_{3,2}$ & $0.28 \pm 0.07$ & $0.095 \pm 0.067$ \\
\hline & $\frac{k_{4,2}}{k_{5,3}}$ & $\begin{array}{c}0.029 \pm 0.039 \\
0.23 \pm 0.24\end{array}$ & $\frac{0.061 \pm 0.075}{0.138 \pm 0.049}$ \\
\hline
\end{tabular}

As Figuras 34,35 e 36 mostram os resultados das concentrações dos três íons ( $\mathrm{Ca}, \mathrm{Ba}$ and $\mathrm{Li}$ ) no cristal crescido três vezes seqüencialmente para os dois sais de partida, bem como os valores calculados teoricamente a partir do modelo descrito na Figura 19 e equações (14), (15), (16),(17) e (18). 


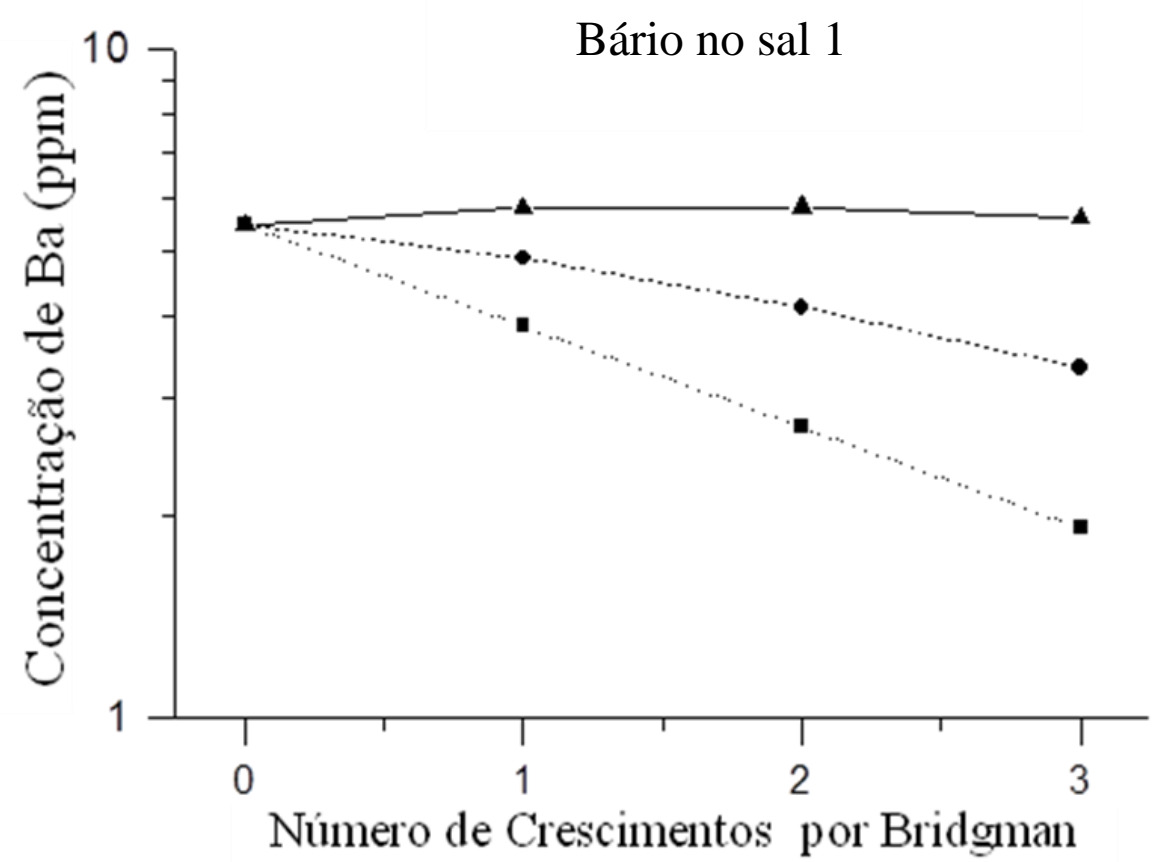

(a)

Bário no sal 2

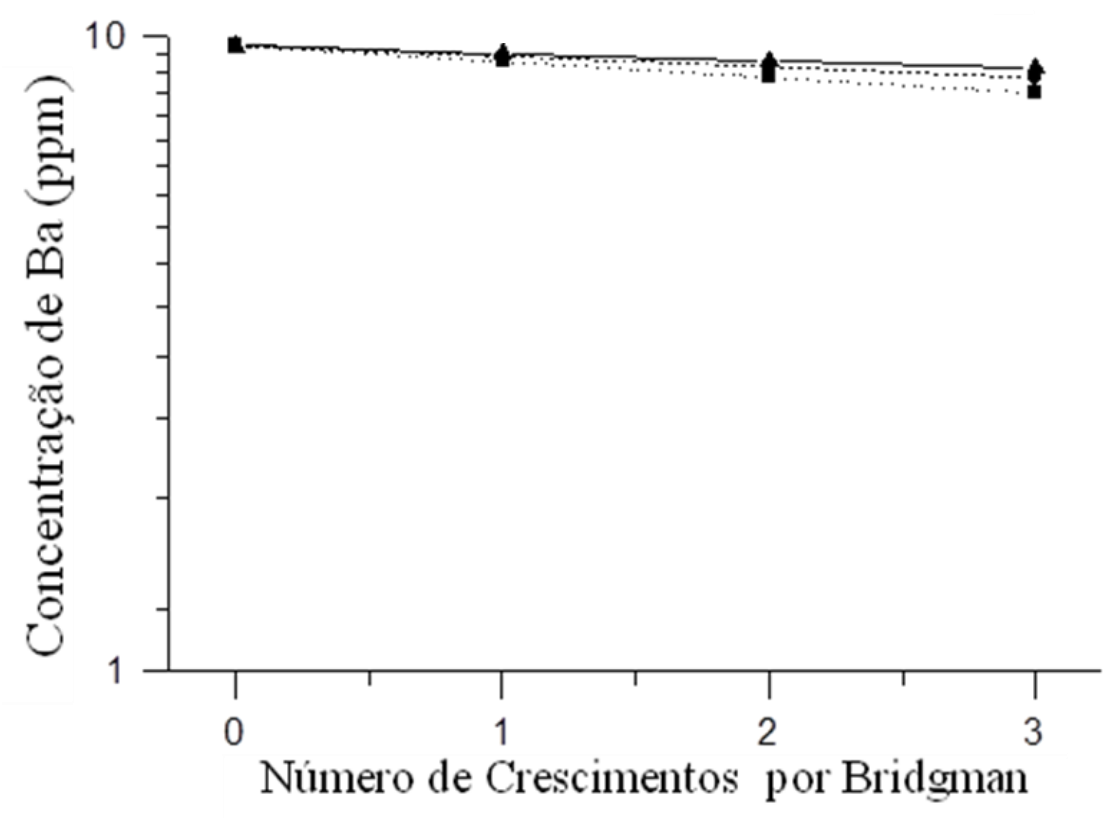

(b)

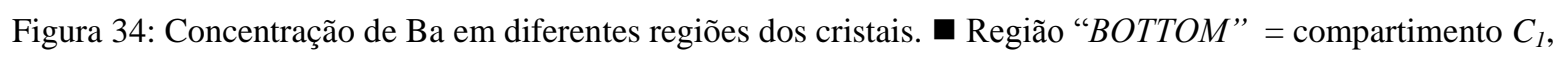

- Região "MIDDLE" = compartimento $C_{2}$ and $\boldsymbol{\Delta}$ Região "TOP" $=$ compartimento $C_{3}$. 
Cálcio no sal 1

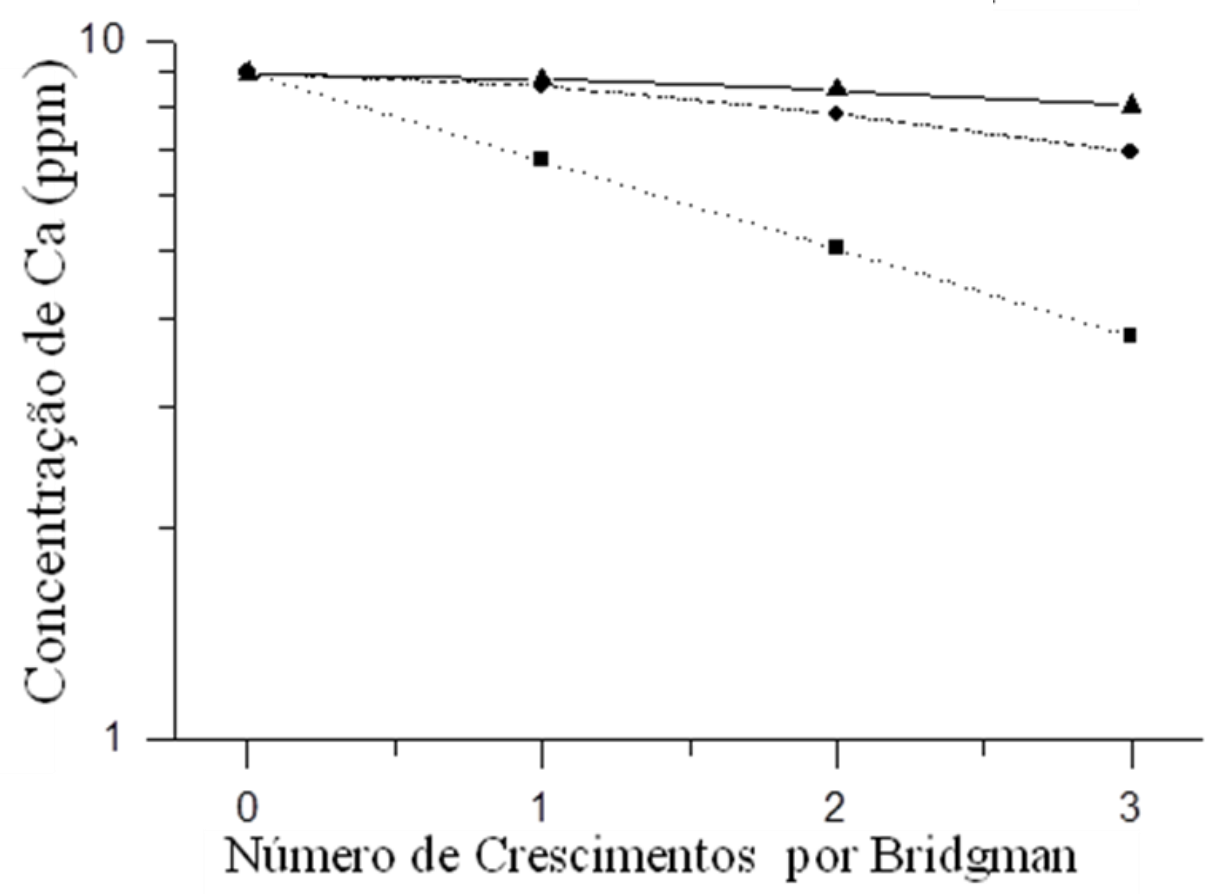

(a)

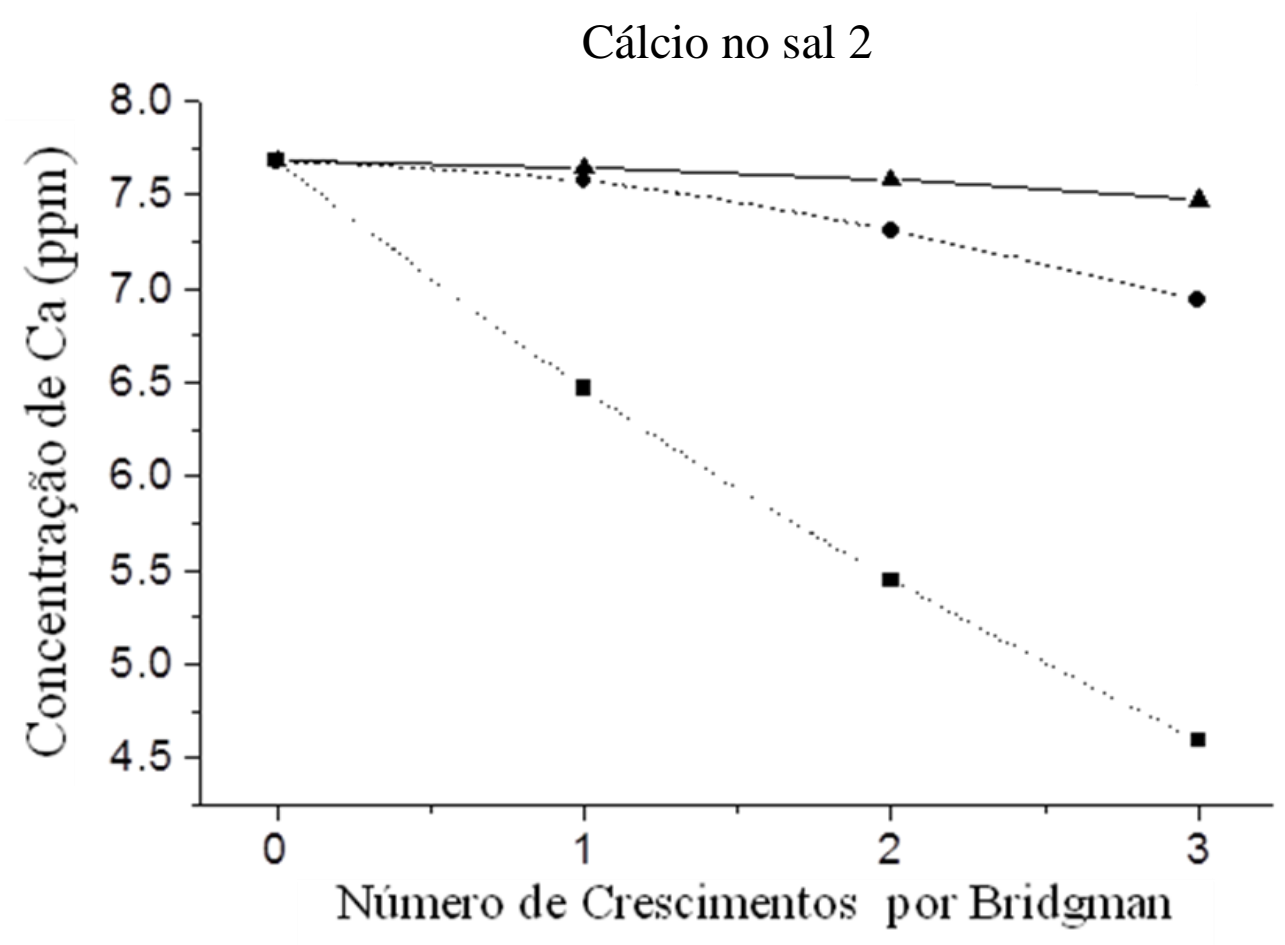

(b)

Figura 35: Concentração de Ca em diferentes regiões dos cristais. $\boldsymbol{a}$ Região "BOTTOM" = compartimento $C_{l}$, Região "MIDDLE" = compartimento $C_{2}$ and $\boldsymbol{\Delta}$ Região "TOP" = compartimento $C_{3}$. 


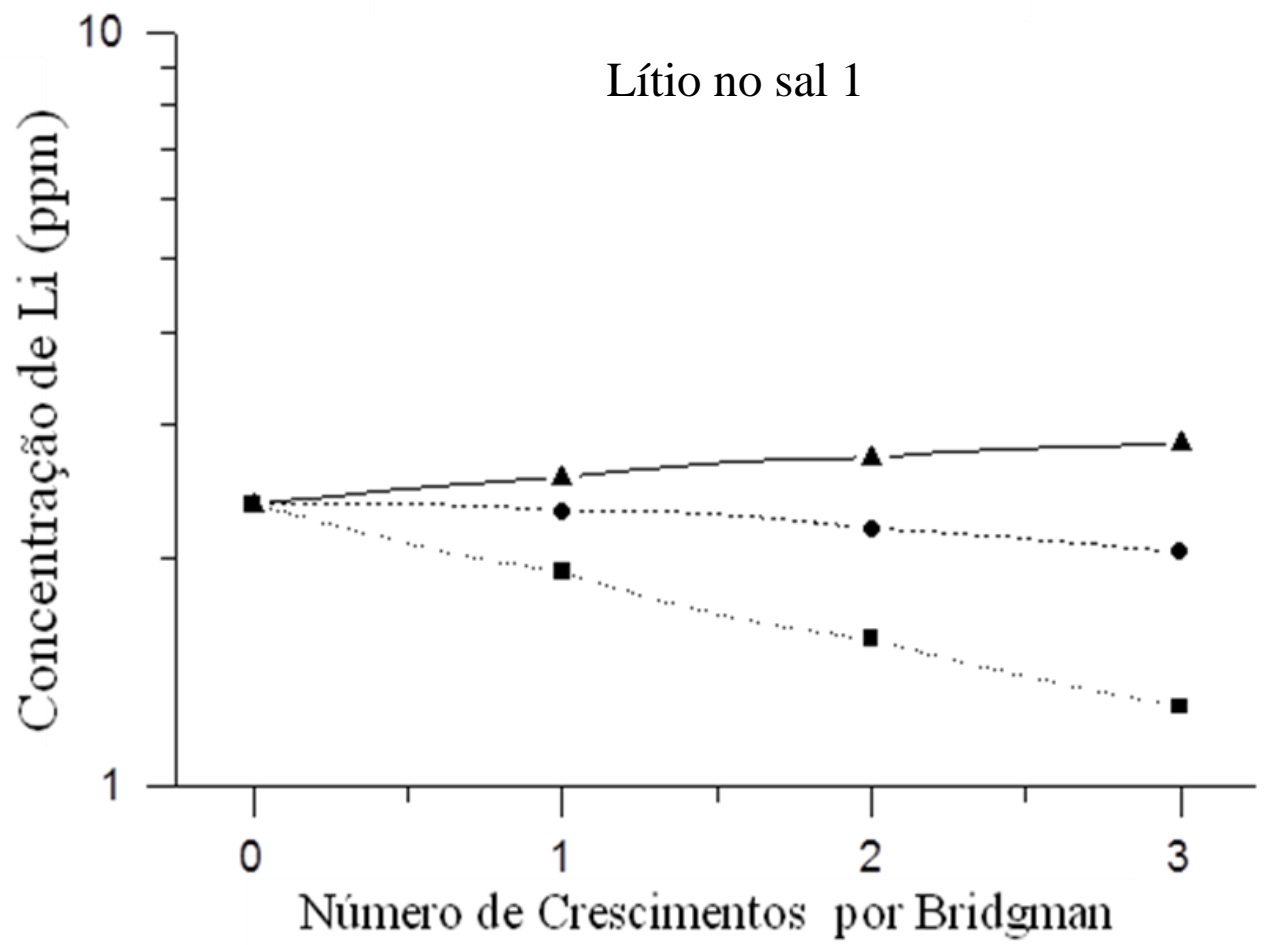

(a)

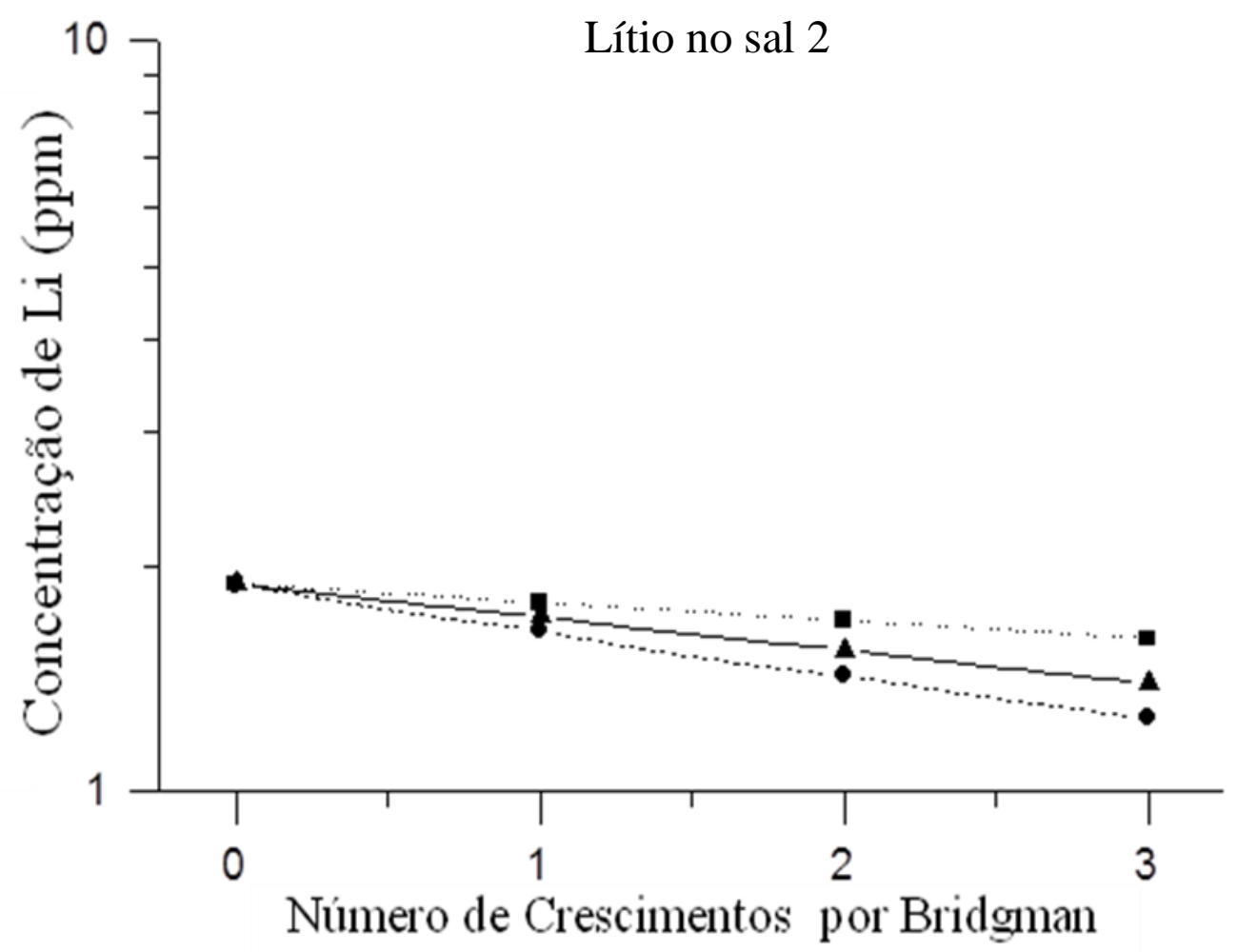

(b)

Figura 36: Concentração de Li em diferentes regiões dos cristais. $\square$ Região "BOTTOM" = compartimento $C_{l}$, Região "MIDDLE" = compartimento $C_{2}$ and $\triangle$ Região "TOP" = compartimento $C_{3}$. 
Para o sal 1, após primeira purificação, a quantidade de impurezas na região "TOP” não foi, significativamente, diferente do material de partida. No entanto, para o sal 2, diferenças significativas foram encontradas para todos os três elementos considerados impurezas na região "TOP”. No caso da região "MIDDLE”, uma diferença significativa nas concentrações das impurezas no cristal foi observada para quase todas as impurezas, comparadas a aquelas encontradas no material de partida (sal 1 e 2).

De acordo com a Tabela 5, para o sal 1, o nível de redução das impurezas na região "MIDDLE", após o terceiro crescimento, foi de 44\% (1-(3.05/5.46)) para Ba, 23\% (1(6.88/8.99)) para Ca e 21\% (1-(1.88/2.39)) para Li. Por outro lado, para o sal 2, os resultados foram inferiores, com 10\% (1-(8.68/9.64)) para Ba, 9\% (1-(6.96/7.69)) para Ca e 31\% (1(1.33/1.92)) para Li. Comparando as médias de $k_{1,2}=k_{2,3}$ (Tabela 5) para ambos sais, resultados similares podem ser alcançados. Deve ser enfatizado que, na teoria compartimental, não há um compromisso rigoroso que o parâmetro $k$ seja igual para todas as regiões do cristal. Entretanto, para o mesmo sal de partida, os valores de $k_{1,2}=k_{2,3}$ encontrados foram próximos, assim esta hipótese deve ser assumida. A diferença no valor médio dos dois sais $(0.28 \pm 0.07$ vs $0.095 \pm 0.067)$ é maior do que esperado pela lei da probabilidade. Assim, observou-se diferença significativa entre o sal 1 e 2 ( $\mathrm{P}=0,0271$.). Esses resultados sugerem que fatores desconhecidos, presente no sal 2, tornam menos eficiente a separação das impurezas ao longo do cristal e, conseqüentemente, a escolha do sal comercial de partida deve ser realizada experimentalmente, independente da declaração nominal da sua pureza.

O modelo mostrado na Figura 19 mostrou ser útil como uma ferramenta para propósito de controle de qualidade. Os parâmetros $k_{i, j}$, que são associados a eficiência da migração das impurezas, podem ser uma importante ferramenta auxiliar para projetar, otimizar e explicar os resultados e processos envolvidos na purificação do sal de partida para crescimento de cristais, como para entender a diminuição na concentração de impurezas na região "MIDDLE" do cristal no segundo crescimento Bridgman. Ainda que pareça uma contradição, esta ocorrência pode ser prevista e quantificada pela análise compartimental. O modelo proposto (Figura 19) proporciona a compreensão deste efeito, desde que é capaz de prever que as impurezas localizadas na região anterior migram para a região subseqüente, contribuindo para o aumento da sua concentração. Assim, o parâmetro $k_{i, j}$ é de grande valia para representar a eficácia da técnica de purificação. Adicionalmente, o modelo pode ser útil para predizer qual o número de repetições de crescimentos Bridgman é requerido para reduzir as impurezas 
presentes no sal de partida a um nível, por exemplo, de $10 \%\left(C_{0}=100 \%\right)$. No presente trabalho aproximadamente, 10 repetições de crescimento Bridgman são necessárias (Figura 37) para alcançar este requerimento.

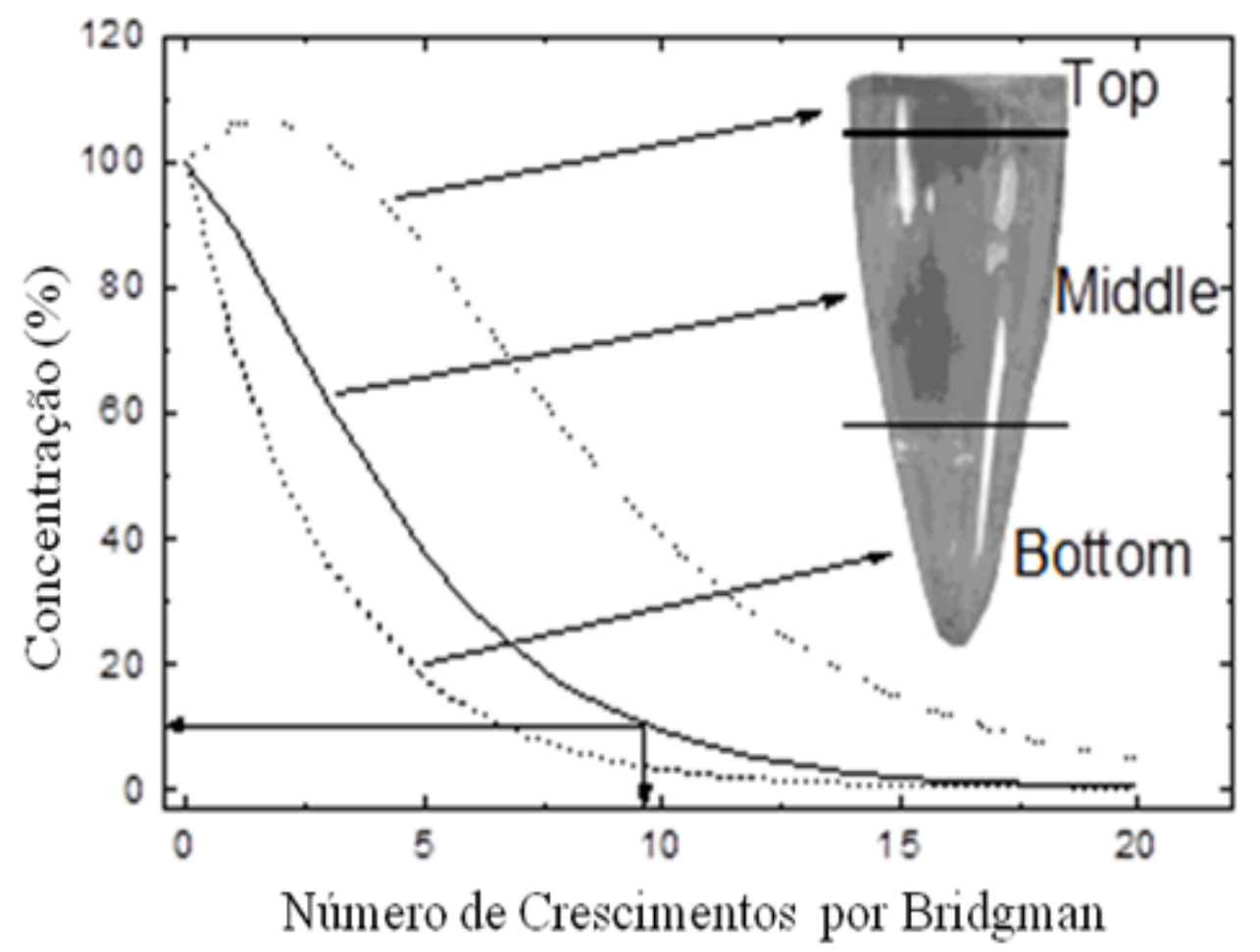

Figura 37: Concentração preditiva (\%) para o sal 1 como uma função do número de repetições do crescimento Bridgman. Curvas calculadas a partir do modelo da Figura 20 e equações (14), (15) e (16). Para alcançar 10\% da concentração inicial na região “MIDDLE” do cristal, aproximadamente, 10 etapas são requeridas. 


\section{CONCLUSÕES}

O método de Bridgman Repetido mostrou ser eficiente para purificação dos cristais de TlBr e melhorar seu desempenho como detector de radiação.

Foi observada uma significativa melhora na cristalinidade e transparência do cristal obtido no terceiro crescimento comparado ao do segundo e primeiro crescimento, para sais de ambas procedências, 1 e 2. Estes resultados demonstram a eficiência de purificação da técnica de Bridgman repetido.

Os cristais obtidos no terceiro crescimento apresentaram transparência e coloração característica (amarelo transparente) de TlBr, para ambos sais. No entanto, os cristais, a partir do sal 2, obtidos no primeiro crescimento apresentaram comportamento diferente ao do sal 1 , com aderência no tubo de quartzo, aspecto enegrecido e estrutura danificada.

Estruturas semelhantes ao modelo cúbico cristalino do TlBr foram encontrados para os cristais desenvolvidos, para ambos sais de partida. O nível de impureza presente nos cristais estudados não interferiu nas suas estruturas cristalinas. Os difratogramas apresentados indicam que os cristais são, preferencialmente, orientados no sentido (101) e (110). Estes resultados estão de acordo com a literatura ${ }^{(1,2,18)}$.

Uma boa morfologia com uniformidades nas camadas da superfície foi observada na superfície dos cristais obtidos com sais 1, enquanto os cristais obtidos com sais 2 apresentaram rugosidade na sua superfície e incrustações de elementos distintos ao cristal.

Pela análise de MEV-BSE foi comprovada a estequiometria adequada de $\mathrm{TlBr}$ nos cristais desenvolvidos, para ambos sais.

Para ambos sais de partida, os cristais de $\mathrm{TlBr}$ crescidos duas e três vezes apresentaram fotopicos definidos nos seus espectros de altura de pulso. No entanto, para o cristal de $\mathrm{TlBr}$ crescido apenas uma vez (sem purificação), foi possível observar a resposta da radiação apenas no modo de corrente. 
Não foi observada diferença significativa nos valores de resistividade dos cristais crescidos duas ou três vezes, no entanto, melhor espectro de altura de pulso foi obtido para o cristal com três crescimentos, com melhor resolução e também, apresentou as linhas de baixa energias do ${ }^{241} \mathrm{Am}$. Esta melhoria deve ser, provavelmente, devido a uma melhor coleta de cargas.

O modelo compartimental definido pelas equações diferenciais lineares pode ser usado para calcular o coeficiente de migração das impurezas e mostrou ser útil para predizer o número de repetições de crescimento Bridgman necessário para atingir o valor de concentração desejável.

A diferença dos valores dos coeficientes de migração das impurezas nos cristais entre os sais 1 e 2 foi significativa. Portanto, a escolha do sal de partida deve ser realizada experimentalmente, independente da declaração nominal da sua pureza. 


\section{REFERÊNCIAS BIBLIOGRÁFICAS}

1. MCGREGOR, D.S.; HERMON H. Room-temperature compound semiconductor radiation detectors. Nucl. Instr and Meth. Phys. Res., v.A395, p.101-124, 1997.

2. KNOLL, G.F. Radiation Detection and Measurement. $3^{\circ}$ ed. New York, N.Y.: John Wiley \& sons, 2009.

3. OLIVEIRA, I.B. Desenvolvimento e caracterização do detector semicondutor de $\mathrm{PbI}_{2}$. São Paulo: 2001. Dissertação (Mestrado) - IPEN/CNEN - USP.

4. OLIVEIRA, I.B. Desenvolvimento de cristal semicondutor de $\mathbf{T l B r}$ para aplicação como detector de radiação. São Paulo, 2006. Tese (Doutoramento) - IPEN/CNEN USP.

5. HITOMI, K.; SHOJI, T.; et al. Radiation damage effects by $25 \mathrm{MeV}$ protons and thermal anneleing effects on thalium bromide nuclear radiation detectors. IEEE Trans. Nuc. Sci., vol.46, p. 213-217, 1999.

6. SCHLESINGER, T.E.; JAMES, R.B. Semiconductors for Room Temperature Nuclear Detector Applications, Semiconductors and Semimetals, vol.43, cap.12, San Diego: Academic Press, 1995.

7. SHAH, K.S.; OLSCHNER, F.; et al. Characterization of thallium bromide nuclear detectors. Nucl. Instr. and Meth. Phys. Res., vol.A299, p.57-59, 1990.

8. BARBOSA, L.B. Preparação e propriedades elétricas e ópticas de cristais de PbI ${ }_{2}$. São Paulo: 1999. Dissertação (Mestrado) - Instituto de Física de São Carlos, USP.

9. HITOMI, K.; KIKUCHI, Y.; SHOJI, T.; ISHII, K. Improvement of energy resolutions in TIBr detectors. Nucl. Instr and Meth. Phys. Res., vol.A607, p.112-115, 2009. 
10. ELSHAZLY, E.S.; TEPPER, G.; BURGER, A. Charge trapping in detector grade thallium bromide and cadmium zinc telluride: Measurement and theory. Nucl. Instr and Meth. Phys. Res., vol.A620, p.279-284, 2010.

11. KOZLOV, V.; HEIKKILA, M.; KOSTAMO, P.; LIPSANEN, H.; LESKELA, M. TIBr purification and single crystal growth for the detector applications. Nucl. Instr and Meth. Phys. Res., vol.A633, p.s72-s74, 2011.

12. MADELUNG, O. Semiconductors: Data Handbook. $3^{\circ}$ Ed., Spriger, U.S.A, caps. 1, 21 e 23, 1999.

13. SELLIN, P. Recent advances in compound semiconductor radiation detectors. Nucl. Instr. and Meth. Phys. Res., vol. A513, pp.332-339, 2003.

14. OLIVEIRA, I.B.; COSTA, F.E.; CHUBACI, J.F.D.; HAMADA, M.M. Purification and preparation of $\mathrm{TlBr}$ crystals for room temperature radiation detector applications. IEEE. Trans. Nucl. Sci., vol.51, pp. 1224-1228, June 2004.

15. KOUZNETSOV, M.S.; LISITSKY, I.S.; ZATOLOKA, S.I.; GOSTILO, V.V. Development of the technology for growing TlBr detector crystals. Nucl. Instr. And Methods Phys. Res., vol. A531, pp.174-180, 2004.

16. PONPON, J.P.; AMANN, M. Etching of mercuric iodide in cation iodide solutions. Applied Surface Science, vol.252, pp.6313-6322, 2006.

17. AHORANTA, J.; UUNILA, M.; HUOVELIN, J.; ANDERSSON, H.; VAINIO, R.; VIRTANEN, A.; KETTUNEN H. Radiation hardness studies of CdTe and HgI2 for the SIXS particle detector on-board the BepiColombo spacecraft. Nucl. Instr. And Meth. Phys. Res., vol. A605, pp. 344-3491, 2009.

18. COSTA, F.E., Desenvolvimento de Sondas Cirúrgicas Radioguiadas com Semicondutores de TlBr e com Cristais Cintiladores de CsI(Tl). São Paulo: 2006. Tese (Doutoramento), IPEN/CNEN - USP. 
19. SANTOS, R.A.; MESQUITA, C.H.; COSTA, F.E.; MARTINS, J.F.T.; HAMADA, M.M. Dependence of the Radiation Response on the TlBr Crystal Purity. Symposium on Radiation Measurements and Applications. University of Michigan, Ann Arbor, Michigan, U.S.A.,2010.

20. VOSS, L.F., CONWAY, A.M. E col. Surface processing of TIBr for improved gamma spectroscopy. IEEE Trans. Nuc. Sci., R05-27 p. 3746-3748, 2010.

21. MARTINS, J.F.T. Desenvolvimento Do Cristal Semicondutor De Iodeto De Mercúrio Para Aplicação Como Detector De Radiação. São Paulo: 2011. Dissertação (Mestrado) - IPEN/CNEN - USP.

22. PFANN, W.G. Zone Melting. New York, John Wiley, 1958.

23. HITOMI, K.; ONODERA, T.; SHOJI, T. Influence of zone purification process on tlbr crystals for radiation detector fabrication. Nucl. Instr. And meth. Phys. Res., vol. A579, pp.153-156, 2007.

24. HITOMI, K.; MURAYAMA, T.; SOJI, T.; SUEHIRO, T.; HIRATATE, Y. Improved spectrometric characteristics of thallium bromide nuclear radiation detectors. Nucl. Instr. And Meth. Phys. Res., vol.A 428, pp. 372-378, 1999.

25. LEFKOWITZ, I.; LOWNDES, R. P. E YOFFE, A. D. Direct observation of excitons in some thallous halide single crystals. J. Phys. Chem. Solids., vol. 26, pp. 1171-1175, 1965.

26. MORSE, G.E. e LAWSON, A. W. The temperature and pressure dependence of the elastic constants of thallium bromide. J. Phys. Chem. Solids. vol. 28, pp. 939-950, 1967.

27. OVERHOF, H. e TREUSCH, J. The energy bands of thallous chloride and bromide. Solid State Communications, vol. 9, pp. 53-56, 1971. 
28. KAPATA, J. e SKUDLARSKI, K. Resolving of the mass spectra of double salt system with the common cation. Internationul Journal of Mass Spectrometry and Ion Physics, vol.47, pp. 257-260, 1983.

29. SKUDLARSKI, K. e KAPALA, J. Thermodynamics of the sublimation of thallium halides investigated by the mass-spectrometric method. J. Chem. Thermodynamic, vol.16, pp. 91-100, 1984.

30. RAHMAN, I.U.; FISHER, W.A.; HOFSTADTER, R.; JING, S. Behavior of thallium bromide conduction counters. Nucl. Instr. And Meth. Phys. Res., vol. A 261, pp. $427-$ 439, 1987.

31. LUCA, L.; GIORGIANNI, U.; PERILlO, P.; SAITTA, G. Spectroscopic studies of complex ion centres in thallium bromide solutions. J. Phys. Chem. Solids vol. 49, no. 4, pp. 363-368, 1988.

32. HITOMI, K.; MUROI, O.; MATSUMOTO, M.; HIRABUKI, R.; SHOJI T.; SUEHIRO, T.; HIRATATE, Y. Recent progress in thallium bromide detectors for X- and gama-ray spectroscopy. Nucl. Instr. And Meth. Phys. Res., vol. A458, pp. 365-369, 2001.

33. GOSTILO, V.; OWENS, A.; BAVDAZ, M.; LISJUTIN, I.; PEACOCK, A.; SIPILA, H; ZATOLOKA, S. A comparison of the X-ray performance of TlBr crystals grown by the Bridgeman-Stockbarger and travelling molten zone methods. Nucl. Instr. And Meth. Phys. Res., vol. A509, pp. 47-51, 2003.

34. ZHOU, D.; QUAN, L.; CHEN, X.; YU, S.; WANG, C.; ZHENG, Z. A Novel Method to Grow Thallium Bromide Single Crystal and Crystal. Crystal Growth \& Design, vol. 9, No. 10, pp. 4298-4300, 2009.

35. TADA, T.; HITOMI, K.; TANAKA, T.; WU, Y.; YUNKIM, S.; YAMAZAKI, H.; ISHII K. Digital pulse processing and electronic noise analysis for improving energy resolutions in planar $\mathrm{TlBr}$ detectors. Nucl. Instr. And Meth. Phys. Res., vol.A638, pp. 92-95, 2011. 
36. KOSTAMO, P.; SHOROHOV, M.; GOSTILO, V.; SIPILA, H.; KOZLOV, V.; LISITSKY, I.; KUZNETSOV, M.; LANKINEN, A.; DANILEWSKY, A.N.; LIPSANEN, H.; LESKELA, M. Characterization of TlBr for X-ray and g-ray detector applications. Nucl. Instr. And Meth. Phys. Res., vol. A607, pp. 129-131, 2009.

37. KOZLOV, V.; ANDERSSON, H.; GOSTIlO, V.; KEMELl, M.; KOSTAMO, P.; KOUZNETSOV, M.S.; LESKELA, M.; LIPSANEN, H.; LISITSKY, I.S.; SHOROHOV, M.; SIPILA, H. Improvements and problems of Bridgman-Stockbarger method for fabrication of $\mathrm{TlBr}$ single crystal detectors. Nucl. Instr. And Meth. Phys. Res., vol. A 607, pp.126-128, 2009.

38. HITOMI, K.; KIKUCHI, Y.; SHOJI, T.; ISHII, K. Improvement of energy resolutions in TlBr detectors. Nucl. Instr. And Meth. Phys. Res., vol.A607, pp. 112-115, 2009.

39. KAZUKAUSKAS, V.; ZIMINSKIJ, A.; VAITKUS, J. V.; GOSTILO, V.; SHOROHOV, M. Photoelectrical properties of $\mathrm{TlBr}$ related to ionic transport and presence of defects. Nucl. Instr. And Meth. Phys. Res., vol.A607, pp. 123-125, 2009.

40. GAZIZOV, I.M.; ZALETIN, V.M. The Sensitivity of Pure and Doped TlBr Crystals. IEEE Trans. Nuc. Sci., R05-4 pp. 3704-3708, 2010.

41. SANTOS, R.A.; MESQUITA , C.H.; COSTA , F.E.; MARTINS, J.F.T.; COTRIN, M.E.B.; HAMADA, M.M. Influence of the TlBr crystal impurities on the detector performance. VIII Encontro da Sociedade Brasileira de Crescimento de Cristais, São Carlos, Brasil, 2010.

42. SANTOS, R.A.; COSTA, F.E.; GENNARI, R.F.; MARTINS, J.F.T.; MARCONDES, R.M.; MESQUITA, C.H.; HAMADA, M.M. Multielementar Segregation Analysis of the Thallium Bromide Impurities Purified by Repeated Bridgman Technique. International Nuclear Atlantic Conference - INAC, Belo Horizonte, Brasil, 2011.

43. KOZLOV, V.; KEMELL, M.; VEHKAMAKI, M.; LESKELA, M. Degradation effects in TlBr single crystals under prolonged bias voltage. Nucl. Instr. And Meth. Phys. Res., vol.A 576, pp.10-14, 2007. 
44. HITOMI, K., SHOJI, T., NIIZEKI, Y. A method for suppressing polarization phenomena in TlBr detectors. Nucl. Instr. And Meth. Phys. Res., vol.A585, pp. 102104, 2008.

45. GAZIZOV, I. M. The Vacancy-Cluster Mechanism of Photocurrent Degradation in TIBr Detectors under $\gamma$-irradiation. IEEE Trans. Nuc. Sci., R05-7 pp. 3709-3715, 2010.

46. KOZOREZOV, A.; GOSTILO, V.; OWENS, A.; QUARATI, F.; SHOROHOV, M.; WEBB, M. A. E WIGMORE, J. K. Polarization effects in thallium bromide x-ray detectors. Journal of Applied Physics, vol. 108, 064507, pp. 1-10, 2010.

47. DÖNMEZ, B.; THRALL, C.L.; HE, Z., CIRIGNANO, L.J.; KIM, H. e SHAH, K.S.. Investigation of Polarization Effect with $\mathrm{TlBr}$ Detectors at Different Operating Temperatures. IEEE Trans. Nuc. Sci., R05-43 pp. 3773-3775, 2010.

48. ONODERA, T.; HITOMI, K.; SOJI, T. Spectroscopic performance and long-term stability of thalium bromide radiation detectors. Nucl. Instr. and Meth. Phys. Res., vol. A568, pp. 433-436, 2006.

49. COSTA, F.E.; RELA, P.R.; OLIVEIRA, I. B.; PEREIRA, M.C.C.; HAMADA, M.M. Surgical Gamma Probe with TIBr Detector Semiconductor for Identification of Sentinel Lymph Node. IEEE. Trans. Nucl. Sci., vol. 53, pp. 1403-1407, 2006.

50. HITOMI, K.; ONODERA, T.; SHOJI, T.; HE, Z. Pixellated TIBr detectors with the depth sensing technique. Nucl. Instr. And Meth. Phys. Res., vol. A578, pp.235-238, 2007.

51. VIEIRA, C.L.; COSTA, F.E.; HAMADA, M.M. Effect of etching on the TIBr crystal surface and its radiation response. International Nuclear Atlantic Conference, INAC, Santos, Brasil, 2007. 
52. KIIM, H.; CHURILOV, A.; CIAMPI, G.; CIRIGNANO, L.; HIGGINS, W.; KIM, S.; OLSCHNER, F. Continued development of thallium bromide and related compounds for gamma-ray spectrometers. Nucl. Instr. And meth. Phys. Res., VOL. A629, pp.192196, 2011.

53. HITOMI, K.; MATSUMOTO, M.; e coll. Characterization of thallium bromide crystals for radiation detector applications. Journal Crystal Growth, vol.225, p. 129-133, 2001.

54. HITOMI, K; MUROI, O.; e col. Thalium bromide photodetectors for scintillation detection. Nucl. Instr. and Meth. Phys. Res., vol.A448, p.571-575, 2000.

55. FARRELL, R.; OLSCHNER, F.; e col. Advances in semiconductor photodetectors for scintillators. Nucl. Instr. and Meth. Phys. Res., vol.A387, p.194-198, 1997.

56. GRIGORJEVA, L.; MILLERS, D. The model of recombination process in TIBr. Nucl. Instr. And Meth. Phys. Res., vol. B191, pp.131-134, 2002.

57. GRIGORJEVA, L.; MILLERS, D.; SHOROHOV, M.; LISITSKII, I.S.; KUZNETSOV, M.S.; ZATOLOKA, S.; GOSTILO, V. Optical investigations of TlBr detector crystals. Nucl. Instr. And Meth. Phys. Res., vol.A 531, pp.197-201, 2004.

58. VAITKUS, J.; GOSTILO, V.; JASINSKAITE, R.; MEKYS, A.; OWENS, A.; ZATOLOKA, S.; ZINDULIS, A. Investigation of degradation of electrical and photoelectrical properties in $\mathrm{TlBr}$ crystals. Nucl. Instr. And Meth. Phys. Res., vol. A 531, pp.192-196, 2004.

59. GOSTILO, V.; GRYAZNOV, D.; LISJUTIN I. Technological limitations and processing-generated defects at the development of pixel and strip arrays. Nucl. Instr. And Meth. Phys. Res., vol.A 487, pp.13-18, 2002.

60. OWENS, A.; BAVDAZ, M.; BRAMMERTZ, G.; GOSTILO, V.; HAACK, N.; KOZOREZOV, A.; LISJUTIN, I.; PEACOCK, A.; ZATOLOKA S. Hard X-ray spectroscopy using a small-format $\mathrm{TlBr}$ array. Nucl. Instr. And Meth. Phys. Res., vol. A 497, pp.359-369, 2003. 
61. ONODERA, T.; HITOMI, K.; SHOJI, T.; HIRATATE, Y. Pixellated thallium bromide detectors for gamma-ray spectroscopy and imaging. Nucl. Instr. And Meth. Phys. Res., vol.A 525, pp.199-204, 2004.

62. HZWSOW, D. C.; e STEVZWSOW, J. R. Optical Constants of T1C1 and T1Br with a Comparison of the Kramers - Kronig and "Two-Angle" Methods of Data Analysis. Physical Review, vol.59, n³ 1967.

63. BERKOWITZ, J.; e WALTER, T. A. Photoionization of HighTemperature Vapors IV. TlF, TlCl, and TlBr. J. Phys. Chem. Physics., vol. 49, nº 3, pp.1184 - 1189, 1698.

64. BROTHERS, A. D. e LYNCH, D. W. Optical Properties of AgCl, AgBr, T1C1, and T1Br under Hydrostatic Pressure. Physical Review, vol. 180, nº 3, pp. 911 - 918, 1969.

65. GRIFFINI, E.; LONGHI, P.; MUSSINI, T. e RONDININI, S. Standard potentials for the (thallium amalgam + aqueous thallous bromide) electrode from 283.15 to $343.15 \mathrm{~K}$ and for the (thallium + aqueous thallous bromide) electrode from 288.15 to $308.15 \mathrm{~K}$, and thermodynamic solubility product of aqueous thallous bromide from 283.15 to 343.15 K. J. Chem. Thermodynamics, vol. 13, pp. 843-848, 1981.

66. WANG, J.X.; ROBINSON, I.K.; ADZIC R.R. Formation of well-ordered surface compounds by coadsorption of thallium and bromide on the $\mathrm{Au}(111)$ electrode surface. Surface Science $\mathrm{n}^{\circ} 412 / 413$, pp. 374-383, 1998.

67. SECCO, E.A.; SECCO, R. A. Cation conductivity in mixed thallium halides. Solid State Ionics, vol.118, pp. 37-42, 1999.

68. DESTEFANO, N.; MULATO, M. Influence of multi-depositions on the final properties of thermally evaporated TIBr films. Nucl. Instr. And Meth. Phys. Res., vol.A624, pp. 114-117, 2010.

69. N. AMRANE, M. BENKRAOUDA, F. HAMED. Ab Initio Calculations of Optical Properties of $\mathrm{TlBr}$ and $\mathrm{TlCl}$ Radiation Detectors. W. J. of Cond. Matter Phys., vol. 1, pp. 63-69, 2011. 
70. YUN, S.; LIM, C.H.; KIM, H.K.; TANGUAY, J.; CUNNINGHAM, I.A. Finding the best photoconductor for digital mammography detectors. Nucl. Instr. And Meth. Phys. Res., vol.A652, pp. 829-833, 2011.

71. CULLITY, B. D. Elements of $x$-ray diffraction. 3a Ed. Massachusetts, Addison-wesley publishing company, inc., 1956.

72. MILLMAN, J.; HALKIAS, C.C. Eletrônica: Dispositivos e Circuitos. $1^{\circ}$ Ed. McGrawHill do Brasil, 1981.

73. KITTEL, C. Introdução à Física do Estado Sólido. $8^{\mathrm{a}}$ Ed. Brasil, LTC, 2006.

74. GARCIA, A. Solidificação - fundamentos e aplicações. $1^{\circ}$ Ed. Editora Unicamp, Brasil, 2001.

75. BUCKLEY, H.E. Crystal Growth. 1a Ed. New York, John Willey, 1950.

76. HOFFMANN, E. e STROOBANT V. Mass Spectrometry- Principles and Applications. 3a Ed. New York, John Willey, 2007.

77. Goldstein, J.I.; Newbury, D.E.; et. al. Scanning Electron Microscopy and X-ray microanalysis. Springer, 2007.

78. BERMAN, M. The formulation and testing of models, Ann NY Acad. Sci., pp.182-94, 1963.

79. P.R. BEVINGTON, Data Reduction and Error Analisys for The Physical Sciences, McGraw-Hill, New York, U.S.A, pp. 204 - 246, 1969.

80. GOULDEN, C.H. Methods of statistical analysis. $2^{\circ}$ Ed. New York, John Wiley, 1956.

81. M. ABRAMOWITZ \& I.A. STEGUN, Laplace Transforms, ch.29, Handbook of Mathematical Functions with Formulas, Graphs and Mathematical Tables, $9^{\text {th }}$ printing, New York, Dover, 1972, pp. 1019 - 1030. 
82. MESQUITA, C. H. AnaComp - Compartmental Analysis Aided by Computer - User Manual. IPEN/CNEN, São Paulo, 1994.

83. BRIDGMAN, P.W. The Thermodynamics of electrical phenomena in metals and a condensed collection of thermodynamic formulas, Dover Publications Inc., New York, U.S.A., 1961. 